\title{
Sex differences in immune responses that underlie COVID-19 disease outcomes
}

https://doi.org/10.1038/s41586-020-2700-3

Received: 4 June 2020

Accepted: 19 August 2020

Published online: 26 August 2020

Check for updates

\begin{abstract}
Takehiro Takahashi' ${ }^{1,21}$, Mallory K. Ellingson ${ }^{2,21}$, Patrick Wong, ${ }^{1,21}$, Benjamin Israelow ${ }^{1,3,21}$, Carolina Lucas ${ }^{1,21}$, Jon Klein ${ }^{1,21}$, Julio Silva ${ }^{1,21}$, Tianyang Mao ${ }^{1,21}$, Ji Eun Oh', Maria Tokuyama1, Peiwen Lu', Arvind Venkataraman', Annsea Park', Feimei Liu', ${ }^{1}$, Amit Meir ${ }^{5}$, Jonathan Sun ${ }^{6}$, Eric Y. Wang', Arnau Casanovas-Massana' ${ }^{2}$, Anne L. Wyllie' ${ }^{2}$, Chantal B. F. Vogels ${ }^{2}$, Rebecca Earnest ${ }^{2}$, Sarah Lapidus ${ }^{2}$, Isabel M. Ott ${ }^{2,7}$, Adam J. Moore ${ }^{2}$, Yale IMPACT Research Team* $^{*}$, Albert Shaw ${ }^{3}$, John B. Fournier ${ }^{3}$, Camila D. Odio ${ }^{3}$, Shelli Farhadian ${ }^{3}$, Charles Dela Cruz ${ }^{8}$, Nathan D. Grubaugh ${ }^{2}$, Wade L. Schulz ${ }^{9,10}$, Aaron M. Ring' ${ }^{1}$, Albert I. Ko ${ }^{2}$, Saad B. Omer ${ }^{2,3,11,12}$ \& Akiko Iwasaki ${ }^{1,13} \bowtie$
\end{abstract}

\begin{abstract}
There is increasing evidence that coronavirus disease 2019 (COVID-19) produces more severe symptoms and higher mortality among men than among women ${ }^{1-5}$. However, whether immune responses against severe acute respiratory syndrome coronavirus (SARS-CoV-2) differ between sexes, and whether such differences correlate with the sex difference in the disease course of COVID-19, is currently unknown. Here we examined sex differences in viral loads, SARS-CoV-2-specific antibody titres, plasma cytokines and blood-cell phenotyping in patients with moderate COVID-19 who had not received immunomodulatory medications. Male patients had higher plasma levels of innate immune cytokines such as IL- 8 and IL-18 along with more robust induction of non-classical monocytes. By contrast, female patients had more robust T cell activation than male patients during SARS-CoV-2 infection. Notably, we found that a poor $T$ cell response negatively correlated with patients' age and was associated with worse disease outcome in male patients, but not in female patients. By contrast, higher levels of innate immune cytokines were associated with worse disease progression in female patients, but not in male patients. These findings provide a possible explanation for the observed sex biases in COVID-19, and provide an important basis for the development of a sex-based approach to the treatment and care of male and female patients with COVID-19.
\end{abstract}

SARS-CoV-2 is the novel coronavirus first detected in Wuhan, China, in November 2019 that causes COVID-196. On 11 March 2020, the World Health Organization (WHO) declared COVID-19 a pandemic ${ }^{7}$. A growing body of evidence reveals that male sex is a risk factor for a more severe disease, including death. Globally, approximately $60 \%$ of deaths from COVID19 are reported in men $^{5}$, and a cohort study of 17 million adults in England reported a strong association between male sex and the risk of death from COVID-19 (hazard ratio 1.59, 95\% confidence interval 1.53-1.65) ${ }^{8}$.

Past studies have shown that sex has a considerable effect on the outcome of infections and has been associated with underlying differences in immune responses to infection ${ }^{9,10}$. For example, the prevalence of hepatitis A and tuberculosis are notably higher in men that in women ${ }^{11}$. Viral loads are consistently higher in male patients with hepatitis $\mathrm{C}$ virus and human immunodeficiency virus (HIV) ${ }^{12,13}$. By contrast, women mount a more robust immune response to vaccines ${ }^{14}$. These findings collectively suggest a more robust ability among women to control infectious agents. However, the mechanism by which SARS-CoV-2 causes more severe disease in male patients than in female patients remains unknown.

To determine the immune responses against SARS-CoV-2 infection in male and female patients, we performed detailed analyses on the sex differences in immune phenotypes by the assessment of viral loads, levels of SARS-CoV-2-specific antibodies, plasma cytokines or chemokines, and blood-cell phenotypes.

\section{Overview of the study design}

Patients who were admitted to the Yale-New Haven Hospital between 18 March and 9 May 2020 and were confirmed positive for SARS-CoV-2

'Department of Immunobiology, Yale University School of Medicine, New Haven, CT, USA. ²Department of Epidemiology of Microbial Diseases, Yale School of Public Health, New Haven, CT,

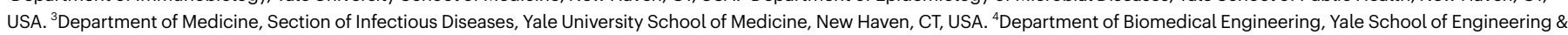
Applied Science, New Haven, CT, USA. ${ }^{5}$ Boyer Center for Molecular Medicine, Department of Microbial Pathogenesis, Yale University, New Haven, CT, USA. ${ }^{6}$ Department of Comparative

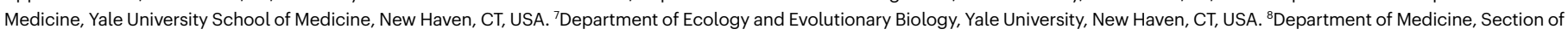

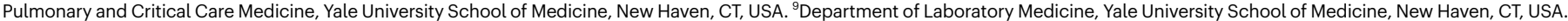

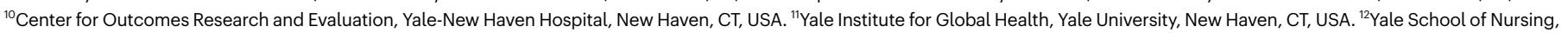
Yale University, Orange, CT, USA. ${ }^{13}$ Howard Hughes Medical Institute, Chevy Chase, MD, USA. ${ }^{21}$ These authors contributed equally: Takehiro Takahashi, Mallory K. Ellingson, Patrick Wong, Benjamin Israelow, Carolina Lucas, Jon Klein, Julio Silva, Tianyang Mao. *A list of authors and their affiliations appears at the end of the paper. ${ }^{凶}$-mail: akiko.iwasaki@yale.edu 
by RT-PCR from nasopharyngeal and/or oropharyngeal swabs in CLIA-certified laboratories were enrolled through the IMPACT biorepository study ${ }^{15}$. In the IMPACT study, biospecimens including blood, nasopharyngeal swabs, saliva, urine and stool samples were collected at study enrolment (baseline denotes the first time point) and longitudinally on average every 3 to 7 days (serial time points). The detailed demographics and clinical characteristics of these 98 participants are shown in Extended Data Table 1. Plasma and peripheral blood mononuclear cells (PBMCs) were isolated from whole blood, and plasma was used for titre measurements of SARS-CoV-2 spike S1 protein-specific IgG and IgM antibodies (anti-S1-IgG and -IgM) and cytokine or chemokine measurements. Freshly isolated PBMCs were stained and analysed by flow cytometry ${ }^{15}$. We obtained longitudinal serial time-point samples from a subset of these 98 study participants ( $n=48$; information in Extended Data Table1). To compare the immune phenotypes between sexes, two sets of data analyses were performed in parallel-baseline and longitudinal, as described below. As a control group, healthcare workers (HCWs) from Yale-New Haven Hospital were enrolled who were uninfected with COVID-19. Demographics and background information for the HCW group and the demographics of HCWs for cytokine assays and flow cytometry assays for the primary analyses are in Extended Data Table 1. Demographic data, time-point information of the samples defined by the days from the symptom onset (DFSO) in each patient, treatment information, and raw data used to generate figures and tables is in Supplementary Table 1.

\section{Baseline analysis}

The baseline analysis was performed on samples from the first time point of patients who met the following criteria: not in intensive care unit (ICU), had not received tocilizumab, and had not received high doses of corticosteroids (prednisone equivalent of more than $40 \mathrm{mg}$ ) before the first sample collection date. This patient group, cohort A, consisted of 39 patients (17 male and 22 female) (Extended Data Tables 1,2). Intersex and transgender individuals were not represented in this study. Figures 1-4 represent analyses of baseline raw values obtained from patients in cohort A. In cohort A patients, male and female patients were matched in terms of age, body mass index (BMI), and DFSO at the first time point sample collection (Extended Data Fig. 1a). However, there were significant differences in age and BMI between HCW controls and patients (patients had higher age and BMI values) (Extended Data Table 1), and therefore an age- and BMI-adjusted difference-in-differences analysis was also performed in parallel (Extended Data Table 3).

\section{Longitudinal analysis}

As parallel secondary analyses, we performed longitudinal analysis on a total patient cohort (cohort B) to evaluate the difference in immune response over the course of the disease between male and female patients. Cohort $B$ included all patient samples from cohort A (including several time-point samples from the cohort A patients) as well as an additional 59 patients who did not meet the inclusion criteria for cohort A. Because cohort B included more severely affected patients in ICU, the average clinical scores were higher in cohort $B$ than in cohort $A$ (mean \pm s.d.: $1.3 \pm 0.5$ (female) and $1.4 \pm 0.5$ (male) for cohort $A$, and $2.5 \pm 1.5$ (female) and $2.7 \pm 1.3$ (male) for cohort B) (Extended Data Table 1). This analysis included several time-point samples from 98 participants in total. Data from cohort B were analysed for sex differences in immune responses among patients using longitudinal analysis, controlling for potential confounding by age, BMI, receipt of immunomodulatory treatment (tocilizumab or corticosteroids), DFSO and ICU status. Second, we conducted a longitudinal analysis that compared male and female patients with COVID-19 to male and female HCWs, controlling for age and BMI. Adjusted least square means difference over time in immune responses between male and female patients with COVID-19 (Extended Data Table 4) and adjusted least square means
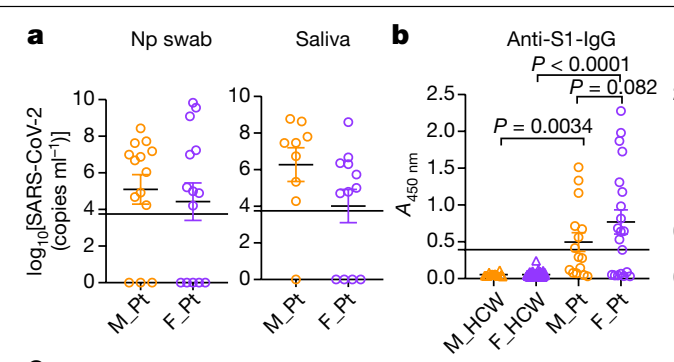

Anti-S1-lgM
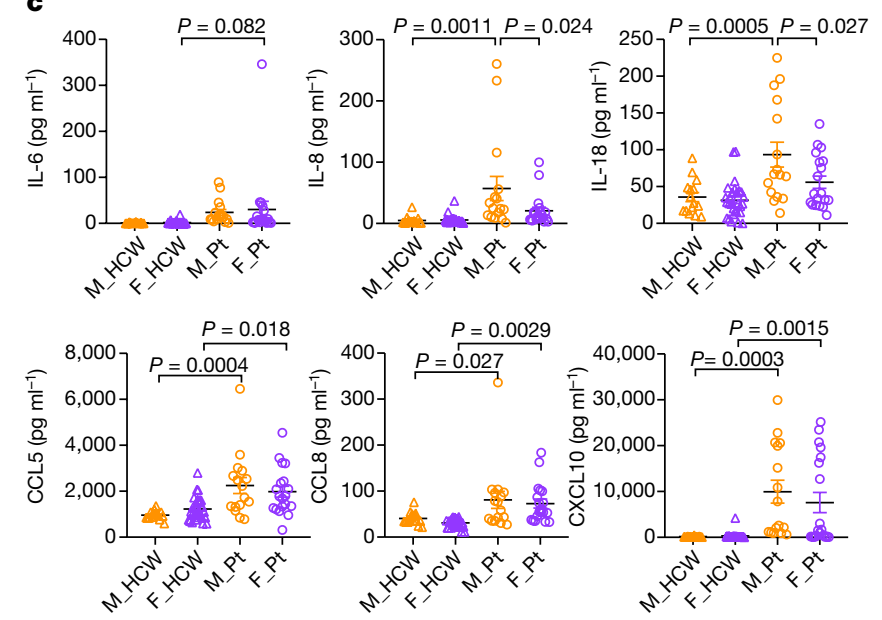

Fig. 1 | Comparison of viral RNA concentrations, titres of anti-SARS-CoV-2 antibodies, and plasma cytokines and chemokine levels at the first sampling of cohort A patients. a, Comparison of viral RNA measured from nasopharyngeal (Np) swab and saliva. $n=14$ for male and female patients (M_Pt and F_Pt, respectively) for nasopharyngeal samples, and $n=9$ and 12 , respectively, for saliva samples. Dotted lines indicate the detection limit of the assay $\left(5,610\right.$ copies $\left.\mathrm{ml}^{-1}\right)$, and negatively tested data are shown on the $x$ axis. ND, not detected. b, Titres of specific IgG and IgM antibodies against SARS-CoV-2 S1 protein were measured. $n=13,74,15$ and 20 for $\operatorname{IgG}$, and $n=3,18,15$ and 20 for IgM, for male HCW (M_HCW), female HCW (F_HCW), M_Pt and F_Pt, respectively. The cut-off values for positivity are shown by the dotted lines. c, Comparison of the plasma levels of representative innate immune cytokines and chemokines. $n=15,28,16$ and 19 for M_HCW, F_HCW, M_Pt and F_Pt, respectively. $P$ values were determined by unpaired two-tailed $t$-test (a) or one-way analysis of variance (ANOVA) with Bonferroni multiple comparison test $(\mathbf{b}, \mathbf{c})$. All $P$ values $<0.10$ are shown. Data are mean \pm s.e.m. The results of all the cytokines or chemokines measured can be found in Extended Data Fig. 1b.

difference over time in immune responses between male and female patients with COVID-19 and male and female HCWs (Extended Data Table 5) were calculated.

\section{Sex differences in cytokines and chemokines}

We first compared the concentrations of viral RNA of male and female patients. For both cohorts A and B, there was no difference by sex in terms of the viral RNA concentrations in nasopharyngeal swab and saliva (Fig. 1a, Extended Data Tables 3, 4).

Anti-SARS-CoV-2 S1-specific IgG and IgM (anti-S1-IgG and -IgM) antibodies were comparable in infected male and female in cohort $A$ (Fig. 1b) and in cohort B (Extended Data Tables 4, 5). Thus, at baseline and during the course of the disease, there were no clear differences in the amount of IgG or IgM generated against the S1 protein between male and female patients.

Next, we analysed the levels of 71 cytokines and chemokines in the plasma. Levels of many pro-inflammatory cytokines, chemokines and growth factors, including IL-1 $\beta$, IL-6, IL-8, TNF, CCL2, CXCL10 and G-CSF, are increased in the plasma of patients with COVID-19 ${ }^{16}$. In line with previous reports, levels of inflammatory cytokine or chemokine were 


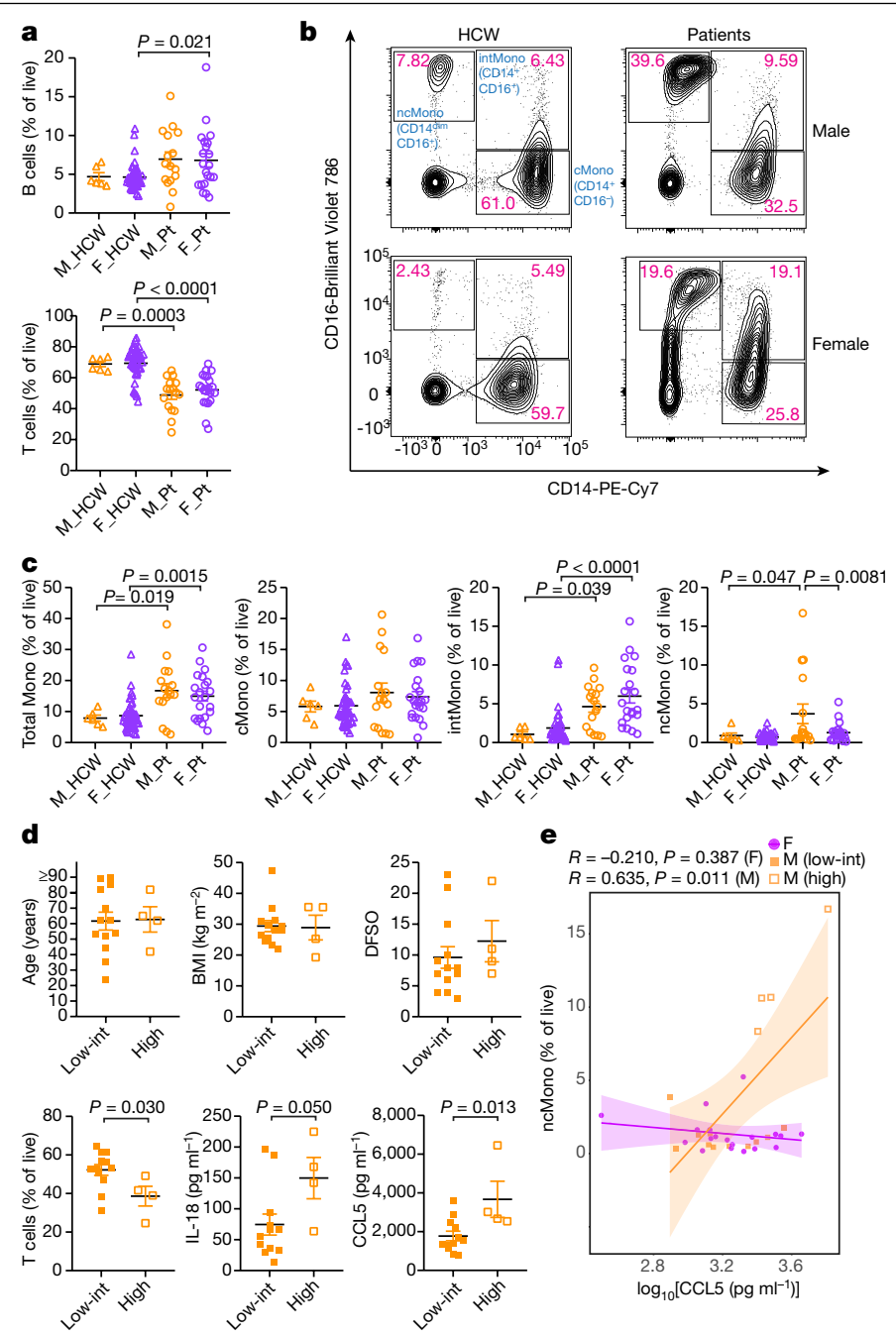

Fig. 2 | Differences in composition of PBMCs between male and female patients in cohort $A$ at the first sampling. a, Comparison on the proportion of B cells (top) and T cells (bottom) in live PBMCs. $n=6,42,16$ and 21 for M_HCW, F_ HCW, M_Pt and F_Pt, respectively. b, Representative 2D plots for CD14 and CD16 in monocytes gate (live/singlets/CD19- $\mathrm{CD}^{-} / \mathrm{CD}^{-} 6^{-} \mathrm{CD}^{-} 6 \mathrm{~b}^{-}$). Numbers in red indicate the percentages of each population in the parent monocyte gate. c, Comparison between percentages of total monocytes, classical monocytes (cMono), intermediate monocytes (intMono) and non-classical monocytes (ncMono) in the live PBMCs. $n=6,42,16$ and 21 for M_HCW, F_HCW, M Pt and F_Pt, respectively. d, Comparison of age, BMI, DFSO, T cells (percentage of live PBMCs) and plasma IL-18 and CCL5 levels between male patients who had high non-classical monocytes and low-intermediate non-classical monocytes. $n=13$ and 4 for 'low-int' and 'high' group, respectively, for age, BMI and DFSO. $n=12$ and 4 for 'low-int' and 'high' group, respectively, for T cells and IL-18 or CCL5 levels. e, Correlation between plasma CCL5 levels and non-classical monocytes (percentage of live cells). Pearson correlation coefficients $(R)$ and $P$ values for each sex are shown. Lines represent linear regression lines and shading represents $95 \%$ confidence intervals for each sex. ncMono-high male patients $(n=4)$ are shown with orange open squares, and ncMono-low-int male patients ( $n=11$ ) are shown with orange closed squares. $n=19$ for female patients (purple circles). Data are mean \pm s.e.m. in a, c and d. $P$ values were determined by one-way ANOVA with Bonferroni multiple comparison test $(\mathbf{a}, \mathbf{c})$ or unpaired two-tailed $t$-test (d). All $P$ values $<0.10$ are shown.

generally higher in patients than in controls (Fig. 1c, Extended Data Figs. 1b, 2a, Extended Data Table 3). The levels of type-I, -II or -III interferon (IFN) were comparable between the sexes in cohort A (Extended Data Fig. 1b, Extended Data Table 3). However, we found higher levels of IFN $\alpha 2$ in female patients than in male patients in cohort B (Extended Data Table 4). The levels of many cytokines, chemokines and growth factors were increased in patients compared to HCWs in both sexes, and the levels between sexes were comparable (Fig. 1c, Extended Data Fig. 1b, Extended Data Table 3). However, levels of IL-8 and IL-18 were significantly higher in male patients than in female patients in cohort A (Fig. 1c). In age- and BMI-adjusted analyses of cohort A, we found that although IL-8 and IL-18 were no longer significantly higher among male patients than in to female patients, IL-8 and CXCL10 were significantly increased in male patients compared to male HCWs than in female patients compared to female HCWs (difference-in-differences, Extended Data Table 3). In adjusted analyses of cohort B, although we did not see significant sex differences in the levels of IL-8 and IL-18, we found significantly higher levels of CCL5 in male patients than in female patients over the course of the disease (Extended Data Table 4) and significantly increased levels of CCL5 in male patients compared to male HCWs than in female patients compared to female HCWs (Extended Data Table 5, difference-in-differences). These data indicated that, although levels of most of the innate inflammatory cytokines and chemokines were comparable, there were a few factors that are more robustly increased at the baseline (IL-8 and IL-18) and during the course of the disease (CCL5) in male patients than in female patients.

\section{Monocyte differences by sex}

Next, we examined the immune cell phenotype by flow cytometry. Freshly isolated PBMCs were stained with specific antibodies to identify T cells, B cells, natural killer T cells, natural killer cells, monocytes, macrophages and dendritic cells to investigate the composition of PBMCs (Extended Data Fig. 2b). Consistent with a previous report on a decrease in T cells in patients ${ }^{16}$, in cohort $\mathrm{A}$, the proportion of T cells in the live cells was significantly lower in patients, whereas the proportion of B cells was higher in both male and female patients than in HCWs (Fig. 2a, Extended Data Table3). There was no difference in the numbers of B cells across all groups, but the numbers of $T$ cells were lower in patients of both sexes (data not shown). By contrast, in cohort B, we found that male patients had significantly lower numbers of $T$ cells, both total counts and as a proportion of live cells, over the course of the disease than female patients (Extended Data Table 4). Next, we found higher populations of monocytes in both sexes in cohort A (Fig. 2b, c, Extended Data Fig. 2b) compared to HCWs. Although $\mathrm{CD}_{14}{ }^{+} \mathrm{CD} 16^{-}$classical monocytes were comparable across all groups, levels of $\mathrm{CD} 14^{+} \mathrm{CD} 16^{+}$intermediate monocytes were increased in patients compared with HCWs, and this increase was more robust in female patients (Fig. 2b, c). By contrast, male patients had higher levels of $\mathrm{CD} 14^{\mathrm{lo}} \mathrm{CD} 16^{+}$non-classical monocytes than controls and female patients (Fig. 2b, c). These differences were observed in age- and BMI-adjusted analyses, too, but were not significant (Extended Data Table 3).

We then divided the 17 cohort A male patients into two groups, namely, a 'high' group who had high percentages of non-classical monocytes (upper quartile 4 patients, all had more than $5 \%$ of non-classical monocytes) and a 'low-intermediate' group (others, 13 patients). We compared age, BMI, DFSO, T cells, and plasma levels of IL-18 and CCL5. Although we found no differences in age, BMI or DFSO (Fig. 2d), we noted that the group with high levels of non-classical monocytes had significantly lower levels of T cells and higher levels of CCL5 in plasma (Fig. 2d). In addition, we found a significant correlation between CCL5 levels and abundance in non-classical monocytes only in male patients (Fig. 2e). These findings suggest that the progression from classical to non-classical monocytes may be arrested at the intermediate stage in female patients, and that increased innate inflammatory cytokines and chemokines are associated with more robust activation of innate immune cells at the baseline as well as more robust longitudinal $\mathrm{T}$ cell decrease in male patients.

\section{Higher $T$ cell activation in female}

We further examined the T cell phenotype in patients with COVID-19. The composition of overall CD4-positive and CD8-positive cells among 

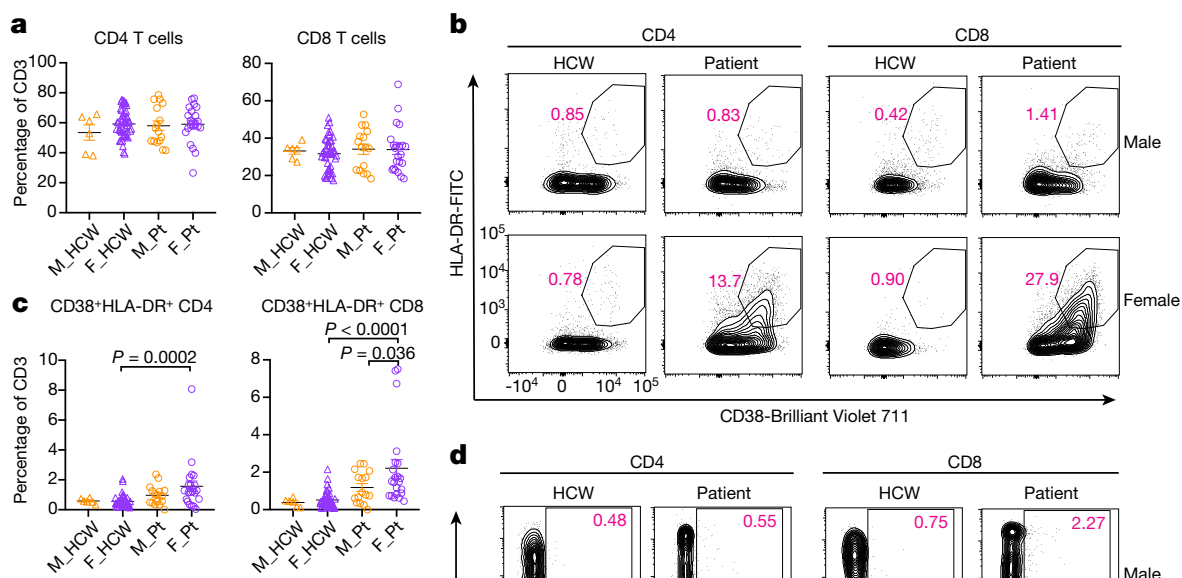

d

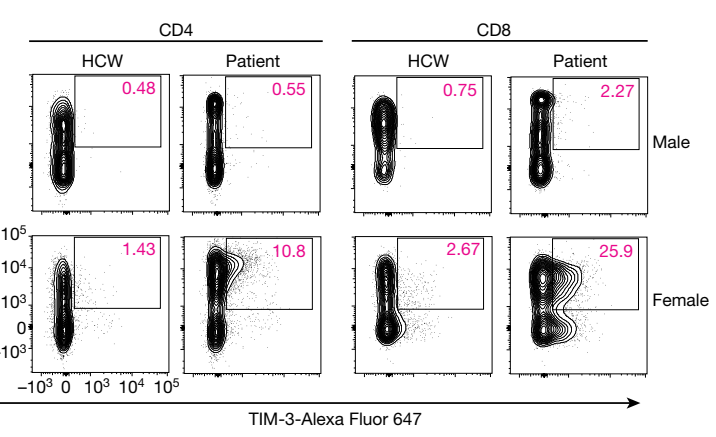

Fig. 3 | Sex difference in $T$ cell phenotype at the first sampling of cohort A patients. a, Percentages of CD4 and CD8 in the CD3-positive cells. b, Representative 2D plots for CD38 and HLA-DR in the CD4 and CD8 T cells. Numbers in red indicate the percentages of CD38 ${ }^{+} \mathrm{HLA}-\mathrm{DR}^{+}$populations in the parent gate (live/singlets/CD3 ${ }^{+} / \mathrm{CD}^{+}$or $\mathrm{CD}^{+}$). c, Percentages of $\mathrm{CD} 38^{+} \mathrm{HLA}-\mathrm{DR}^{+}$ CD4 or CD8 cells in CD3-positive cells. d, Representative 2D plots for PD-1 and
TIM-3 in the CD4 and CD8 T cells. Numbers in red indicate the percentages of PD $-1^{+} \mathrm{TIM}^{+} 3^{+}$populations in the parent gate (live/singlets $/ \mathrm{CD} 3^{+} / \mathrm{CD} 4^{+}$or $\mathrm{CD} 8^{+} /$ CD45RA ${ }^{-}$). e, Percentages of PD-1 ${ }^{+}$TIM- $3^{+}$CD4 or CD8 cells in CD3-positive cells. $n=6,45,16$ and 22 for M_HCW, F_HCW, M_Pt and F_Pt, respectively. $P$ values were determined by one-way ANOVA with Bonferroni multiple comparison test. Data are mean \pm s.e.m. All $P$ values $<0.10$ are shown.
T cells were similar between all groups in cohort A(Fig. 3a, Extended Data Fig. 2c, Extended Data Table 3). Detailed phenotyping of T cells for naive T cells, central or effector memory $T\left(T_{C M} / T_{E M}\right)$ cells, follicular helper $T\left(T_{F H}\right)$ cells, regulatory $T\left(T_{\text {reg }}\right)$ cells revealed no remarkable differences in the frequency of these subsets between sexes (Extended Data Fig. 2c). However, we observed higher levels of CD38 and HLA-DR-positive activated $\mathrm{T}$ cells in female patients than in male patients (Fig. $3 \mathrm{~b}, \mathrm{c}$ ). In parallel, PD-1- and TIM-3-positive terminally differentiated T cells were more prevalent among female patients than male patients (Fig. 3d, e). These findings were seen in both CD4 and CD8 T cells, but the differences were more robust in CD8 T cells (Fig. 3c, e, Extended Data Table 3). We also stained for intracellular cytokines such as IFN $\gamma$, granzyme $B(G z B)$, TNF, IL- 6 and IL- 2 in CD8 T cells, and IFN $\gamma$, TNF, IL-17A, IL- 6 and IL- 2 in CD4 T cells. Levels of these cytokines were higher in patients than in controls, and were generally comparable between sexes in the patients (Extended Data Fig. 2d). Analyses of T cell phenotypes in cohort B did not reveal any significant differences between sexes (Extended Data Tables 4 and 5). Therefore, female patients with COVID-19 had more abundant activated and terminally differentiated $T$ cell populations than male patients at baseline in unadjusted analyses.

\section{Sex-dependent immunity and disease course}

We investigated whether certain immune phenotypes were correlated with disease trajectory, and whether these phenotypes and factors differed between the sexes. To this end, we evaluated the disease course of patients in cohort A. The clinical scores at the first sample collection $\left(C_{1}\right)$ were 1 or 2 for all of the patients in cohort A. The patients were categorized into a 'deteriorated' group if the patients marked a score of 3 or higher after the first sample collection date as their maximum clinical scores during admission $\left(C_{\max }\right)$. By contrast, if the patients maintained the score of 1 or 2, they were categorized as 'stabilized' (Extended Data Table 2$)$. Both in male $(n=17)$ and female $(n=22)$ patients from cohort
A, 6 patients of each sex deteriorated during the course of the disease (35.3\% and $27.3 \%$, respectively), and the intervals between the dates at which the patients reached $C_{\max }$ (DFSO at $C_{\max }$ ) and the first sample collection (DFSO at $C_{1}$ ) were not significantly different between deteriorated male and female patients (mean \pm s.d. $=3.7 \pm 4.1$ and $4.2 \pm 2.7$, respectively; $P=0.81$ by unpaired two-tailed $t$-test).

We first examined age, BMI, viral loads and titres of anti-S1-IgG antibodies between the stabilized and deteriorated groups in a sex-aggregated manner. We found that the deteriorated group had on average a higher BMI than the stabilized group. Although the age was not statistically different, the stabilized group spanned a larger age range than the deteriorated group, who were generally of a more advanced age. The viral load and antibody titres were comparable (Fig. 4a). Next, we examined these factors in a sex-disaggregated manner, and found that the deteriorated male (M_deteriorated) group was on average significantly older than the stabilized male (M_stabilized) group, whereas the two female groups (F_deteriorated and F_stabilized) were comparable in age (Fig. 4b). In addition, BMI was higher for the M_deteriorated than the M_Stabilized group, whereas there was no difference in BMI between the F_deteriorated and F_stabilized groups (Fig. 4b). By contrast, the F_deteriorated group had higher viral load in saliva than the $F_{-}$stabilized group, whereas there was no difference in the male groups (Fig. 4b). The levels of antibodies were comparable between the deteriorated and stabilized groups both in male and female, but stabilized female tended to have higher antibody levels (Fig. 4b).

We further investigated whether the key factors identified in the previous analyses correlated with disease progression in male and female patients. We observed that regardless of sex, some chemokines and growth factors, such as CXCL10 (also known as IP-10) and M-CSF, were increased in patients that went on to develop worse disease. However, there were some innate immune factors, such as CCL5, TNFSF10 (also known as TRAIL) and IL-15, that were specifically increased only in female patients that subsequently progressed to worse disease, 

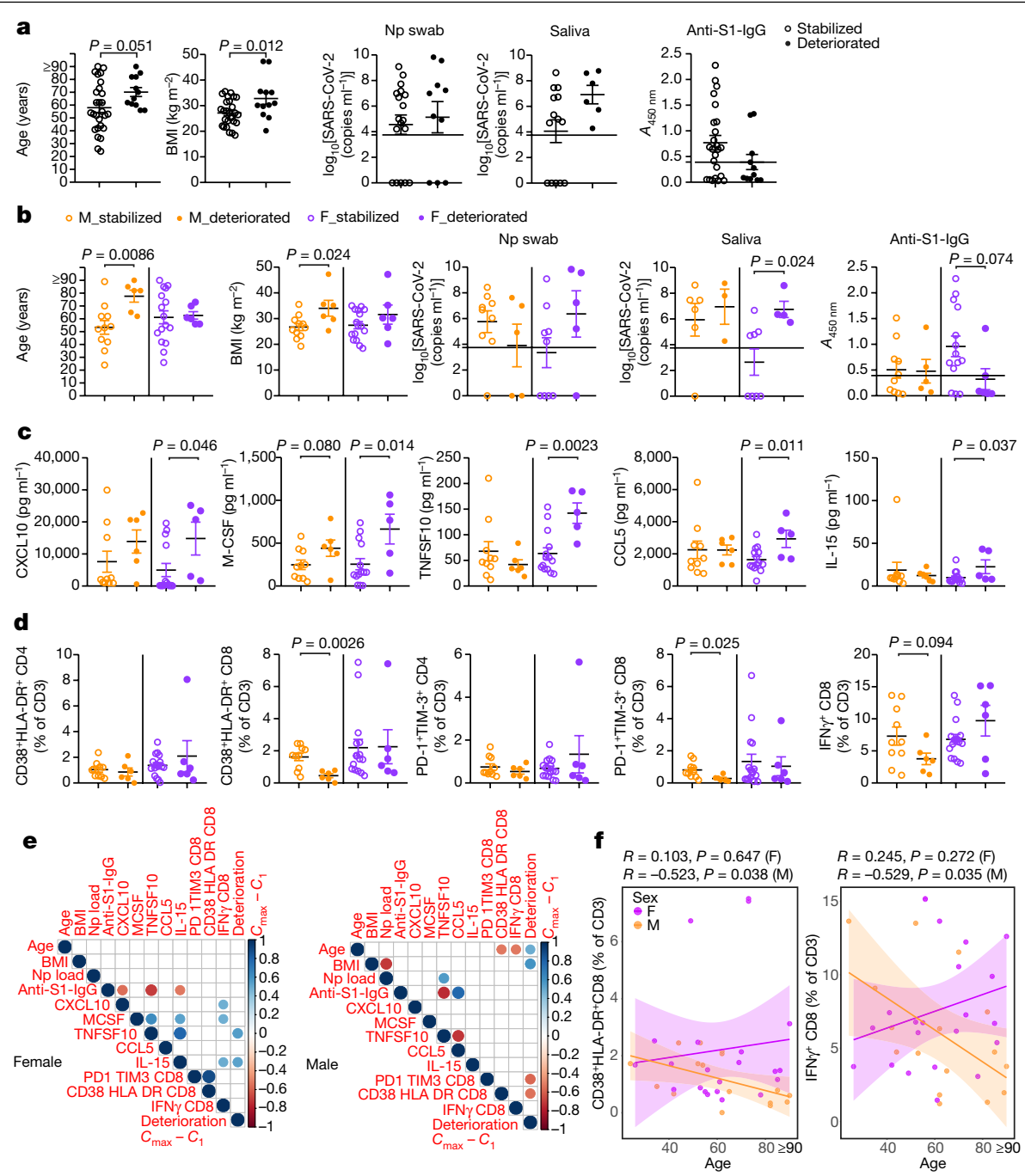

Fig. 4 | Differential immune phenotypes at the first sampling and disease progression between sexes in cohort A patients. a, b, Sex-aggregated (a) and sex-disaggregated (b) comparison of age, BMI, RNA concentration in nasopharyngeal swab and saliva, and anti-S1-IgG antibodies between the stabilized and deteriorated group. $n=11,6,16$ and 6 for age and BMI, $n=9,5$, 9 and 5 for nasopharyngeal swab, $n=6,3,8$ and 4 for saliva, and $n=10,5,14$ and 6 for anti-S1-IgG antibodies, for M_stabilized, M_deteriorated, F_stabilized and F_deteriorated group, respectively. Dotted lines in the viral concentration and anti-S1-IgG panels indicate the detection limit and cut-off value for positivity, respectively. c, Cytokine or chemokine comparison between stabilized and deteriorated groups. $n=10,6,14$ and 5 for the M_stabilized, M_deteriorated, F_stabilized and F_deteriorated groups, respectively. d, Comparisons in the proportions of activated $\left(\mathrm{CD} 38^{+} \mathrm{HLA}-\mathrm{DR}^{+}\right)$and terminally differentiated (PD-1 $\left.{ }^{+} \mathrm{TIM}-3^{+}\right) \mathrm{CD} 4$ or CD8 T cells, and IFN $\gamma^{+} \mathrm{CD} 8 \mathrm{~T}$ cells in CD3-positive $\mathrm{T}$ cells are shown. $n=10,6,16$ and 6 for $\mathrm{M}$ stabilized, M deteriorated, $\mathrm{F}$ stabilized and F_deteriorated group, respectively. e, Pearson correlation heat maps of the indicated parameters are shown for each sex. For viral RNA concentrations and cytokine or chemokine levels, log-transformed values were used for the calculation of the correlations. The size and colour of the circles indicate the correlation coefficient $(R)$, and only statistically significant correlations $(P<0.05)$ are shown. Clinical deterioration from the first time point was scored by $C_{\max }-C_{1} \cdot n=17$ and 22 for male and female, respectively. f, Correlation between age and CD38 $8^{+} \mathrm{HLA}^{-D R^{+}} \mathrm{CD} 8 \mathrm{~T}$ cells (left) and IFN $\gamma^{+} \mathrm{CD} 8 \mathrm{~T}$ cells (right). Pearson correlation coefficient $(R)$ and $P$ values for each correlation and sex are shown. Lines represent linear regression lines and shading represents $95 \%$ confidence intervals for each sex. $P$ values were determined by unpaired two-tailed $t$-test in a-d. Data are mean \pm s.e.m. All $P$ values $<0.10$ are shown. but this difference was not observed in male patients (Fig. 4c). In the age- and DFSO-adjusted analysis of cohort A, we also found that CCL5 was only increased in female patients that progressed to worse disease compared to the stabilized patients, but no such correlation was found in male patients (Extended Data Table 6).

T cell phenotypes in these groups showed that male patients whose disease worsened had a significantly lower proportion of activated $\mathrm{T}$ cells $\left(\mathrm{CD} 38^{+} \mathrm{HLA}-\mathrm{DR}^{+}\right)$and terminally differentiated $\mathrm{T}$ cells $\left(\mathrm{PD}-1^{+} \mathrm{TIM}-3^{+}\right)$and tendencies for fewer IFN ${ }^{+}+\mathrm{CD} 8 \mathrm{~T}$ cells at the first sample collection, compared with their counterpart male who did not progressed to worse disease (Fig. 4d). However, in female patients, the deteriorated group had similar levels of these types of CD8 T cells compared with the stabilized group (Fig. 4d).
We finally examined the correlations between age, BMI, viral loads, anti-S1 antibodies, cytokines or chemokines, activated or terminally differentiated or IFN $\gamma$-producing CD8 T cells, and clinical disease course (' $C_{\max }-C_{1}$ ' was used for the deterioration score). The correlation matrix showed that in female patients, higher levels of innate immunity cytokines, such as TNFSF10 and IL-15, were positively correlated with disease progression, whereas there was no association between CD8 T cell status and deterioration (Fig. 4e, results of ageand DFSO-adjusted analysis in Extended Data Table 6). In particular, CXCL10, M-CSF and IL-15 were positively correlated with IFN $\gamma^{+} \mathrm{CD} 8$ T cells in female patients (Fig. $4 \mathrm{~d}$ ).

By contrast, in male patients, progressive disease was associated with higher age, higher BMI, and poor CD8 T cell activation (Fig. 4e). 


\section{Article}

Poor CD8 T cell activation and poor production of IFN $\gamma$ by CD8 T cells were significantly correlated with patients' age, whereas these correlations were not seen in female patients (Fig. 4e, f). These differences seemed to highlight the differences between the sexes in the immune responses against SARS-CoV-2 as well as the difference of the potential prognostic or predictive factors for clinical deterioration of COVID-19.

\section{Discussion}

Our results revealed key differences in immune responses during the disease course of SARS-CoV-2 infection in male and female patients. First, we found that the levels of several important pro-inflammatory innate immunity chemokines and cytokines such as IL-8, IL-18 (at baseline) and CCL5 (longitudinal analysis) were higher in male patients, which correlated with higher non-classical monocytes (at baseline). Second, we observed a more robust $T$ cell response among female patients than male patients at baseline. In particular, activated CD8 T cells were significantly increased only in female patients but not in male patients compared with healthy volunteers. Analysis of their clinical trajectory showed that, although poor $\mathrm{T}$ cell responses were associated with future progression of disease in male patients, higher levels of innate immune cytokines were associated with worsening of COVID-19 disease in female patients. Notably, the T cell response was significantly and negatively correlated with patients' age in male, but not female, patients. These data indicate key differences in the baseline immune capabilities in male and female patients during the early phase of SARS-CoV-2 infection, and suggest a potential immunological underpinning of the distinct mechanisms of disease progression between sexes. These analyses also provide a potential basis for taking sex-dependent approaches to prognosis, prevention, care, and therapy for patient with COVID-19.

Although our study provides a strong basis for further investigation into how COVID-19 disease dynamics may differ between male and female patients, it is important to note that there are some limitations to the analyses presented in this Article. First, we acknowledge that the healthy HCWs used as the control population were not matched to patients on the basis of age, BMI or underlying risk factors. To account for this, we performed adjusted analyses for the baseline and longitudinal comparisons between patients (cohort A and the full patient population, cohort B) and HCWs, controlling for age and BMI. However, we cannot rule out residual confounding due to underlying risk factors not available for the HCW controls.

Collectively, these data suggest that vaccines and therapies to increase T cell immune responses to SARS-CoV-2 might be warranted for male patients, whereas female patients might benefit from therapies that dampen innate immune activation early during disease. The immune landscape in patients with COVID-19 is considerably different between the sexes, and these differences may underlie heightened disease vulnerability in men.

\section{Online content}

Any methods, additional references, Nature Research reporting summaries, source data, extended data, supplementary information, acknowledgements, peer review information; details of author contributions and competing interests; and statements of data and code availability are available at https://doi.org/10.1038/s41586-020-2700-3.

1. Chen, N. et al. Epidemiological and clinical characteristics of 99 cases of 2019 novel coronavirus pneumonia in Wuhan, China: a descriptive study. Lancet 395, 507-513 (2020).

2. Li, Q. et al. Early transmission dynamics in Wuhan, China, of novel coronavirus-infected pneumonia. N. Engl. J. Med. 382, 1199-1207 (2020).

3. Yang, X. et al. Clinical course and outcomes of critically ill patients with SARS-CoV-2 pneumonia in Wuhan, China: a single-centered, retrospective, observational study. Lancet Respir. Med. 8, 475-481 (2020).

4. Meng, Y. et al. Sex-specific clinical characteristics and prognosis of coronavirus disease-19 infection in Wuhan, China: a retrospective study of 168 severe patients. PLoS Pathog. 16, e1008520 (2020)

5. Gebhard, C., Regitz-Zagrosek, V., Neuhauser, H. K., Morgan, R. \& Klein, S. L. Impact of sex and gender on COVID-19 outcomes in Europe. Biol. Sex Differ. 11, 29 (2020).

6. Zhu, N. et al. A novel coronavirus from patients with pneumonia in China, 2019. N. Engl. J. Med. 382, 727-733 (2020).

7. WHO. WHO Director-General's Opening Remarks at the Media Briefing on COVID-19 - 11 March 2020 https://www.who.int/dg/speeches/detail/who-director-general-s-openingremarks-at-the-media-briefing-on-covid-19---11-march-2020 (2020).

8. Williamson, E. J. et al. Factors associated with COVID-19-related death using OpenSAFELY. Nature 584, 430-436 (2020).

9. Klein, S. L. \& Flanagan, K. L. Sex differences in immune responses. Nat. Rev. Immunol. 16, 626-638 (2016).

10. Fischer, J., Jung, N., Robinson, N. \& Lehmann, C. Sex differences in immune responses to infectious diseases. Infection 43, 399-403 (2015).

11. Guerra-Silveira, F. \& Abad-Franch, F. Sex bias in infectious disease epidemiology: patterns and processes. PLoS One 8, e62390 (2013).

12. Moore, A. L. et al. Virologic, immunologic, and clinical response to highly active antiretroviral therapy: the gender issue revisited. J. Acquir. Immune Defic. Syndr. 32, 452-461 (2003).

13. Collazos, J., Asensi, V. \& Cartón, J. A. Sex differences in the clinical, immunological and virological parameters of HIV-infected patients treated with HAART. AIDS 21, 835-843 (2007).

14. Fink, A. L., Engle, K., Ursin, R. L., Tang, W. Y. \& Klein, S. L. Biological sex affects vaccine efficacy and protection against influenza in mice. Proc. Natl Acad. Sci. USA 115, 12477-12482 (2018)

15. Lucas, C. et al. Longitudinal analyses reveal immunological misfiring in severe COVID-19. Nature 584, 463-469 (2020).

16. Huang, C. et al. Clinical features of patients infected with 2019 novel coronavirus in Wuhan, China. Lancet 395, 497-506 (2020).

Publisher's note Springer Nature remains neutral with regard to jurisdictional claims in published maps and institutional affiliations.

(C) The Author(s), under exclusive licence to Springer Nature Limited 2020

Yale IMPACT Research Team*

Kelly Anastasio ${ }^{14}$, Michael H. Askenase ${ }^{15}$, Maria Batsu ${ }^{16}$, Hannah Beatty ${ }^{16}$, Santos Bermejo ${ }^{16}$, Sean Bickerton ${ }^{17}$, Kristina Brower ${ }^{2}$, Molly L. Bucklin', Staci Cahill ${ }^{14}$, Melissa Campbell ${ }^{3}$, Yiyun Cao', Edward Courchaine ${ }^{17}$, Rupak Datta ${ }^{3}$, Giuseppe Deluliis ${ }^{8}$, Bertie Geng ${ }^{16}$, Laura Glick ${ }^{16}$, Ryan Handoko ${ }^{16}$, Chaney Kalinich ${ }^{2}$, William Khoury-Hanold', Daniel Kim', Lynda Knaggs ${ }^{16}$, Maxine Kuang ${ }^{14}$, Eriko Kudo', Joseph Lim ${ }^{18}$, Melissa Linehan', Alice Lu-Culligan', Amyn A. Malik"1, Anjelica Martin', Irene Matos ${ }^{16}$, David McDonald ${ }^{16}$, Maksym Minasyan $^{16}$, Subhasis Mohanty ${ }^{3}$, M. Catherine Muenker ${ }^{2}$, Nida Naushad ${ }^{16}$, Allison Nelson ${ }^{16}$, Jessica Nouws ${ }^{16}$, Marcella Nunez-Smith ${ }^{19}$, Abeer Obaid ${ }^{16}$, Isabel Ott ${ }^{2}$, Hong-Jai Park ${ }^{16}$, Xiaohua Peng $^{16}$, Mary Petrone ${ }^{2}$, Sarah Prophet ${ }^{20}$, Harold Rahming ${ }^{16}$, Tyler Rice', Kadi-Ann Rose $^{16}$, Lorenzo Sewanan ${ }^{16}$, Lokesh Sharma ${ }^{8}$, Denise Shepard ${ }^{16}$, Erin Silva ${ }^{16}$, Michael Simonov $^{16}$, Mikhail Smolgovsky ${ }^{16}$, Eric Song ${ }^{1}$, Nicole Sonnert ${ }^{1}$, Yvette Strong ${ }^{16}$, Codruta Todeasa $^{16}$, Jordan Valdez ${ }^{16}$, Sofia Velazquez ${ }^{15}$, Pavithra Vijayakumar ${ }^{16}$, Haowei Wang ${ }^{3}$, Annie Watkins ${ }^{2}$, Elizabeth B. White ${ }^{2}$ \& Yexin Yang'

${ }^{14}$ Yale Center for Clinical Investigation, Yale University School of Medicine, New Haven, CT, USA. ${ }^{15}$ Department of Neurology, Yale University School of Medicine, New Haven, CT, USA. ${ }^{16}$ Yale School of Medicine, New Haven, CT, USA. ${ }^{17}$ Department of Biochemistry and of Molecular Biology, Yale University School of Medicine, New Haven, CT, USA. ${ }^{18}$ Yale Viral Hepatitis Program, Yale University School of Medicine, New Haven, CT, USA. ${ }^{19}$ Equity Research and Innovation Center, Yale University, New Haven, CT, USA. ${ }^{20}$ Department of Molecular, Cellular and Developmental Biology, Yale University School of Medicine, New Haven, CT, USA. 


\section{Methods}

No statistical methods were used to predetermine sample size. The experiments were not randomized. Investigators were blinded during experiments in terms of the sex or other clinical background information, with the sample labels having de-identified patient IDs that did not contain any of this information.

\section{Ethics statement}

This study was approved by Yale Human Research Protection Program Institutional Review Boards (FWA00002571, Protocol ID. 2000027690). Informed consent was obtained from all enrolled patients and healthcare workers.

\section{Patients and HCWs}

Adult patients ( $\geq 18$ years old) admitted to Yale-New Haven Hospital between 18 March and 9 May 2020, positive for SARS-CoV-2 by RT-PCR from nasopharyngeal and/or oropharyngeal swabs, and able to provide informed consent (surrogate consent accepted) were eligible for the Yale IMPACT Biorepository study, and 198 patients were enrolled in this period. All patients necessitated hospitalization for their symptoms and had an WHO score ${ }^{17}$ of at least 3 at admission (denoting hospitalized, mild disease). At the initial screening, clinical PCR tests were performed in CLIA-certified laboratory and only the PCR-positive patients were enrolled. Only after the confirmation of PCR-positivity, the patients were enrolled and the first time point samples for this study were collected for each patient. The first time point samples were collected at $11.4 \pm 8.1,10.2 \pm 6.3,11.7 \pm 7.2$ and $12.1 \pm 7.3$ (mean \pm s.d.) DFSO in cohort $A$ female, cohort A male, cohort B female and cohort B male, respectively (Extended Data Fig. 1a, right panel for cohort A, Extended Data Table1).

Among these patients, we could obtain whole blood for flow cytometry analysis using fresh PBMCs, plasma for cytokine or chemokine measurements, anti-S1 antibody measurements and nasopharyngeal swab and saliva from total of 98 individuals for the present study. For longitudinal analyses, biospecimens (blood, nasopharyngeal swabs, saliva, urine, and/or stool) were collected at study enrolment (baseline) and on average every 3 to 7 days while in the hospital in 48 of these 98 patients.

The patients were assessed with a locally developed clinical scoring system for disease severity; (1): admitted and observed without supplementary oxygen; (2) required $\leq 3$ I supplementary oxygen via nasal canal to maintain $\mathrm{SpO}_{2}>92 \%$; (3) received tocilizumab, which per hospital treatment protocol required that the patient to require $>31$ supplementary oxygen to maintain $\mathrm{SpO}_{2}>92 \%$, or, required $>2$ I supplementary oxygen to maintain $\mathrm{SpO}_{2}>92 \%$ and had a high-sensitivity C-reactive protein (CRP) > 70; (4) the patient required ICU-level care; (5) the patient required intubation and mechanical ventilation. In relation to the WHO scoring ${ }^{17}$, our clinical scores 1, 2/3, 4 and 5 largely correspond to WHO scores 3, 4,5 and 6/7, respectively. Detailed demographic information for the entire cohort ( 98 cohort $B$ patients, and several time-point samples from 54 patients among them) and of cohort $A$ (39 patients) are shown in Extended Data Tables 1-3. For the patients who are 90 years old or older, their ages were protected health information, and '90' was put as the surrogate value for the analyses. Among 198 total patients enrolled in IMPACT study in this period, we obtained whole blood, nasopharyngeal swabs or saliva samples from 98 patients for the present study. Individuals with active chemotherapy against cancers, pregnant patients, patients with background haematological abnormalities, patients with autoimmune diseases and patients with a history of organ transplantation and on immunosuppressive agents, were excluded from this study.

As a control group, COVID-19-uninfected HCWs from Yale-New Haven Hospital were enrolled. HCWs were tested every 2 weeks for PCR and serology. For the control group, the PBMCs and plasma analysis were done when both tests were negative. That is, if either or both of these tests were positive, these samples were excluded from the analyses. In some HCWs, samples were collected for the assays at up to two time points. In these cases, if the data for a certain type of assay were available for both of these time points, only the first time point data were used and otherwise data for either time point were used in the main analyses with cohort $\mathrm{A}$.

\section{Viral RNA measurement}

SARS-CoV-2 RNA concentrations were measured from nasopharyngeal samples and saliva samples by RT-PCR as previously described ${ }^{18,19}$. In short, total nucleic acid was extracted from $300 \mu \mathrm{l}$ of viral transport media from the nasopharyngeal swab or $300 \mu$ of whole saliva using the MagMAX Viral/Pathogen Nucleic Acid Isolation kit (ThermoFisher Scientific) using a modified protocol and eluted into $75 \mu$ l of elution buffer $^{19}$. For SARS-CoV-2 RNA detection, $5 \mu$ l of RNA template was tested as previously described ${ }^{18}$, using the US CDC real-time RT-PCR primer/ probe sets for 2019-nCoV_N1, 2019-nCoV_N2, and the human RNase P (RP) as an extraction control. Virus RNA copies were quantified using a tenfold dilution standard curve of RNA transcripts that we previously generated $^{18}$. If the RNA concentration was lower than the limit of detection (ND) that was determined previously ${ }^{18}$, the value was set to 0 and used for the analyses.

\section{Isolation of plasma}

Plasma samples were collected after whole blood centrifugation at $400 \mathrm{~g}$ for $10 \mathrm{~min}$ at room temperature with brake off. The plasma was then carefully transferred to $15-\mathrm{ml}$ conical tubes and then aliquoted and stored at $-80^{\circ} \mathrm{C}$ for subsequent analysis.

\section{SARS-CoV-2 specific antibody measurement}

ELISAs were performed as previously described ${ }^{20}$. In short, Triton X-100 and RNase A were added to serum samples at final concentrations of $0.5 \%$ and $0.5 \mathrm{mg} \mathrm{ml}^{-1}$ respectively and incubated at room temperature for 30 min before use to reduce risk from any potential virus in serum. Then, 96-well MaxiSorp plates (Thermo Scientific 442404) were coated with $50 \mu \mathrm{l}$ per well of recombinant SARS-CoV-2S1 protein (ACROBiosystems S1N-C52H3-100 $\mu \mathrm{g}$ ) at a concentration of $2 \mu \mathrm{g} \mathrm{ml}^{-1}$ in PBS and were incubated overnight at $4^{\circ} \mathrm{C}$. The coating buffer was removed, and plates were incubated for $1 \mathrm{~h}$ at room temperature with $200 \mu$ lof blocking solution (PBS with 0.1\% Tween-20,3\% milk powder). Serum was diluted 1:50 in dilution solution (PBS with $0.1 \%$ Tween-20,1\% milk powder) and $100 \mu \mathrm{l}$ of diluted serum was added for two hours at room temperature. Plates were washed three times with PBS-T (PBS with 0.1\% Tween-20) and $50 \mu \mathrm{l}$ of HRP anti-Human IgG Antibody (GenScript A00166, 1:5,000) or anti-Human IgM-Peroxidase Antibody (Sigma-Aldrich A6907, 1:5,000) diluted in dilution solution were added to each well. After $1 \mathrm{~h}$ of incubation at room temperature, plates were washed six times with PBS-T. Plates were developed with $100 \mu$ l of TMB Substrate Reagent Set (BD Biosciences 555214) and the reaction was stopped after $12 \mathrm{~min}$ by the addition of 100 ul of $2 \mathrm{~N}$ sulfuric acid. Plates were then read at a wavelength of $450 \mathrm{~nm}$ and $570 \mathrm{~nm}$.

The cut-off values for sero-positivity were determined as 0.392 and 0.436 for anti-S1-IgG and anti-S1 IgM, respectively. Eighty pre-pandemic plasma samples were assayed to establish the negative baselines, and these values were statistically determined with confidence level of $99 \%$.

\section{Cytokine and chemokine measurement}

Patients' sera isolated as above were stored in $-80^{\circ} \mathrm{C}$ until the measurement of the cytokines. The sera were shipped to Eve Technologies on dry ice, and levels of 71 cytokines and chemokines were measured with Human Cytokine Array/Chemokine Array 71-Plex Panel (HD71). All the samples were measured upon the first thaw.

The shipment of the samples and measurements were done in two separate batches, but the measurements were performed with the same assay kits using the same standard curves, therefore minimizing the batch effects between the measurements. 
For the out of range values of the measurements, either the lowest highest extrapolatable values or the lowest or highest standard curve were recorded following the instructions of HD71 assay, and included in the analyses. Among all the samples measured, we found that two samples had outlier values (beyond $1.5 \times$ interquartile range) in more than half of the 71 cytokines or chemokines measured, suggesting the technical error and/or poor sample qualities in the measurements. Therefore, cytokine or chemokine data of these individuals were excluded from the analyses.

\section{Isolation of PBMCs}

The PBMCs were isolated from heparinized whole blood using Histopaque density gradient under the biosafety level $2+$ facility. To isolate PBMCs, blood 1:1 diluted in PBS was layered over in Histopaque in a SepMate tube and centrifuged for $10 \mathrm{~min}$ at $1,200 \mathrm{~g}$. The PBMC layer was collected by quickly pouring the content into a new $50-\mathrm{ml}$ tube. The cells were washed twice with PBS to remove any remaining histopaque and to remove platelets. The pelleted cells were treated with ACK buffer for red cell lysis and then counted. The percentage viability was estimated using Trypan blue staining.

\section{Flow cytometry}

Using the freshly isolated PBMCs, the staining was performed in three separate panels for (1) PBMC cell composition, (2) T cell surface staining, and (3) T cell intracellular staining. Exact antibody clones and vendors that were used for flow cytometric analysis are as follows: BB515 anti-HLA-DR (G46-6), BV785 anti-CD16 (3G8), PE-Cy7 anti-CD14 (HCD14), BV605 anti-CD3 (UCHT1), BV711 anti-CD19 (SJ25C1), BV421 anti-CD11c (3.9), AlexaFluor647 anti-CD1c (L161), Biotin anti-CD141 (M80), PE anti-CD304 (12C2), APCFire750 anti-CD11b (ICRF44), PerCP/ Cy5.5 anti-CD66b (G10F5), BV785 anti-CD4 (SK3), APCFire750 or PE-Cy7 or BV711 anti-CD8 (SK1), BV421 anti-CCR7 (G043H7), AlexaFluor 700 anti-CD45RA (HI100), PE anti-PD1 (EH12.2H7), APC anti-TIM-3 (F38-2E2), BV711 anti-CD38 (HIT2), BB700 anti-CXCR5 (RF8B2), PE-Cy7 anti-CD127 (HIL-7R-M21), PE-CF594 anti-CD25 (BC96), BV711 anti-CD127 (HIL-7R-M21), BV421 anti-IL-17a (N49-653), AlexaFluor 700 anti-TNF (MAb11), PE or APC/Fire750 anti-IFNy (4S.B3), FITC anti-GranzymeB (GB11), AlexaFluor 647 anti-IL-4 (8D4-8), BB700 anti-CD183/CXCR3 (1C6/CXCR3), PE-Cy7 anti-IL-6 (MQ2-13A5), PE anti-IL-2 (5344.111), BV785 anti-CD19(SJ25C1), BV421 anti-CD138 (MI15), AlexaFluor700 anti-CD20 (2H7), AlexaFluor 647 anti-CD27 (M-T271), PE/Dazzle594 anti-IgD (IA62), PE-Cy7 anti-CD86 (IT2.2), APC/Fire750 anti-IgM (MHM-88), BV605 anti-CD24 (M1/69), APC/Fire 750 anti-CD10 (HI10a), BV421 anti-CD15 (SSEA-1), AlexaFluor 700 Streptavidin (ThermoFisher). Freshly isolated PBMCs were plated at $1 \times 10^{6}-2 \times 10^{6}$ cells in a 96-well U-bottom plate. Cells were resuspended in Live/Dead Fixable Aqua (ThermoFisher) for $20 \mathrm{~min}$ at $4{ }^{\circ} \mathrm{C}$. Following a wash, cells were then blocked with Human TruStan FcX (BioLegend) for $10 \mathrm{~min}$ at room temperature. Cocktails of desired staining antibodies were directly added to this mixture for $30 \mathrm{~min}$ at room temperature. For secondary stains, cells were washed and supernatant aspirated; to each cell pellet, a cocktail of secondary markers was added for $30 \mathrm{~min}$ at $4{ }^{\circ} \mathrm{C}$. Before analysis, cells were washed and resuspended in $100 \mu \mathrm{l}$ of $4 \%$ paraformaldehyde for 30 min at $4{ }^{\circ} \mathrm{C}$. For intracellular cytokine staining following stimulation, cells were resuspended in $200 \mu \mathrm{l} \mathrm{CRPMI}$ (RPMI-1640 supplemented with $10 \% \mathrm{FBS}$, $2 \mathrm{mM} \mathrm{L}$-glutamine, $100 \mathrm{U} \mathrm{ml}^{-1}$ penicillin, and $100 \mathrm{mg} \mathrm{ml}^{-1}$ streptomycin, $1 \mathrm{mM}$ sodium pyruvate, and $50 \mu \mathrm{M} 2$-mercaptoethanol) and stored at $4{ }^{\circ} \mathrm{C}$ overnight. Subsequently, these cells were washed and stimulated with $1 \times$ Cell Stimulation Cocktail (eBioscience) in $200 \mu \mathrm{l} \mathrm{cRPMI}$ for $1 \mathrm{~h}$ at $37^{\circ} \mathrm{C}$. Directly to this, $50 \mu \mathrm{l}$ of $5 \times$ Stimulation Cocktail (plus protein transport inhibitor) (eBioscience) was added for an additional $4 \mathrm{~h}$ of incubation at $37^{\circ} \mathrm{C}$. After stimulation, cells were washed and resuspended in $100 \mu \mathrm{l}$ of $4 \%$ paraformaldehyde for $30 \mathrm{~min}$ at $4^{\circ} \mathrm{C}$. To quantify intracellular cytokines, these samples were permeabilized with $1 \times$ Permeabilization Buffer from the FOXP3/Transcription Factor Staining
Buffer Set (eBioscience) for 10 min at $4{ }^{\circ} \mathrm{C}$. All further staining cocktails were made in this buffer. Permeabilized cells were then washed and resuspended in a cocktail containing Human TruStan FcX (BioLegend) for 10 min at $4{ }^{\circ} \mathrm{C}$. Finally, intracellular staining cocktails were directly added to each sample for $1 \mathrm{~h}$ at $4{ }^{\circ} \mathrm{C}$. After this incubation, cells were washed and prepared for analysis on an Attune NXT (ThermoFisher). Data were analysed using FlowJo software v.10.6 software (Tree Star).

Set of markers used to identify each subset of cells are summarized in Extended Data Table 7, and gating strategies for the key cell populations presented in the main figures are shown in Extended Data Fig. 3a-c. For most samples, all available staining panels were implemented and analysed. The few exceptions pertained to those samples during which a mechanical malfunction occurred, which depleted the sample before acquisition, or to the samples with poor staining qualities. In these cases, data for these samples or panels were missing and not available. All the data available were used for the analyses, and the data used to generate figures and tables can be found in Supplementary Table1, and the raw fcs files are available at ImmPort as described in the 'Data Availability' section.

\section{Statistical analysis for the primary analyses}

For the primary analyses shown in the main figures, Graph Pad Prism $(v, 8.0)$ was used for all statistical analysis. Unless otherwise noted, one-way ANOVA with Bonferroni's multiple comparison test was used for the comparisons between $M_{-} P t$ versus F_Pt, M_Pt versus $M_{-} H C W$, $\mathrm{F}_{-} \mathrm{Pt}$ versus $\mathrm{F}_{-} \mathrm{HCW}$, and $\mathrm{M}_{-} \mathrm{HCW}$ versus $\mathrm{F}_{-} \mathrm{HCW}$ for the comparisons. For two-group comparisons including the comparison between stabilized group and deteriorated group in each sex (Fig. 4a-d), two-sided unpaired $t$-test was used for the comparison. Bioconductor R (v.3.6.3) package ggplot2 (v.3.3.0) was used to generate heat maps (Extended Data Fig. 2), $X-Y$ graphs for correlation analyses (Figs. 2e, 4f), and Pearson correlation heat maps (Fig. 4e).

\section{Statistical analysis for the secondary analyses}

All multivariable analyses were conducted using R v.3.6.1 (for data cleaning) and SAS version 9.4 (Cary, NC; for data analysis). The code used for data cleaning and data analysis is available at https://github.com/ muhellingson/covid_immresp. We conducted longitudinal analyses of the differences in immune response by sex for patients with COVID-19 and differences in immune response between patients with COVID-19 and HCWs by sex and adjusted linear regression to evaluate differences in immune response by sex at baseline and the differences in immune response by sex and patient trajectory.

Longitudinal difference in immune response in all patients positive for COVID-19 (cohort B) by sex. A marginal linear model was fitted to evaluate the difference in various immune responses (outcome) in patients by sex (exposure). We used an auto-regressive correlation structure to account for correlation between repeated observations in an individual over time. To account for the small sample size and unequal follow-up between participants, we used the Morel-BokossaNeerchal (MBN) correction. In addition to sex, the model contained time-independent terms for age (in years) and BMI and time-dependent terms for days from symptom onset (self-reported), ICU status (as a proxy for disease severity) and treatment with either tocilizumab or corticosteroids. A patient was defined as 'on tocilizumab' at a given time point if they had received the treatment within 14 days before the time the sample was taken. Patients were defined as 'on corticosteroids' if they had received the treatment on the same day the sample was taken. The resulting regression coefficients were interpreted as the difference in the adjusted least square means immune response between female and male patients.

Difference in immune response between patients with COVID-19 (cohort A) and HCWs by sex at baseline. We used linear regression to evaluate the difference in immune response between female and 
male patients at the first time point for those patients who had not received corticosteroids or tocilizumab before enrolment (cohort A). The model contained terms for sex, patient trajectory (worsened versus stable), age, BMI, and an interaction term for sex and group (patient versus HCWs). We calculated the least square means for each group (female patients who worsened, female patients who stabilized, male patients who worsened and male patients who stabilized) and evaluated the differences in the least square means of the different immune response outcomes by group and sex. $P$ values and 95\% confidence intervals were calculated with a Tukey correction for multiple pairwise comparisons. The regression coefficient of the interaction term between sex and group was interpreted as the difference-in-differences of the two comparisons by sex or by group (for example, the difference-in-differences between female and male patients and female and male $\mathrm{HCWs}$ ).

Longitudinal difference in immune response between all patients with COVID-19 (cohort B) and HCWs by sex. We used a marginal linear model with a compound symmetric correlation structure and the MBN correction to evaluate the difference in immune responses between patients and HCWs by sex, controlling for age and BMI. We calculated the least square means for each group (female patients, female HCWs, male patient, male HCWs) and evaluated the differences in adjusted least square means to compare study groups by sex (female patients versus male patients, female HCWs versus male HCWs, female patients versus female $\mathrm{HCWs}$ and male patients versus male $\mathrm{HCWs}$ ). $P$ values and $95 \%$ confidence intervals were corrected using the Tukey correction for multiple pairwise comparisons. The regression coefficient of the interaction term between sex and study group was interpreted as the difference-in-differences between the two comparisons by sex or by group.

Multivariable patient trajectory analysis. We used linear regression to evaluate the difference in baseline immune response between patients who worsened after the baseline sample was taken and those who stabilized by sex. The model contained terms for sex, patient trajectory (worsened versus stable), age, days from symptom onset and an interaction term for sex and patient trajectory. We calculated the adjusted least square means for each group (female patients who worsened, female patients who stabilized, male patients who worsened and male patients who stabilized) and evaluated the differences in least square means of the different immune responses by patient trajectory and sex using the Tukey correction for multiple comparisons. The regression coefficient of the interaction term between sex and patient trajectory was interpreted as the difference-in-differences between the two patient trajectories by sex or sex by the two patient trajectories.

\section{Reporting summary}

Further information on research design is available in the Nature Research Reporting Summary linked to this paper.

\section{Data availability}

All of the background information of HCWs, clinical information of patients, and raw data used in this study are included in the Supplementary Table 1 . In addition, all of the raw fcs files for the flow cytometry analysis are uploaded in ImmPort (https://www.immport.org/shared/ home, study ID: SDY1648).

17. WHO. R\&D Blueprint Novel Coronavirus COVID-19 Therapeutic Trial Synopsis https://www. who.int/blueprint/priority-diseases/key-action/COVID-19_Treatment_Trial_Design_Master_ Protocol_synopsis_Final_18022020.pdf (2020).

18. Vogels, C. B. F. et al. Analytical sensitivity and efficiency comparisons of SARS-CoV-2 RT-qPCR primer-probe sets. Nat. Microbiol. 5, 1299-1305 (2020)

19. Wyllie, A. L. et al. Saliva or nasopharyngeal swab specimens for detection of SARS-CoV-2. N. Engl. J. Med. https://doi.org/10.1056/NEJMc2016359 (2020).

20. Amanat, F. et al. A serological assay to detect SARS-CoV-2 seroconversion in humans. Nat. Med. 26, 1033-1036 (2020).

Acknowledgements We thank M. Linehan for technical and logistical assistance. This work was supported by the Women's Health Research at Yale Pilot Project Program (A.I., A.M.R.), Fast Grant from Emergent Ventures at the Mercatus Center, Mathers Foundation, the Beatrice Kleinberg Neuwirth Fund, Yale Institute for Global Health, and the Ludwig Family Foundation. IMPACT received support from the Yale COVID-19 Research Resource Fund. A.I. is an Investigator of the Howard Hughes Medical Institute. CBFV is supported by NWO Rubicon 019.181EN.004. A.M. is supported by NIH grant R37AIO41699.

Author contributions A.I., S.B.O. and A.I.K. conceived the study. C.L., P.W., J.K., J. Silva, T.M. and J.E.O. defined parameters for flow cytometry experiments, collected and processed patient PBMC samples. P.W. acquired and analysed the flow cytometry data. B.I., J.K., C.L. and C.D.O. collected epidemiological and clinical data. F.L., A.M., J. Sun, E.Y.W. and A.M.R. acquired and analysed ELISA data. A.L.W., C.B.F.V., I.M.O., R.E., S.L., P.L., A.V., A.P. and M.T. performed the virus RNA concentration assays. N.D.G. supervised viral RNA concentration assays. A.C.-M. and A.J.M. processed and stored patient specimens, J.B.F., C.D.C. and S.F. assisted in patient recruitment, W.L.S. supervised clinical data management, A.S. coordinated and secured funding for PBMC collection. T.T. designed the analysis scheme, analysed and interpreted the data for the baseline analyses. M.K.E. and S.B.O. designed the analysis scheme, and interpreted the data for the longitudinal analyses. M.K.E. analysed the longitudinal data. T.T., M.K.E. and A.I. drafted the manuscript. A.I., A.M.R. and S.B.O. revised the manuscript. A.I. secured funds and supervised the project. Authors from the Yale IMPACT Research Team contributed to collection and storage of patient samples, as well as the collection of the patients' epidemiological and clinical data.

Competing interests The authors declare no competing interests.

Additional information

Supplementary information is available for this paper at https://doi.org/10.1038/s41586-0202700-3.

Correspondence and requests for materials should be addressed to $A . I$.

Peer review information Nature thanks Petter Brodin, Malik Peiris and the other, anonymous, reviewer(s) for their contribution to the peer review of this work. Peer reviewer reports are available.

Reprints and permissions information is available at http://www.nature.com/reprints. 
Age

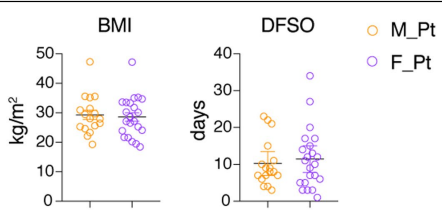

M_Pt

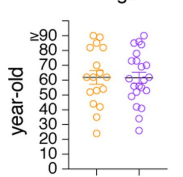

$10-$
0

b $1 \mathrm{~L}-1$
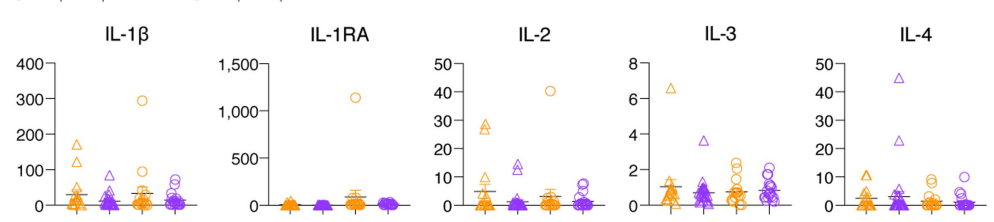

M_HCW $\triangle$ F_HCW $\circ$ M_Pt $\circ$ F_Pt
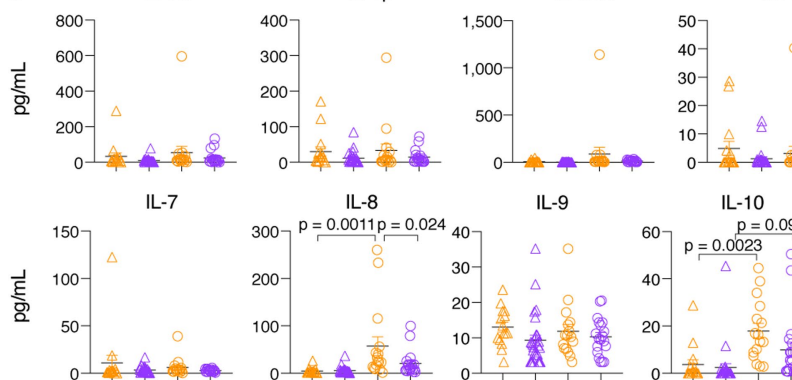

$\mathrm{IL}-12 \mathrm{p} 40$

IL-12p70
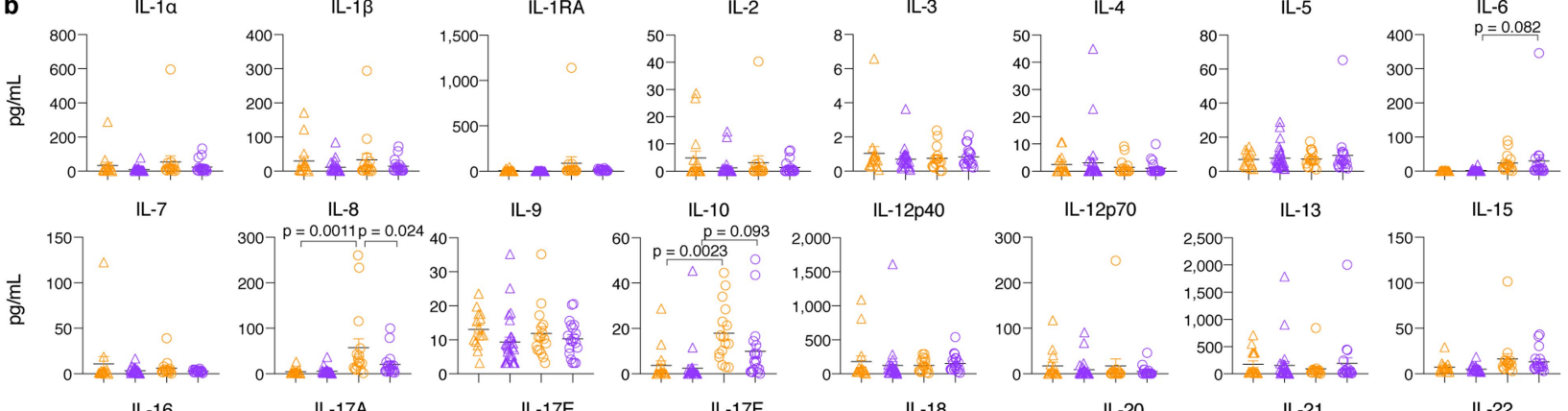

$\mathrm{IL}-15$
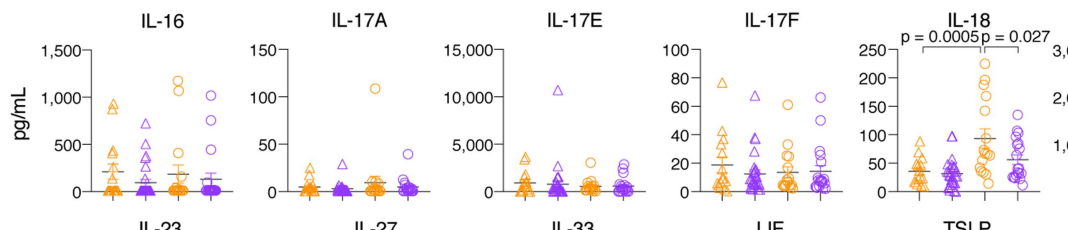

(1)

IL-21
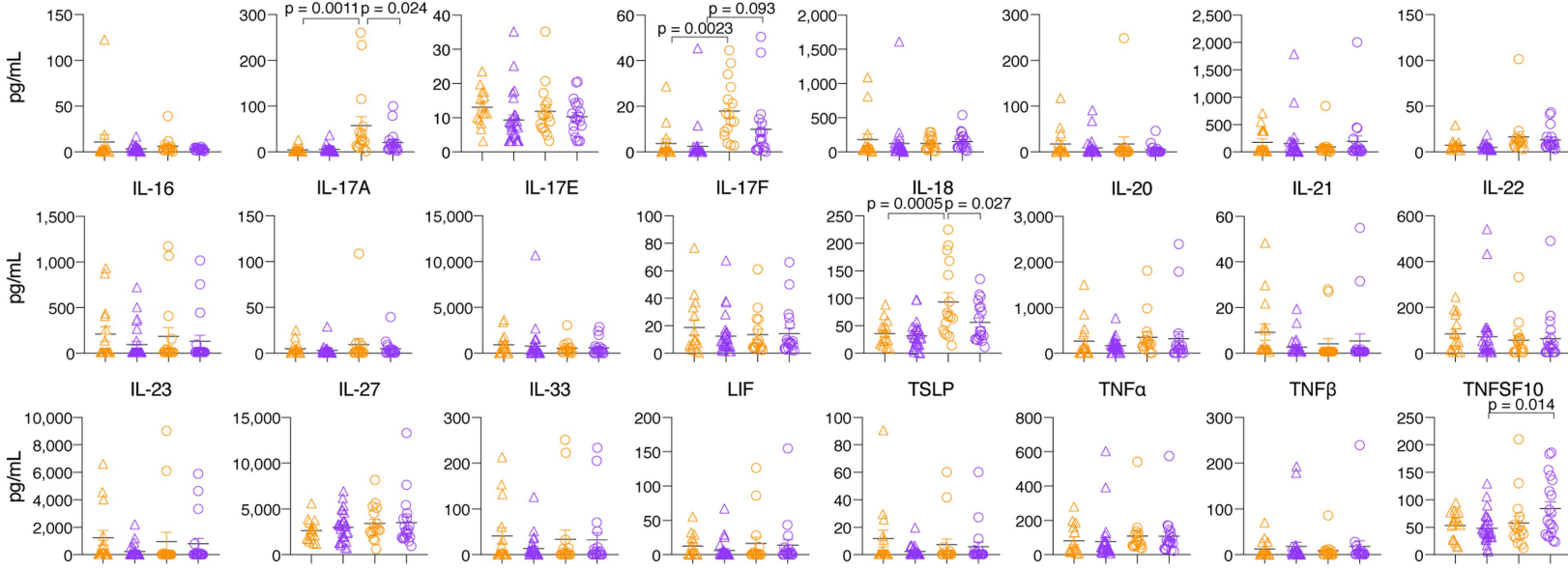

TSLP
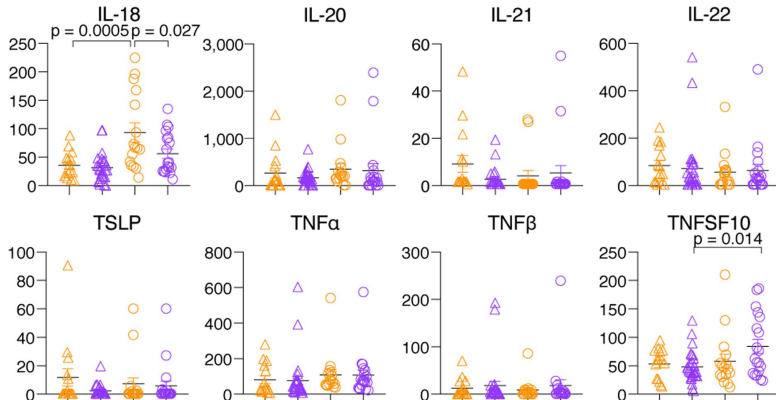

$\mathrm{CD} 40 \mathrm{~L}$
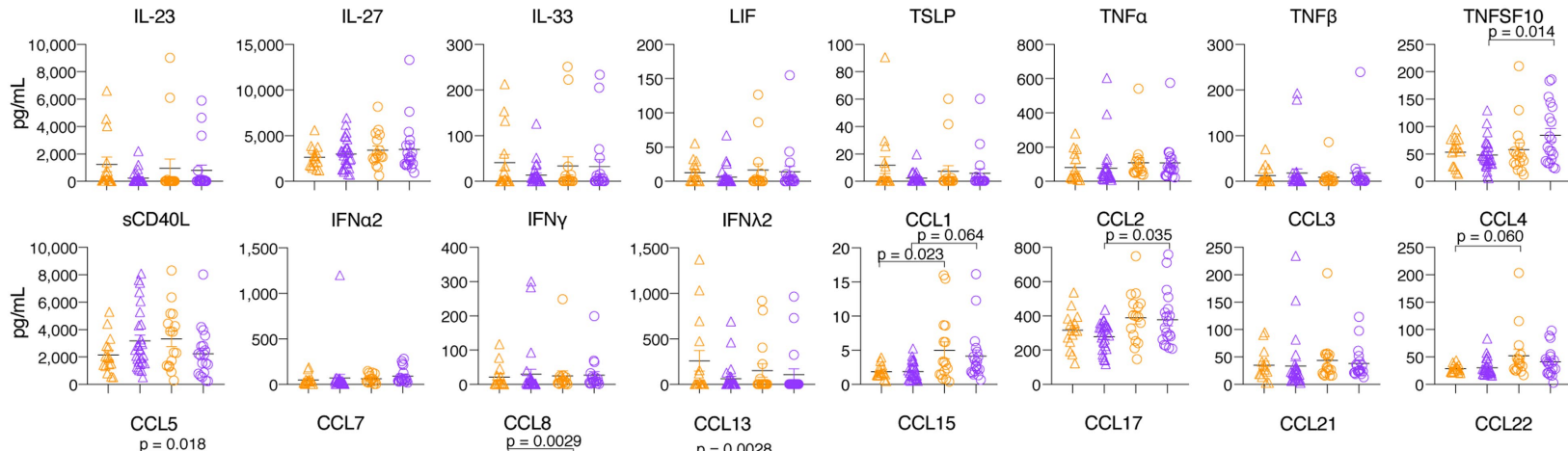

$$
\text { CCL13 }
$$

CCL15

CCL17
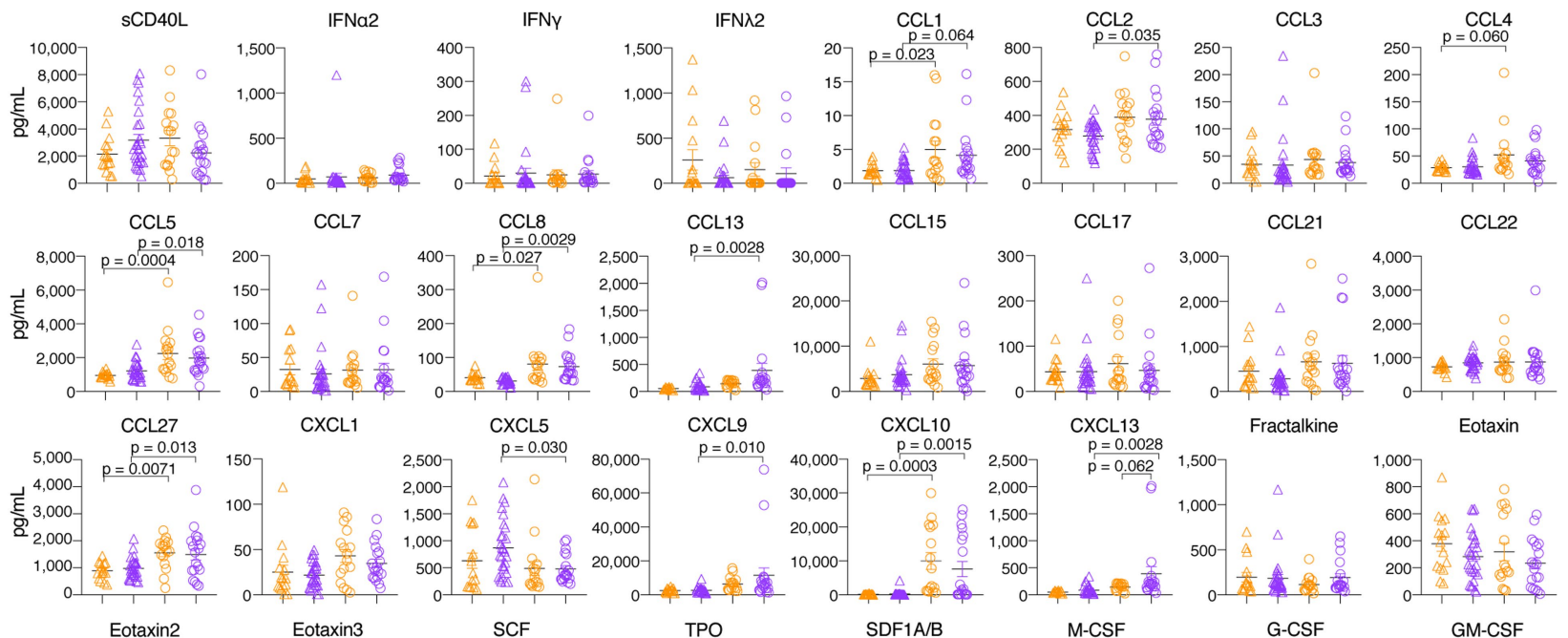

$2,500-$
2,000
1,500

$p=0.0028$

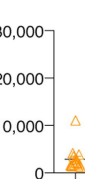

CCL21

CCL22

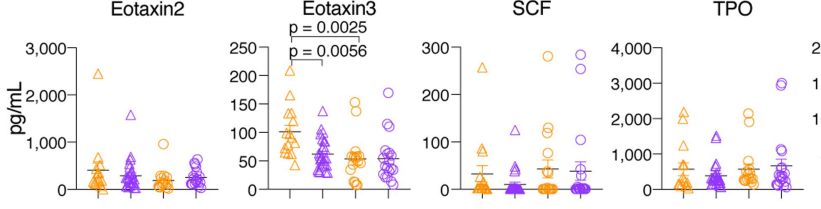

$\frac{\circ}{8}$
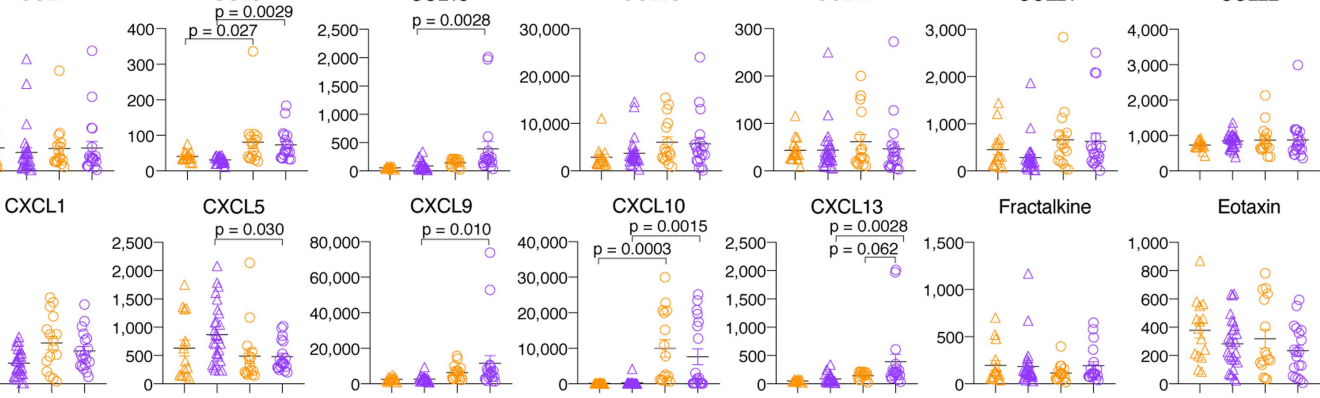

Fractalkine

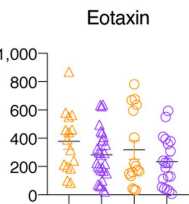

SDF1A/B
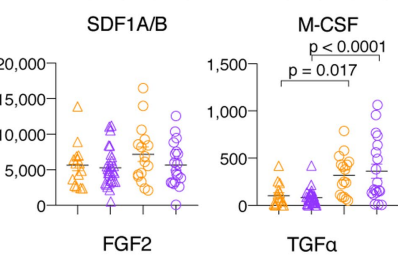

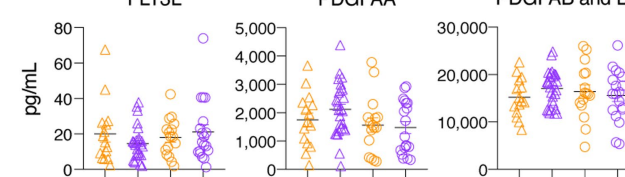
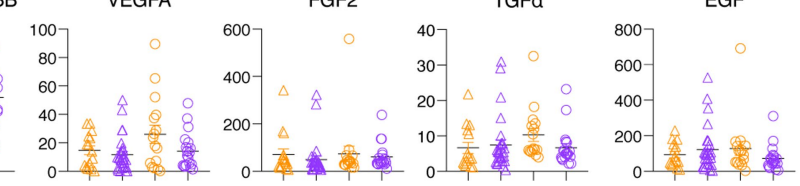

Extended Data Fig. 1|Comparison of basic clinical parameters of cohort $A$ patient samples and plasma levels of 71 cytokines and chemokines at the first sampling of cohort A. a, Comparisons of age, BMI and DFSO at the first sampling between male and female patients in cohort A. $n=17$ and 22 for M_Pt and F_Pt, respectively. $\mathbf{b}$, Comparison of the plasma levels of 71 cytokines and chemokines. $n=15,28,16$ and 19 for M_HCW, F_HCW, M_Pt and F_Pt, respectively. Data are mean \pm s.e.m. $P$ values were determined by unpaired two-tailed $t$-test (a) or one-way ANOVA with Bonferroni multiple comparison test (b). All $P$ values $<0.10$ are shown. 
a

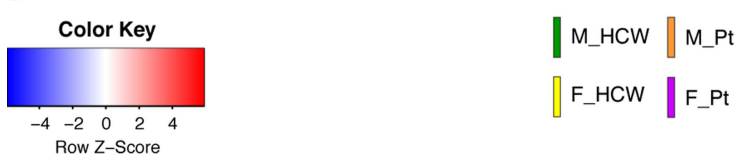

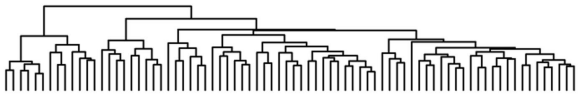

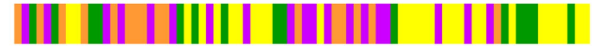

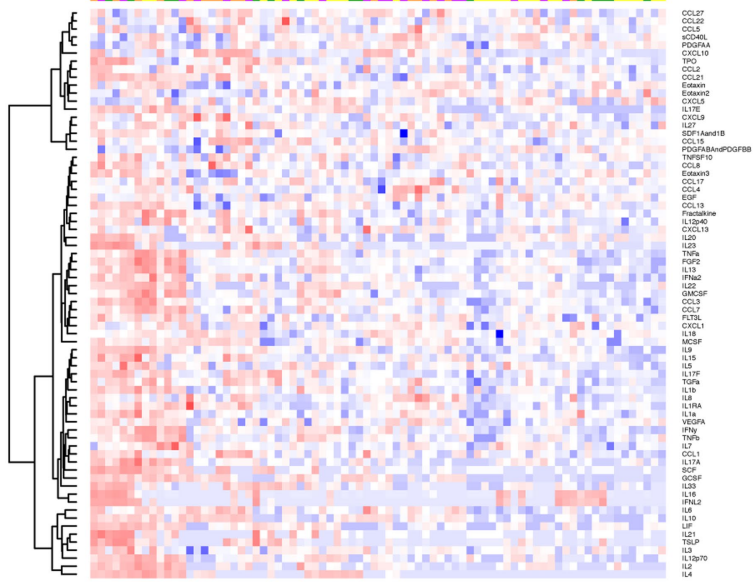

c
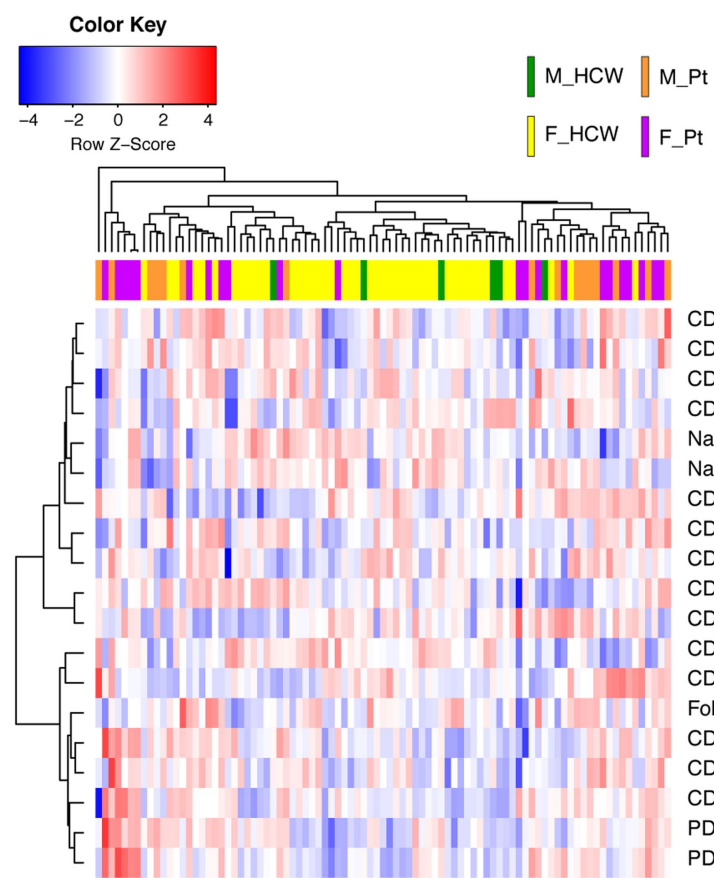

CD4Tfh

CD4nTreg

CD8Tcm

CD8Tem

NaiveCD4

NaiveCD8 CD8Temra

CD4Tcm

CD4Tem

CD4

CD8

CD4rnTreg

CD4Temra

FollCD8

CD38+HLA-DR+CD4

CD4effTreg

CD38+HLA-DR+CD8

PD-1+Tim3+CD4

PD-1+Tim3+CD8

b

d
Extended Data Fig. 2 | Heat maps of cytokines and chemokines, PBMC composition, $T$ cell subsets, and $T$ cell cytokine expression at the first sampling of cohort $A$ patients. a, A heat map of the plasma levels $\left(\mathrm{pg} \mathrm{ml}^{-1}\right)$ of 71 cytokines and chemokines. $n=15,28,16$ and 19 for M_HCW, F_HCW, M_Pt and F_Pt, respectively. $\mathbf{b}$, A heat map for the composition of PBMCs (percentage in live PBMCs). $n=6,42,16$ and 21 for M_HCW, F_HCW, M_Pt and F_Pt, respectively.
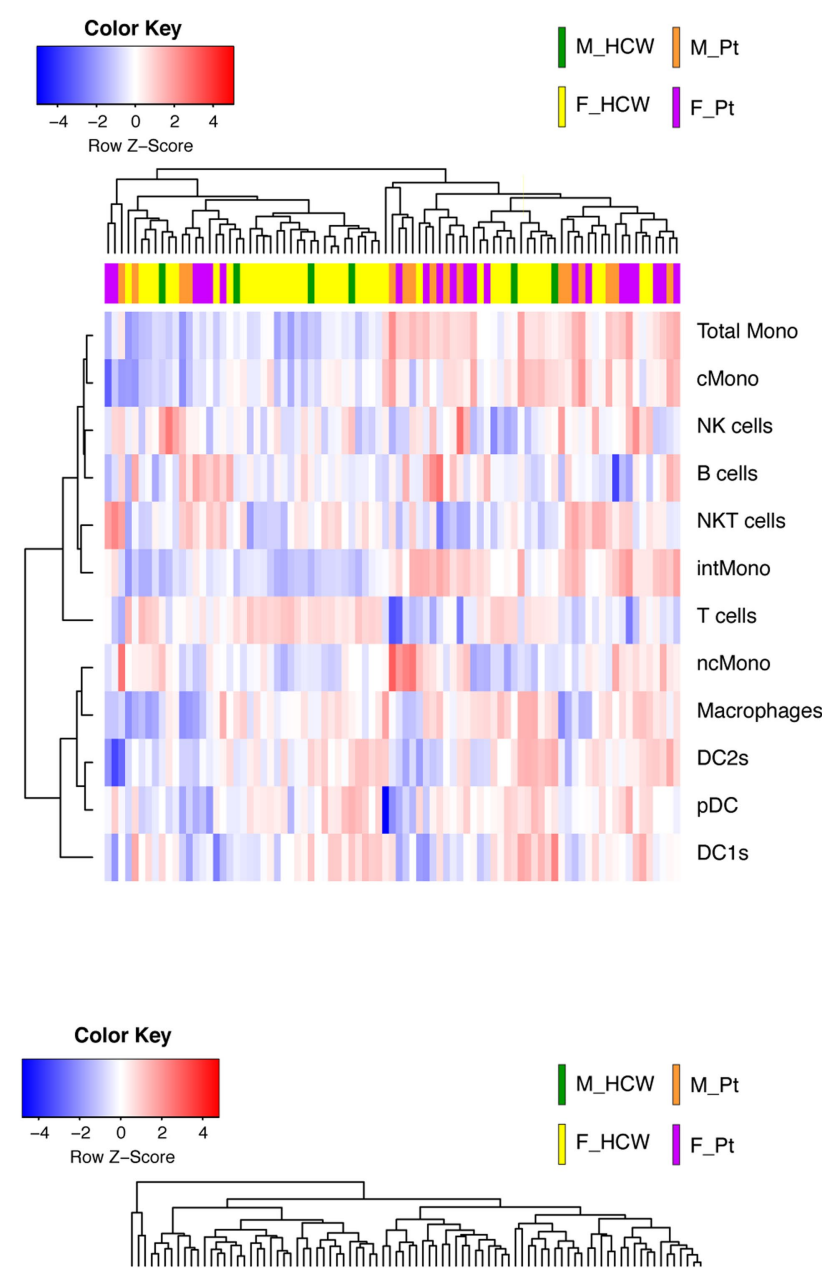
| | ||| || | ||||||| ||||||||||

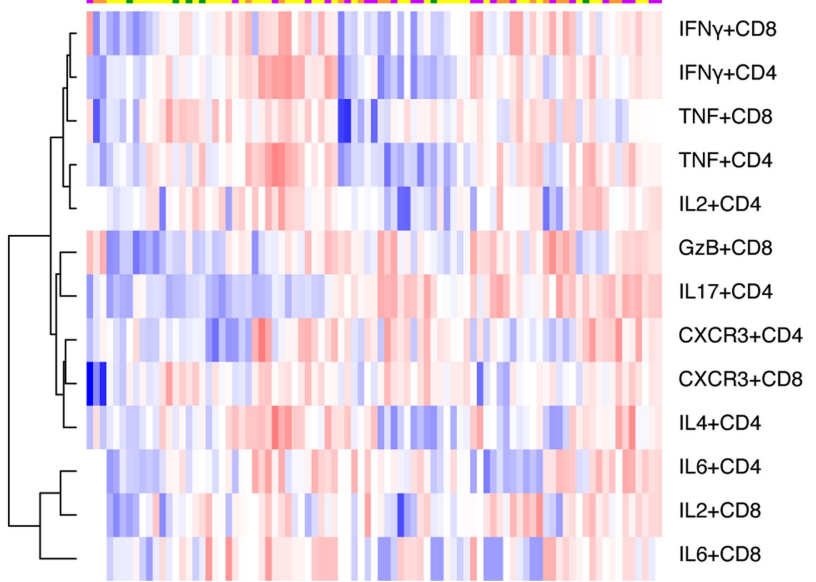

c, A heat map for the T cell subsets (percentage in $\mathrm{CD}^{+}{ }^{+}$cells). $n=6,45,16$ and 22 for M_HCW, F_HCW, M_Pt and F_Pt, respectively. d, A heat map for the intracellular cytokine staining of T cells (percentage in $C D 3^{+}$cells). $n=6,43,16$ and 22 for M_HCW, F_HCW, M_Pt and F_Pt, respectively. In all of these heat maps, log-transformed values were used for heat map generation. 
a
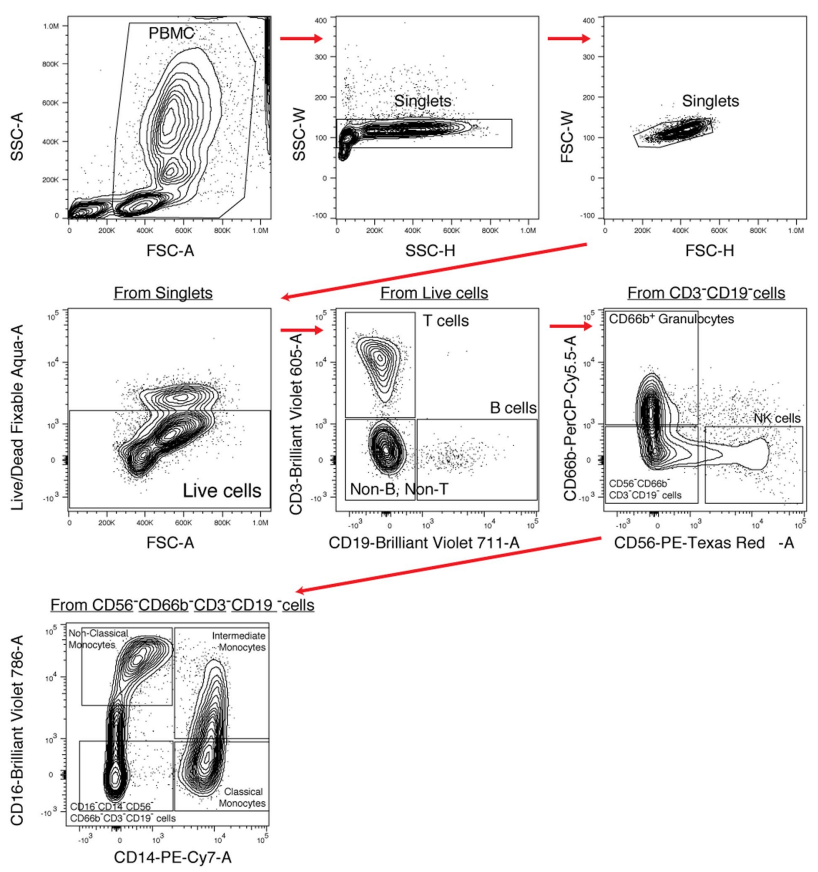

c
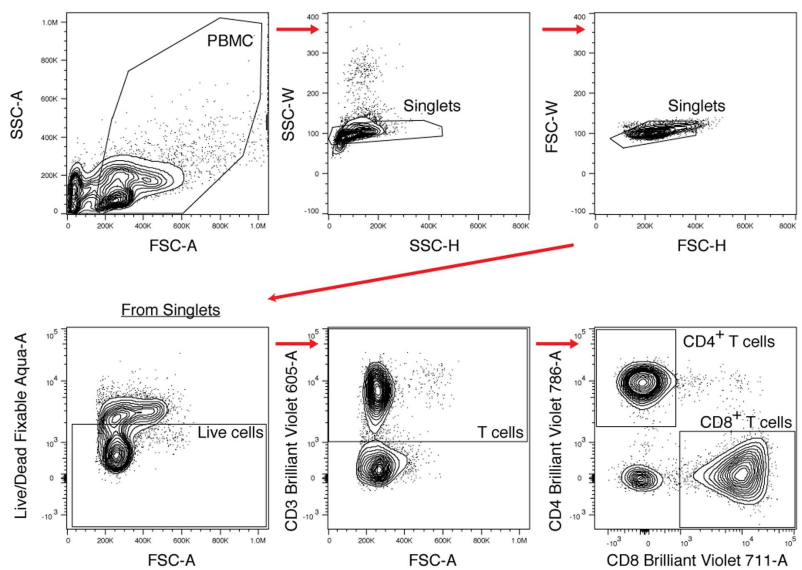

b
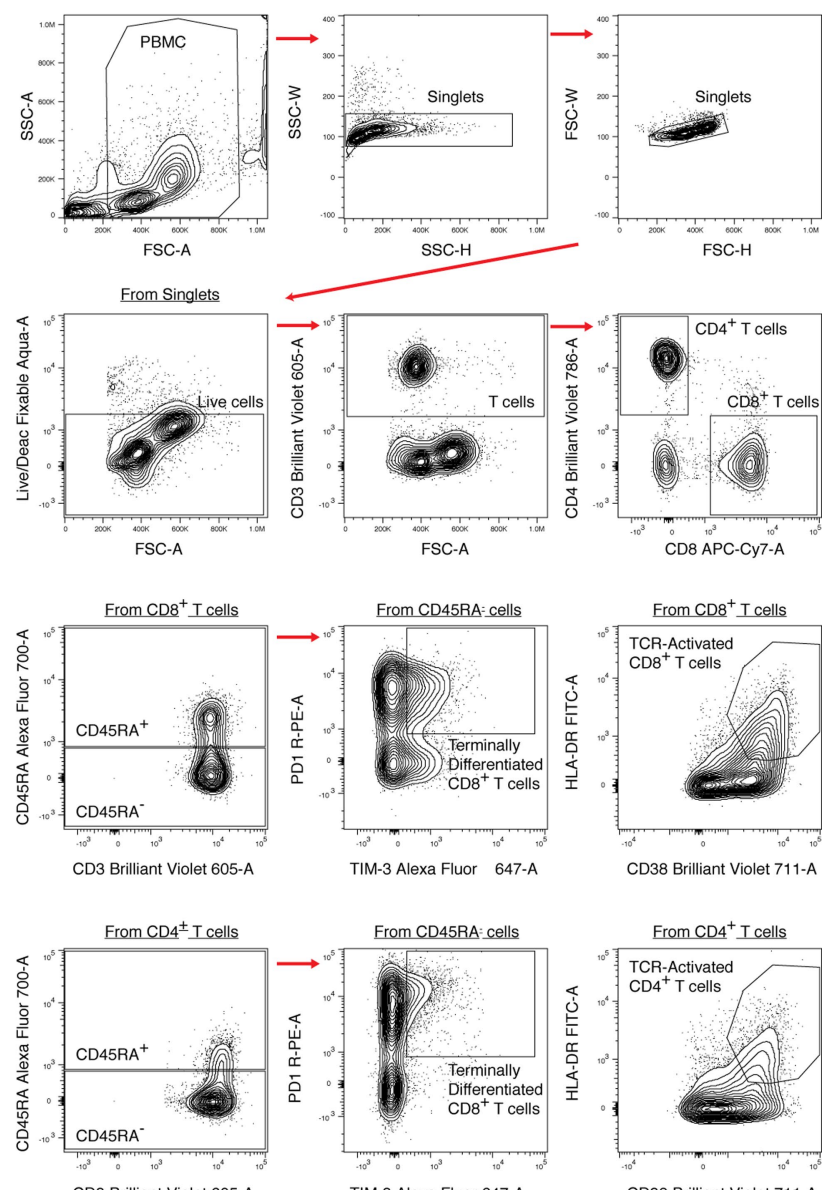

TIM-3 Alexa Fluor 647-A

CD38 Brilliant Violet 711-A

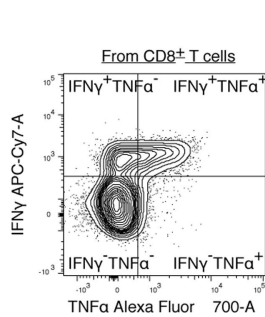

Extended Data Fig. 3 | Flow cytometry gating strategy. a-c, Gating strategy used for monocytes (a), CD38 ${ }^{+} \mathrm{HLA}-\mathrm{DR}{ }^{+}$and PD-1 $1^{+} \mathrm{TIM}-3^{+} \mathrm{CD} 4$ or CD8 T cells $(\mathbf{b})$, and $\mathrm{T}$ cell intracellular staining for IFN $\gamma^{+} \mathrm{CD} 8 \mathrm{~T}$ cells $(\mathbf{c})$. 
Extended Data Table 1 | Demographic and clinical characteristics of cohort A, cohort B and HCW comparison groups

\begin{tabular}{|c|c|c|c|c|c|c|c|c|c|c|}
\hline & \multicolumn{2}{|c|}{$\begin{array}{l}\text { Cohort A Patients } \\
\qquad(\mathrm{N}=39)\end{array}$} & \multicolumn{2}{|c|}{$\begin{array}{l}\text { Cohort B Patients } \\
\qquad(\mathrm{N}=98)\end{array}$} & \multicolumn{2}{|c|}{$\begin{array}{l}\text { Healthcare Workers (N } \\
=64)\end{array}$} & \multicolumn{2}{|c|}{$\begin{array}{l}\text { Healthcare Workers with } \\
\text { cytokine/chemokine } \\
\text { measurements }(\mathrm{N}=43)\end{array}$} & \multicolumn{2}{|c|}{$\begin{array}{l}\text { Healthcare Workers with } \\
\text { flow cytometry }(N=51)\end{array}$} \\
\hline & $\begin{array}{l}\text { Female } \\
-\mathrm{N}(\%)\end{array}$ & $\begin{array}{l}\text { Male - } \\
\mathrm{N}(\%)\end{array}$ & $\begin{array}{l}\text { Female } \\
-\mathrm{N}(\%)\end{array}$ & $\begin{array}{l}\text { Male - } \\
\mathrm{N}(\%)\end{array}$ & $\begin{array}{l}\text { Female }-\mathrm{N} \\
(\%)\end{array}$ & $\begin{array}{l}\text { Male }-N \\
(\%)\end{array}$ & Female - N (\%) & $\begin{array}{l}\text { Male }-N \\
(\%)\end{array}$ & Female - N (\%) & $\begin{array}{l}\text { Male - } \\
\mathrm{N}(\%)\end{array}$ \\
\hline Total & $\begin{array}{r}22 \\
(56.4)\end{array}$ & $\begin{array}{r}17 \\
(43.6)\end{array}$ & $\begin{array}{r}51 \\
(52.0)\end{array}$ & $\begin{array}{r}47 \\
(48.0)\end{array}$ & $45(70.3)$ & $19(29.7)$ & $28(59.5)$ & $15(40.5)$ & $45(88.0)$ & $6(12.0)$ \\
\hline Ethnicity* & & & & & & & & & & \\
\hline $\begin{array}{r}\text { Black/African } \\
\text { American }\end{array}$ & $4(18.2)$ & $5(29.4)$ & $\begin{array}{r}18 \\
(35.3)\end{array}$ & $\begin{array}{r}11 \\
(23.4)\end{array}$ & $2(4.4)$ & $1(5.3)$ & $0(0.0)$ & $0(0.0)$ & $2(4.6)$ & $1(16.7)$ \\
\hline White & $\begin{array}{r}14 \\
(63.6)\end{array}$ & 9 (52.9) & $\begin{array}{r}26 \\
(51.0)\end{array}$ & $\begin{array}{r}27 \\
(57.5)\end{array}$ & $38(84.4)$ & $11(57.9)$ & $26(100.0)$ & $9(60.0)$ & $38(84.1)$ & $4(66.8)$ \\
\hline Hispanic & 4 (18.2) & $2(11.8)$ & $6(11.8)$ & $8(17.0)$ & $3(6.7)$ & $2(10.5)$ & $0(0.0)$ & $1(6.7)$ & $3(6.8)$ & $1(16.7)$ \\
\hline Other & $0(0.0)$ & $0(0.0)$ & $1(2.0)$ & $1(2.1)$ & $2(4.4)$ & 5 (26.3) & $2(0.0)$ & 5 (33.3) & 1 (2.3) & $0(0.0)$ \\
\hline $\begin{array}{r}\text { BMI }^{*}-\text { Mean } \\
\text { (SD) }\end{array}$ & $\begin{array}{l}28.6 \\
(6.8)\end{array}$ & $\begin{array}{l}29.3 \\
(6.6)\end{array}$ & $\begin{array}{l}32.4 \\
(9.9)\end{array}$ & $\begin{array}{l}30.3 \\
(6.0)\end{array}$ & $26.4(5.7)$ & $28.8(6.4)$ & $26.4(5.8)$ & $31.3(6.6)$ & $27.4(6.1)$ & $\begin{array}{l}28.0 \\
(6.9)\end{array}$ \\
\hline$<18$ & $1(4.6)$ & $0(0.0)$ & 2 (3.9) & $0(0.0)$ & $1(2.2)$ & $0(0.0)$ & $0(0.0)$ & $0(0.0)$ & $2(4.6)$ & $0(0.0)$ \\
\hline $18-24.9$ & $6(27.3)$ & $4(23.5)$ & $8(15.7)$ & 7 (14.9) & $19(42.2)$ & $3(15.8)$ & $18(54.6)$ & $2(13.3)$ & $17(36.4)$ & $3(50.0)$ \\
\hline $25-29.9$ & $5(22.7)$ & 7 (41.2) & $\begin{array}{r}11 \\
(21.6)\end{array}$ & $\begin{array}{r}18 \\
(38.3)\end{array}$ & $11(24.4)$ & $9(47.4)$ & $6(27.3)$ & $7(46.7)$ & $13(29.6)$ & $1(16.8)$ \\
\hline $30-34.9$ & $8(36.4)$ & $2(11.8)$ & $\begin{array}{r}19 \\
(37.3)\end{array}$ & $\begin{array}{r}11 \\
(23.4)\end{array}$ & $5(11.1)$ & $1(5.3)$ & $0(0.0)$ & $1(6.7)$ & $6(13.6)$ & $\begin{array}{r}0 \\
(0.0)\end{array}$ \\
\hline $35+$ & $2(9.1)$ & $4(23.5)$ & $\begin{array}{r}11 \\
(21.6)\end{array}$ & $\begin{array}{r}11 \\
(21.6)\end{array}$ & $8(17.8)$ & $6(31.6)$ & $4(18.2)$ & $5(33.3)$ & $7(15.9)$ & $2(33.3)$ \\
\hline \multicolumn{11}{|l|}{$\begin{array}{r}\text { COVID Risk } \\
\text { Factors }^{\dagger}\end{array}$} \\
\hline $\begin{array}{r}\text { Recent cancer } \\
\text { treatment }\end{array}$ & $3(13.6)$ & $1(5.9)$ & $3(5.9)$ & $4(8.5)$ & & & & & & \\
\hline $\begin{array}{r}\text { Chronic heart } \\
\text { disease }\end{array}$ & $3(13.6)$ & 7 (41.2) & $\begin{array}{r}12 \\
(23.5)\end{array}$ & $\begin{array}{r}12 \\
(25.5)\end{array}$ & & & & & & \\
\hline Hypertension & $7(31.8)$ & $\begin{array}{r}10 \\
(58.8)\end{array}$ & $\begin{array}{r}23 \\
(45.1)\end{array}$ & $\begin{array}{r}27 \\
(57.5)\end{array}$ & & & & & & \\
\hline $\begin{array}{r}\text { Chronic lung } \\
\text { disease }\end{array}$ & $4(18.2)$ & $4(23.5)$ & $\begin{array}{r}17 \\
(33.3)\end{array}$ & $6(12.8)$ & & & & & & \\
\hline $\begin{array}{r}\text { Immunosuppr } \\
\text { ession }\end{array}$ & $3(13.6)$ & $1(5.9)$ & $4(7.8)$ & $1(2.1)$ & & & & & & \\
\hline $\begin{array}{r}\text { Received } \\
\text { Tocilizumab }^{\ddagger}\end{array}$ & & & $\begin{array}{r}31 \\
(60.8)\end{array}$ & $\begin{array}{r}33 \\
(64.7)\end{array}$ & & & & & & \\
\hline $\begin{array}{r}\text { Received } \\
\text { Corticosteroi } \\
\mathbf{d s}^{\ddagger}\end{array}$ & & & $7(13.7)$ & 7 (14.9) & & & & & & \\
\hline $\begin{array}{r}\text { Admitted to } \\
\text { the ICU }\end{array}$ & & & $\begin{array}{r}13 \\
(25.5)\end{array}$ & $\begin{array}{r}12 \\
(25.5)\end{array}$ & & & & & & \\
\hline \multicolumn{11}{|l|}{$\begin{array}{r}\text { Number of } \\
\text { samples }\end{array}$} \\
\hline 1 & & & $\begin{array}{r}27 \\
(52.9)\end{array}$ & $\begin{array}{r}22 \\
(46.8)\end{array}$ & 37 (82.2) & $18(94.7)$ & $21(72.7)$ & $14(93.3)$ & $43(95.5)$ & $\begin{array}{r}6 \\
(100.0)\end{array}$ \\
\hline 2 & & & $\begin{array}{r}12 \\
(23.5)\end{array}$ & $\begin{array}{r}18 \\
(38.3)\end{array}$ & $8(17.8)$ & $1(5.3)$ & 7 (27.3) & $1(6.7)$ & $2(4.5)$ & $0(0.0)$ \\
\hline 3 & & & $8(15.7)$ & $3(6.4)$ & $0(0.0)$ & $0(0.0)$ & $0(0.0)$ & $0(0.0)$ & $0(0.0)$ & $0(0.0)$ \\
\hline 4 & & & $2(3.9)$ & $4(8.5)$ & $0(0.0)$ & $0(0.0)$ & $0(0.0)$ & $0(0.0)$ & $0(0.0)$ & $0(0.0)$ \\
\hline 5 & & & $0(0.0)$ & $0(0.0)$ & $0(0.0)$ & $0(0.0)$ & $0(0.0)$ & $0(0.0)$ & $0(0.0)$ & $0(0.0)$ \\
\hline 6 & & & $1(2.0)$ & $0(0.0)$ & $0(0.0)$ & $0(0.0)$ & $0(0.0)$ & $0(0.0)$ & $0(0.0)$ & $0(0.0)$ \\
\hline 7 & & & $0(0.0)$ & $0(0.0)$ & $0(0.0)$ & $0(0.0)$ & $0(0.0)$ & $0(0.0)$ & $0(0.0)$ & $0(0.0)$ \\
\hline 8 & & & $1(2.0)$ & $0(0.0)$ & $0(0.0)$ & $0(0.0)$ & $0(0.0)$ & $0(0.0)$ & $0(0.0)$ & $0(0.0)$ \\
\hline $\begin{array}{r}\text { Age - mean } \\
\text { (SD) }\end{array}$ & $\begin{array}{r}61.6 \\
(17.4)\end{array}$ & $\begin{array}{r}61.9 \\
(19.5)\end{array}$ & $\begin{array}{r}64.0 \\
(16.9)\end{array}$ & $\begin{array}{r}61.9 \\
(16.7)\end{array}$ & $37.9(11.9)$ & $\begin{array}{r}43.1 \\
(13.2)\end{array}$ & $42.3(12.8)$ & $\begin{array}{r}47.5 \\
(11.2)\end{array}$ & $37.6(11.0)$ & $\begin{array}{l}29.0 \\
(7.6)\end{array}$ \\
\hline $\begin{array}{r}\text { Days from } \\
\text { symptom } \\
\text { onset - mean } \\
(S D)^{\ddagger}\end{array}$ & $\begin{array}{r}11.4 \\
(8.1)\end{array}$ & $\begin{array}{l}10.2 \\
(6.3)\end{array}$ & $\begin{array}{l}11.7 \\
(7.2)\end{array}$ & $\begin{array}{l}12.1 \\
(7.3)\end{array}$ & & & & & & \\
\hline $\begin{array}{r}\text { Clinical } \\
\text { Score - } \\
\text { mean }(S D)^{\ddagger}\end{array}$ & $1.3(0.5)$ & $1.4(0.5)$ & $2.5(1.5)$ & $2.7(1.3)$ & & & & & & \\
\hline
\end{tabular}

${ }^{*}$ Cells may not sum to total owing to missing data.

+Categories not mutually exclusive.

₹Grey areas indicate that data are not available or not applicable. 


\section{Article}

\section{Extended Data Table 2 | Background and sample information of 39 cohort A patients}

\begin{tabular}{|c|c|c|c|c|c|c|c|c|c|c|c|}
\hline ID & Sex & $\begin{array}{l}\text { Age } \\
\text { (yr-old) }\end{array}$ & Ethnicity & $\begin{array}{l}\text { BMI } \\
\left(\mathrm{kg} / \mathrm{m}^{2}\right)\end{array}$ & $\begin{array}{l}\text { COVID } \\
\text { Risk } \\
\text { factors }^{\dagger}\end{array}$ & $\mathrm{C1}^{\ddagger}$ & $\begin{array}{l}\text { DFSO } \\
\text { at } \mathrm{C1}^{\S}\end{array}$ & Cmax" & $\begin{array}{l}\text { DFSO at } \\
\text { the first day } \\
\text { of Cmax }\end{array}$ & $\begin{array}{l}\text { Deteriorated } \\
(C \text { max }>C 1, \\
\text { yes }=1, \text { no }=0)\end{array}$ & Available data type $^{\#}$ \\
\hline Pt003 & $\mathrm{F}$ & 49 & 5 & 35.0 & 0 & 1 & 17 & 1 & & 0 & $\mathrm{~N}, \mathrm{~S}, \mathrm{E}, \mathrm{F} 1, \mathrm{~F} 2, \mathrm{~F} 3$ \\
\hline Pt005 & $\mathrm{F}$ & 42 & 5 & 19.5 & 0 & 1 & 14 & 1 & & 0 & $E, F 1, F 2, F 3$ \\
\hline Pt019 & $\mathrm{F}$ & 56 & 3 & 30.1 & 3 & 2 & 5 & 3 & 11 & 1 & $\mathrm{~N}, \mathrm{~S}, \mathrm{G}, \mathrm{M}, \mathrm{E}, \mathrm{F} 1, \mathrm{~F} 2, \mathrm{~F} 3$ \\
\hline Pt022 & $\mathrm{F}$ & 56 & 3 & 30.3 & $3,4,5$ & 1 & 7 & 3 & 14 & 1 & $\mathrm{~N}, \mathrm{G}, \mathrm{M}, \mathrm{E}, \mathrm{F} 1, \mathrm{~F} 2, \mathrm{~F} 3$ \\
\hline Pt032 & $\mathrm{F}$ & 69 & 5 & 23.9 & 0 & 1 & 7 & 1 & & 0 & $\mathrm{~N}, \mathrm{G}, \mathrm{M}, \mathrm{E}, \mathrm{F} 1, \mathrm{~F} 2, \mathrm{~F} 3$ \\
\hline Pt036 & $\mathrm{F}$ & 73 & 3 & 20.2 & $1,2,3$ & 1 & 10 & 3 & 15 & 1 & $\mathrm{~N}, \mathrm{~S}, \mathrm{G}, \mathrm{M}, \mathrm{E}, \mathrm{F} 1, \mathrm{~F} 2, \mathrm{~F} 3$ \\
\hline Pt038 & $\mathrm{F}$ & 41 & 6 & 33.3 & 4 & 1 & 34 & 1 & & 0 & $N, S, G, M, E, F 1, F 2, F 3$ \\
\hline Pt044 & $\mathrm{F}$ & 26 & 5 & 33.5 & 0 & 1 & 20 & 1 & & 0 & $\mathrm{~N}, \mathrm{~S}, \mathrm{G}, \mathrm{M}, \mathrm{E}, \mathrm{F} 1, \mathrm{~F} 2, \mathrm{~F} 3$ \\
\hline Pt055 & $\mathrm{F}$ & 61 & 5 & 26.6 & 5 & 2 & 3 & 3 & 8 & 1 & $\mathrm{~N}, \mathrm{~S}, \mathrm{G}, \mathrm{M}, \mathrm{E}, \mathrm{F} 1, \mathrm{~F} 2, \mathrm{~F} 3$ \\
\hline Pt058 & $\mathrm{F}$ & 62 & 5 & 21.6 & 5 & 1 & 9 & 1 & & 0 & $\mathrm{~S}, \mathrm{G}, \mathrm{M}, \mathrm{E}, \mathrm{F} 1, \mathrm{~F} 2, \mathrm{~F} 3$ \\
\hline Pt070 & $\mathrm{F}$ & 53 & 5 & 27.1 & 0 & 2 & 12 & 1 & & 0 & $\mathrm{~N}, \mathrm{~S}, \mathrm{G}, \mathrm{M}, \mathrm{E}, \mathrm{F} 1, \mathrm{~F} 2, \mathrm{~F} 3$ \\
\hline Pt085 & $\mathrm{F}$ & 85 & 6 & 21.7 & 0 & 1 & 5 & 1 & & 0 & $\mathrm{G}, \mathrm{M}, \mathrm{E}, \mathrm{F} 1, \mathrm{~F} 2, \mathrm{~F} 3$ \\
\hline Pt086 & $\mathrm{F}$ & $\geq 90$ & 5 & 18.5 & 1 & 2 & 3 & 1 & & 0 & $\mathrm{~N}, \mathrm{G}, \mathrm{M}, \mathrm{E}, \mathrm{F} 1, \mathrm{~F} 2, \mathrm{~F} 3$ \\
\hline Pt087 & $\mathrm{F}$ & 60 & 5 & 47.2 & 0 & 2 & 1 & 3 & 2 & 1 & $\mathrm{~N}, \mathrm{G}, \mathrm{M}, \mathrm{E}, \mathrm{F} 1, \mathrm{~F} 2, \mathrm{~F} 3$ \\
\hline Pt092 & $\mathrm{F}$ & 78 & 5 & 28.6 & 2,3 & 1 & 6 & 1 & & 0 & $\mathrm{~N}, \mathrm{~S}, \mathrm{G}, \mathrm{M}, \mathrm{E}, \mathrm{F} 1, \mathrm{~F} 2, \mathrm{~F} 3$ \\
\hline Pt105 & $\mathrm{F}$ & 86 & 5 & 27.1 & 3 & 1 & 15 & 1 & & 0 & $\mathrm{~S}, \mathrm{G}, \mathrm{M}, \mathrm{F} 1, \mathrm{~F} 2, \mathrm{~F} 3$ \\
\hline Pt113 & $\mathrm{F}$ & 73 & 5 & 31.8 & $1,2,3$ & 1 & 13 & 1 & & 0 & $\mathrm{~N}, \mathrm{G}, \mathrm{M}, \mathrm{E}, \mathrm{F} 1, \mathrm{~F} 2, \mathrm{~F} 3$ \\
\hline Pt119 & $\mathrm{F}$ & 84 & 3 & 33.6 & 3,4 & 1 & 12 & 1 & & 0 & $\mathrm{~N}, \mathrm{G}, \mathrm{M}, \mathrm{F} 1, \mathrm{~F} 2, \mathrm{~F} 3$ \\
\hline Pt122 & $\mathrm{F}$ & 34 & 5 & 34.7 & 0 & 1 & 3 & 1 & & 0 & $\mathrm{G}, \mathrm{M}, \mathrm{E}, \mathrm{F} 1, \mathrm{~F} 2, \mathrm{~F} 3$ \\
\hline Pt123 & $\mathrm{F}$ & 52 & 5 & 24.1 & 4 & 1 & 17 & 1 & & 0 & $\mathrm{G}, \mathrm{M}, \mathrm{E}, \mathrm{F} 1, \mathrm{~F} 2, \mathrm{~F} 3$ \\
\hline Pt164 & $\mathrm{F}$ & 70 & 6 & 35.2 & 0 & 2 & 11 & 3 & 12 & 1 & $\mathrm{~S}, \mathrm{G}, \mathrm{M}, \mathrm{F} 2, \mathrm{~F} 3$ \\
\hline Pt170 & $\mathrm{F}$ & 55 & 6 & 25.2 & 0 & 1 & 27 & 1 & & 0 & $\mathrm{~S}, \mathrm{G}, \mathrm{M}, \mathrm{E}, \mathrm{F} 1, \mathrm{~F} 2, \mathrm{~F} 3$ \\
\hline Pt004 & M & 62 & 5 & 27.9 & 0 & 1 & 21 & 1 & & 0 & $\mathrm{~N}, \mathrm{~S}, \mathrm{G}, \mathrm{M}, \mathrm{E}, \mathrm{F} 1, \mathrm{~F} 2, \mathrm{~F} 3$ \\
\hline Pt007 & M & 44 & 5 & 25.6 & 3,4 & 1 & 10 & 1 & & 0 & $\mathrm{~N}, \mathrm{~S}, \mathrm{G}, \mathrm{M}, \mathrm{E}, \mathrm{F} 1, \mathrm{~F} 2, \mathrm{~F} 3$ \\
\hline Pt008 & M & 54 & 5 & 31.5 & $2,3,4$ & 1 & 15 & 1 & & 0 & $\mathrm{E}, \mathrm{F} 1, \mathrm{~F} 2$ \\
\hline Pt010 & M & 62 & 3 & 31.0 & 2,3 & 1 & 7 & 3 & 9 & 1 & $\mathrm{~N}, \mathrm{~S}, \mathrm{G}, \mathrm{M}, \mathrm{E}, \mathrm{F} 1, \mathrm{~F} 2, \mathrm{~F} 3$ \\
\hline Pt013 & M & 82 & 5 & 35.6 & 2,3 & 2 & 22 & 3 & 24 & 1 & $\mathrm{~N}, \mathrm{G}, \mathrm{M}, \mathrm{E}, \mathrm{F} 1, \mathrm{~F} 2, \mathrm{~F} 3$ \\
\hline Pt020 & M & 65 & 98 & 25.3 & 2,3 & 2 & 11 & 3 & 14 & 1 & $\mathrm{~N}, \mathrm{~S}, \mathrm{E}, \mathrm{F} 1, \mathrm{~F} 2, \mathrm{~F} 3$ \\
\hline Pt025 & M & 62 & 5 & 35.5 & 3 & 2 & 9 & 1 & & 0 & $N, S, G, M, E, F 1, F 2, F 3$ \\
\hline Pt027 & M & 70 & 5 & 24.6 & 1,4 & 1 & 3 & 1 & & 0 & $\mathrm{~N}, \mathrm{~S}, \mathrm{G}, \mathrm{M}, \mathrm{E}, \mathrm{F} 3$ \\
\hline Pt047 & M & 82 & 3 & 35.2 & 2,3 & 2 & 23 & 5 & 24 & 1 & $N, S, G, M, E, F 1, F 2, F 3$ \\
\hline Pt060 & M & $\geq 90$ & 5 & 29.8 & 2,3 & 2 & 9 & 3 & 11 & 1 & $\mathrm{~N}, \mathrm{G}, \mathrm{M}, \mathrm{E}, \mathrm{F} 1, \mathrm{~F} 2, \mathrm{~F} 3$ \\
\hline Pt063 & M & 85 & 3 & 47.3 & 3 & 1 & 8 & 4 & 20 & 1 & $\mathrm{G}, \mathrm{M}, \mathrm{E}, \mathrm{F} 1, \mathrm{~F} 2, \mathrm{~F} 3$ \\
\hline Pt068 & M & 24 & 3 & 29.5 & 0 & 2 & 8 & 1 & & 0 & $\mathrm{G}, \mathrm{M}, \mathrm{F} 1, \mathrm{~F} 2, \mathrm{~F} 3$ \\
\hline Pt074 & M & 35 & 3 & 28.0 & 0 & 1 & 4 & 1 & & 0 & $\mathrm{~N}, \mathrm{G}, \mathrm{M}, \mathrm{E}, \mathrm{F} 1, \mathrm{~F} 2, \mathrm{~F} 3$ \\
\hline Pt089 & M & 52 & 6 & 22.1 & 0 & 1 & 7 & 1 & & 0 & $N, S, G, M, E, F 1, F 2, F 3$ \\
\hline Pt095 & M & 42 & 6 & 19.3 & 0 & 1 & 7 & 1 & & 0 & $\mathrm{~N}, \mathrm{G}, \mathrm{M}, \mathrm{E}, \mathrm{F} 1, \mathrm{~F} 2, \mathrm{~F} 3$ \\
\hline Pt110 & M & 89 & 5 & 23.3 & 2,3 & 2 & 4 & 1 & & 0 & $\mathrm{~N}, \mathrm{G}, \mathrm{M}, \mathrm{E}, \mathrm{F} 1, \mathrm{~F} 2, \mathrm{~F} 3$ \\
\hline Pt116 & M & 53 & 5 & 26.4 & 4,5 & 1 & 6 & 1 & & 0 & $\mathrm{~N}, \mathrm{~S}, \mathrm{G}, \mathrm{M}, \mathrm{E}, \mathrm{F} 1, \mathrm{~F} 2, \mathrm{~F} 3$ \\
\hline
\end{tabular}

*Ethnicity: (1) American Indian/Alaskan native; (2) Asian; (3) Black/African American; (4) Native Hawaiian/Pacific Islander; (5) White; (6) Hispanic; (9) Multiple; (98) Unknown/unavailable. +COVID-related risk factors: (0) No; (1) cancer treatment within 1 year; (2) chronic heart disease; (3) hypertension; (4) chronic lung disease (asthma, chronic obstructive pulmonary disease (COPD) and interstitial lung disease (ILD)); (5) immunosuppression.

${ }^{\ddagger} C_{1}$, clinical score at the first sample collection date.

$\S$ Days from symptom onset at the first sample collection.

$\| C_{\text {max }}$ maximum clinical score during the admission after the first time point sample collection.

IDays from symptom onset at the first day $C_{\max }$ was recorded in deteriorated patients.

\#Collected sample or data types at the first sample collection date.

E, plasma cytokine/chemokine ELISA; F1, flow cytometry PBMC cell composition staining; F2, flow cytometry T cell surface staining; F3, flow cytometry T cell intracellular staining; G, plasma anti-S1-IgG; M, plasma anti-S1-IgM; N, nasopharyngeal viral load; S, saliva viral load. 
Extended Data Table 3 | Adjusted least square means difference in immune response at baseline between male and female patients with COVID-19 in cohort A and male and female HCW controls

\begin{tabular}{|c|c|c|c|c|c|c|c|c|c|c|}
\hline & \multicolumn{2}{|c|}{$\begin{array}{c}\text { Female Patients vs. } \\
\text { Male Patients }\end{array}$} & \multicolumn{2}{|c|}{$\begin{array}{c}\text { Female Healthcare } \\
\text { Workers vs. Male } \\
\text { Healthcare Workers* }\end{array}$} & \multicolumn{2}{|c|}{$\begin{array}{c}\text { Female Patients vs. } \\
\text { Female Healthcare } \\
\text { Workers }^{\star}\end{array}$} & \multicolumn{2}{|c|}{$\begin{array}{c}\text { Male Patients vs. Male } \\
\text { Healthcare Workers }\end{array}$} & \multicolumn{2}{|c|}{$\begin{array}{l}\text { Difference-in- } \\
\text { Differences* }^{*}\end{array}$} \\
\hline & $\begin{array}{l}\text { Adjusted } \\
\text { Difference } \\
(95 \% \mathrm{Cl})\end{array}$ & $\begin{array}{l}\mathrm{p} \text { - } \\
\text { value }\end{array}$ & $\begin{array}{l}\text { Adjusted } \\
\text { Difference (95\% } \\
\mathrm{Cl})\end{array}$ & $\begin{array}{l}p- \\
\text { value }\end{array}$ & $\begin{array}{l}\text { Adjusted } \\
\text { Difference } \\
(95 \% \mathrm{Cl})\end{array}$ & $p$-value & $\begin{array}{l}\text { Adjusted } \\
\text { Difference } \\
(95 \% \mathrm{Cl})\end{array}$ & $\begin{array}{l}\mathrm{p}- \\
\text { value }\end{array}$ & $\begin{array}{l}\text { Adjusted } \\
\text { Difference } \\
(95 \% \mathrm{Cl}) \\
\end{array}$ & $\begin{array}{l}\mathrm{p}- \\
\text { value }\end{array}$ \\
\hline \multicolumn{11}{|l|}{ Antibody } \\
\hline Anti-S1lgG ${ }^{\dagger}$ & $\begin{array}{r}0.08(-0.19 \\
0.35)\end{array}$ & 0.87 & $\begin{array}{r}0.01(-0.26 \\
0.27)\end{array}$ & 0.99 & $\begin{array}{r}0.31(0.07 \\
0.55)\end{array}$ & 0.005 & $\begin{array}{r}0.24(-0.12 \\
0.60)\end{array}$ & 0.31 & $\begin{array}{r}0.07(-0.21 \\
0.36)\end{array}$ & 0.62 \\
\hline Anti-S1lg $M^{\ddagger}$ & $\begin{array}{r}0.11(-0.20 \\
0.41)\end{array}$ & 0.79 & $\begin{array}{r}0.04(-0.52 \\
0.61)\end{array}$ & 0.99 & $\begin{array}{r}0.54(0.18 \\
0.89)\end{array}$ & 0.001 & $\begin{array}{r}0.47(-0.16 \\
1.10)\end{array}$ & 0.20 & $\begin{array}{r}0.06(-0.42 \\
0.55)\end{array}$ & 0.79 \\
\hline \multicolumn{11}{|l|}{ Interferons ${ }^{\S}$} \\
\hline IFN $\alpha 2$ & $\begin{array}{r}0.19(-0.25 \\
0.63)\end{array}$ & 0.65 & $\begin{array}{r}-0.14(-0.59 \\
0.31)\end{array}$ & 0.84 & $\begin{array}{r}0.48(0.03 \\
0.93)\end{array}$ & 0.03 & $\begin{array}{r}0.15(-0.35 \\
0.64)\end{array}$ & 0.87 & $\begin{array}{r}0.34(-0.13 \\
0.80)\end{array}$ & 0.16 \\
\hline $\mathrm{IFN} \gamma$ & $\begin{array}{r}0.13(-0.53 \\
0.78)\end{array}$ & 0.96 & $\begin{array}{r}-0.11(-0.78 \\
0.56)\end{array}$ & 0.97 & $\begin{array}{r}0.48(-0.19 \\
1.15)\end{array}$ & 0.25 & $\begin{array}{r}0.24(-0.50 \\
0.98)\end{array}$ & 0.83 & $\begin{array}{r}0.24(-0.45 \\
0.94)\end{array}$ & 0.49 \\
\hline IFN $\lambda 2$ & $\begin{array}{r}-0.31(-1.17 \\
0.54)\end{array}$ & 0.77 & $\begin{array}{r}-0.69(-1.56 \\
0.19)\end{array}$ & 0.18 & $\begin{array}{r}0.05(-0.83 \\
0.94)\end{array}$ & 0.99 & $\begin{array}{r}-0.32(-1.29 \\
0.65)\end{array}$ & 0.82 & $\begin{array}{r}0.37(-0.54 \\
1.28)\end{array}$ & 0.42 \\
\hline \multicolumn{11}{|l|}{$\begin{array}{l}\text { Cytokines, } \\
\text { Chemokines }\end{array}$} \\
\hline $\mathrm{IL}-1 \beta$ & $\begin{array}{r}-0.06(-0.70 \\
0.58)\end{array}$ & 0.99 & $\begin{array}{r}-0.36(-1.02 \\
0.30)\end{array}$ & 0.48 & $\begin{array}{r}0.21(-0.45 \\
0.87)\end{array}$ & 0.84 & $\begin{array}{r}-0.09(-0.82 \\
0.63)\end{array}$ & 0.99 & $\begin{array}{r}0.30(-0.38 \\
0.98)\end{array}$ & 0.38 \\
\hline IL-1RA & $\begin{array}{r}-0.11(-0.52 \\
0.30)\end{array}$ & 0.90 & $\begin{array}{r}-0.10(-0.52 \\
0.32)\end{array}$ & 0.93 & $\begin{array}{r}0.55(0.13 \\
0.97)\end{array}$ & 0.006 & $\begin{array}{r}0.56(0.09 \\
0.32)\end{array}$ & 0.01 & $\begin{array}{r}-0.01(-0.45 \\
0.43)\end{array}$ & 0.96 \\
\hline IL-18 & $\begin{array}{r}-0.20(-0.54 \\
0.14)\end{array}$ & 0.40 & $\begin{array}{r}-0.13(-0.48 \\
0.22)\end{array}$ & 0.76 & $\begin{array}{r}0.30(-0.05 \\
0.65)\end{array}$ & 0.11 & $\begin{array}{r}0.38(-0.01 \\
0.76)\end{array}$ & 0.06 & $\begin{array}{r}-0.07(-0.43 \\
0.29)\end{array}$ & 0.69 \\
\hline IL-6 & $\begin{array}{r}-0.20(-0.71 \\
0.31)\end{array}$ & 0.73 & $\begin{array}{r}0.28(-0.24 \\
0.80)\end{array}$ & 0.49 & $\begin{array}{r}0.73(0.21 \\
1.26)\end{array}$ & 0.002 & $\begin{array}{r}1.22(0.64 \\
1.79)\end{array}$ & $<0.001$ & $\begin{array}{r}-0.48(-1.02 \\
0.06)\end{array}$ & 0.08 \\
\hline IL-8 & $\begin{array}{r}-0.33(-0.70 \\
0.04)\end{array}$ & 0.10 & $\begin{array}{r}0.11(-0.27 \\
0.48)\end{array}$ & 0.88 & $\begin{array}{r}0.43(0.05 \\
0.81)\end{array}$ & 0.02 & $\begin{array}{r}0.87(0.45 \\
1.28)\end{array}$ & $<0.001$ & $\begin{array}{r}-0.44(-0.83,- \\
0.04)\end{array}$ & 0.03 \\
\hline CXCL10 & $\begin{array}{r}-0.45(-0.97 \\
0.08)\end{array}$ & 0.13 & $\begin{array}{r}0.15(-0.39 \\
0.69)\end{array}$ & 0.89 & $\begin{array}{r}0.76(0.22 \\
1.31)\end{array}$ & 0.003 & $\begin{array}{r}1.36(0.76 \\
1.96)\end{array}$ & $<0.001$ & $\begin{array}{r}-0.60(-1.16,- \\
0.03)\end{array}$ & 0.04 \\
\hline CCL2 & $\begin{array}{r}-0.0002(- \\
0.15,0.15)\end{array}$ & 1.00 & $\begin{array}{r}-0.02(-0.18 \\
0.13)\end{array}$ & 0.98 & $\begin{array}{r}0.07(-0.08 \\
0.22)\end{array}$ & 0.60 & $\begin{array}{r}0.05(-0.12 \\
0.22)\end{array}$ & 0.88 & $\begin{array}{r}0.02(-0.13 \\
0.18)\end{array}$ & 0.76 \\
\hline CCL5 & $\begin{array}{r}-0.07(-0.25 \\
0.12)\end{array}$ & 0.78 & $\begin{array}{r}0.09(-0.10 \\
0.28)\end{array}$ & 0.60 & $\begin{array}{r}0.22(0.03 \\
0.41)\end{array}$ & 0.02 & $\begin{array}{r}0.37(0.16 \\
0.58)\end{array}$ & $<0.001$ & $\begin{array}{r}-0.15(-0.35 \\
0.04)\end{array}$ & 0.12 \\
\hline M-CSF & $\begin{array}{r}-0.16(-0.86 \\
0.54)\end{array}$ & 0.93 & $\begin{array}{r}0.13(-0.59 \\
0.85)\end{array}$ & 0.96 & $\begin{array}{r}0.70(-0.02 \\
1.42)\end{array}$ & 0.06 & $\begin{array}{r}0.99(0.20 \\
1.79)\end{array}$ & 0.008 & $\begin{array}{r}-0.29(-1.04 \\
0.45)\end{array}$ & 0.37 \\
\hline CCL4 & $\begin{array}{r}-0.09(-0.31 \\
0.12)\end{array}$ & 0.67 & $-0.03(-0.25,0.9)$ & 0.98 & $\begin{array}{r}0.06(-0.16 \\
0.28)\end{array}$ & 0.90 & $\begin{array}{r}0.12(-0.13 \\
0.36)\end{array}$ & 0.58 & $\begin{array}{r}-0.06(-0.29 \\
0.17)\end{array}$ & 0.59 \\
\hline TNFSF10 & $\begin{array}{r}0.18(-0.06 \\
0.42)\end{array}$ & 0.21 & $\begin{array}{r}0.002(-0.25 \\
0.25)\end{array}$ & 1.00 & $\begin{array}{r}0.15(-0.10 \\
0.40)\end{array}$ & 0.38 & $\begin{array}{r}-0.03(-0.30 \\
0.25)\end{array}$ & 0.99 & $\begin{array}{r}0.18(-0.08 \\
0.44)\end{array}$ & 0.17 \\
\hline G-CSF & $\begin{array}{r}-0.29(-1.12 \\
0.55)\end{array}$ & 0.80 & $\begin{array}{r}-0.23(-1.09 \\
0.62)\end{array}$ & 0.89 & $\begin{array}{r}0.35(-0.51 \\
1.21)\end{array}$ & 0.70 & $\begin{array}{r}0.41(-0.54 \\
1.35)\end{array}$ & 0.67 & $\begin{array}{r}-0.06(-0.94 \\
083)\end{array}$ & 0.90 \\
\hline \multicolumn{11}{|l|}{$\begin{array}{l}\text { PBMC } \\
\text { Composition" }\end{array}$} \\
\hline T Cells & $\begin{array}{r}3.57(-4.78 \\
11.92)\end{array}$ & 0.68 & $\begin{array}{r}2.55(-8.54 \\
13.64)\end{array}$ & 0.93 & $\begin{array}{r}-13.35(-21.42 \\
-5.18)\end{array}$ & $<0.001$ & $\begin{array}{r}-14.37(-27.87 \\
-0.86)\end{array}$ & 0.03 & $\begin{array}{r}1.02(-9.50 \\
11.54)\end{array}$ & 0.85 \\
\hline $\begin{array}{l}\text { T Cells }\left(10^{6}\right. \\
\text { cells/mL })^{\pi}\end{array}$ & $\begin{array}{r}-0.02(-0.48 \\
0.44)\end{array}$ & 0.99 & $\begin{array}{r}0.10(-0.39 \\
0.58)\end{array}$ & 0.96 & $\begin{array}{r}-0.36(-0.79 \\
0.06)\end{array}$ & 0.12 & $\begin{array}{r}-0.25(-0.88 \\
0.38)\end{array}$ & 0.73 & $\begin{array}{r}-0.11(-0.62 \\
0.39)\end{array}$ & 0.65 \\
\hline B Cells & $\begin{array}{r}-0.08(-2.57 \\
2.41)\end{array}$ & 0.99 & $\begin{array}{r}0.15(-3.15 \\
3.44)\end{array}$ & 0.99 & $\begin{array}{r}2.49(0.06 \\
4.92)\end{array}$ & 0.04 & $\begin{array}{r}2.72(-1.30 \\
6.74)\end{array}$ & 0.29 & $\begin{array}{r}-0.23(-3.36 \\
2.90)\end{array}$ & 0.89 \\
\hline $\begin{array}{l}\text { B Cells }\left(10^{6}\right. \\
\text { cells } / \mathrm{mL})^{\pi}\end{array}$ & $\begin{array}{r}-0.01(-0.05 \\
0.03)\end{array}$ & 0.94 & $\begin{array}{r}0.01(-0.03 \\
0.05)\end{array}$ & 0.92 & $\begin{array}{r}-0.01(-0.04 \\
0.03)\end{array}$ & 0.97 & $\begin{array}{r}0.01(-0.04 \\
0.06)\end{array}$ & 0.92 & $\begin{array}{r}-0.02(-0.06 \\
0.02)\end{array}$ & 0.39 \\
\hline Total Monocytes & $\begin{array}{r}-1.92(-7.44 \\
3.60)\end{array}$ & 0.80 & $\begin{array}{r}0.26(-7.07 \\
7.59)\end{array}$ & 0.99 & $\begin{array}{r}5.74(0.33 \\
11.14)\end{array}$ & 0.03 & $\begin{array}{r}7.92(-1.02 \\
16.85)\end{array}$ & 0.10 & $\begin{array}{r}-2.18(-9.14 \\
4.78)\end{array}$ & 0.53 \\
\hline cMono & $\begin{array}{r}-0.83(-4.38 \\
2.71)\end{array}$ & 0.93 & $\begin{array}{r}0.001(-4.70 \\
4.71)\end{array}$ & 1.00 & $\begin{array}{r}2.01(-1.46 \\
5.47)\end{array}$ & 0.43 & $\begin{array}{r}2.84(-2.89 \\
8.56)\end{array}$ & 0.56 & $\begin{array}{r}-0.84(-5.30 \\
3.63)\end{array}$ & 0.71 \\
\hline intMono & $\begin{array}{r}1.33(-1.12 \\
3.77)\end{array}$ & 0.49 & $\begin{array}{r}0.48(-2.77 \\
3.73)\end{array}$ & 0.98 & $\begin{array}{r}3.21(0.82 \\
5.60)\end{array}$ & 0.004 & $\begin{array}{r}3.26(-1.59 \\
6.32)\end{array}$ & 0.40 & $\begin{array}{r}0.85(-2.24 \\
3.93)\end{array}$ & 0.59 \\
\hline ncMono & $\begin{array}{r}-2.44(-4.47,- \\
0.42)\end{array}$ & 0.01 & $\begin{array}{r}-0.25(-2.94 \\
2.43)\end{array}$ & 0.99 & $\begin{array}{r}0.40(-1.58 \\
2.37)\end{array}$ & 0.95 & $\begin{array}{r}2.58(-0.69 \\
5.86)\end{array}$ & 0.17 & $\begin{array}{r}-2.19(-4.74 \\
0.36)\end{array}$ & 0.09 \\
\hline \multicolumn{11}{|l|}{$\begin{array}{l}\text { T Cell } \\
\text { Phenotypes }\end{array}$} \\
\hline CD4 & $\begin{array}{r}1.29(-8.04 \\
10.61)\end{array}$ & 0.98 & $\begin{array}{r}5.03(-7.44 \\
17.50)\end{array}$ & 0.72 & $\begin{array}{r}-1.80(-10.84 \\
7.23)\end{array}$ & 0.95 & $\begin{array}{r}1.94(-13.27 \\
17.16)\end{array}$ & 0.99 & $\begin{array}{r}3.74(-15.54 \\
8.05)\end{array}$ & 0.53 \\
\hline CD8 & $\begin{array}{r}-0.34(-8.99 \\
8.30)\end{array}$ & 0.99 & $\begin{array}{r}-1.36(-12.91 \\
10.20)\end{array}$ & 0.99 & $\begin{array}{r}2.56(-5.81 \\
10.93)\end{array}$ & 0.85 & $\begin{array}{r}1.55(-12.55 \\
16.65)\end{array}$ & 0.99 & $\begin{array}{r}1.01(-9.91 \\
11.94)\end{array}$ & 0.85 \\
\hline $\begin{array}{l}\text { CD38+HLA- } \\
\text { DR+CD4 }\end{array}$ & $\begin{array}{r}0.60(-0.20 \\
1.39)\end{array}$ & 0.21 & $\begin{array}{r}-0.07(-1.14 \\
0.99)\end{array}$ & 0.99 & $\begin{array}{r}0.88(0.11 \\
1.66)\end{array}$ & 0.02 & $\begin{array}{r}0.21(-1.09 \\
1.51)\end{array}$ & 0.97 & $\begin{array}{r}0.67(-0.34 \\
1.68)\end{array}$ & 0.19 \\
\hline $\begin{array}{l}\text { CD38+HLA- } \\
\text { DR+CD8 }\end{array}$ & $\begin{array}{r}1.03(0.05 \\
2.05)\end{array}$ & 0.049 & $\begin{array}{r}0.18(-1.19 \\
1.55)\end{array}$ & 0.99 & $\begin{array}{r}1.79(0.80 \\
2.78)\end{array}$ & $<0.001$ & $\begin{array}{r}0.94(-0.73 \\
2.61)\end{array}$ & 0.46 & $\begin{array}{r}0.85(-0.45 \\
2.15)\end{array}$ & 0.20 \\
\hline PD-1+TIM-3+CD4 & $\begin{array}{r}0.18(-0.36 \\
0.73)\end{array}$ & 0.81 & $\begin{array}{r}-0.04(-0.77 \\
0.69)\end{array}$ & 0.99 & $\begin{array}{r}0.41(-0.11 \\
0.94)\end{array}$ & 0.18 & $\begin{array}{r}0.19(-0.70 \\
1.08)\end{array}$ & 0.94 & $\begin{array}{r}0.22(-0.46 \\
0.91)\end{array}$ & 0.52 \\
\hline PD-1+TIM-3+CD8 & $\begin{array}{r}0.65(-0.11 \\
1.41)\end{array}$ & 0.12 & $\begin{array}{r}-0.05(-1.06 \\
0.97)\end{array}$ & 0.99 & $\begin{array}{r}1.14(0.41 \\
1.88) \\
\end{array}$ & $<0.001$ & $\begin{array}{r}0.45(-0.80 \\
0.97) \\
\end{array}$ & 0.78 & $\begin{array}{r}0.70(-0.27 \\
1.66) \\
\end{array}$ & 0.15 \\
\hline
\end{tabular}

*Adjusted for age and BMI.

${ }^{\dagger} A_{450 \mathrm{~nm} ;} n_{\mathrm{PT}_{-} \mathrm{F}}=20, n_{\mathrm{Pt} \mathrm{M}}=15, n_{\mathrm{HCWF}_{-}}=74, n_{\mathrm{HCW}_{\mathrm{M}}}=13$.

${ }^{\ddagger} A_{450}$ nm; $; n_{\text {PT_F }}=20, n_{\text {PLM }}=15, n_{\text {HCW }_{-}}=18, n_{\mathrm{HCW}_{-} \mathrm{M}}=3$.

$\S \log _{10}\left(\mathrm{pg} \mathrm{ml}^{-1}\right) ; n_{\mathrm{PT} F}=19, n_{\mathrm{Pt} \mathrm{M}}=16, n_{\mathrm{HCW}_{\mathrm{F}}}=28, n_{\mathrm{HCW}_{-} \mathrm{M}}=15$.

$\|$ As percentage of live cells, unless otherwise indicated; $n_{\mathrm{PT} F_{-}}=21, n_{\mathrm{Pt}_{-} \mathrm{M}}=16, n_{\mathrm{HCW}_{-}}=51, n_{\mathrm{HCW}_{-} \mathrm{M}}=6$.

In $n_{\mathrm{PT} F}=33, n_{\mathrm{Pt} M}=40, n_{\mathrm{HCWF}_{\mathrm{F}}}=51, n_{\mathrm{HCW} \mathrm{M}}=6$.

\#As a percentage of CD3-positive cells; $n_{\text {PT_F }}=21, n_{\text {PLM }}=16, n_{\text {HCW_F }_{-}}=51, n_{\text {HCW_M }_{-}}=6$.

$P$ values were determined using two-sided $t$-test with Tukey correction for multiple pairwise comparisons. 


\section{Article}

Extended Data Table 4 | Adjusted least square means difference over time in immune response between male and female patients with COVID-19 in cohort B

\begin{tabular}{|c|c|c|}
\hline & \multicolumn{2}{|c|}{ Female Patients vs. Male Patients* } \\
\hline & $\begin{array}{l}\text { Adjusted Difference } \\
(95 \% \mathrm{Cl})\end{array}$ & $\mathrm{p}$-value \\
\hline \multicolumn{3}{|l|}{ Viral Load $^{\dagger}$} \\
\hline Nasopharyngeal & $0.18(-0.58,0.94)$ & 0.63 \\
\hline Saliva & $-0.15(-1.19,0.90)$ & 0.78 \\
\hline \multicolumn{3}{|l|}{ Antibody ${ }^{\ddagger}$} \\
\hline Anti-S1lgG & $-0.06(-0.30,0.18)$ & 0.63 \\
\hline Anti-S1lgM & $0.02(-0.16,0.19)$ & 0.86 \\
\hline \multicolumn{3}{|l|}{ Interferon Response ${ }^{\S}$} \\
\hline IFNa2 & $0.25(0.04,0.47)$ & 0.02 \\
\hline $\mathrm{IFN} \gamma$ & $0.21(-0.04,0.46)$ & 0.10 \\
\hline IFN $\lambda 2$ & $-0.18(-0.55,0.20)$ & 0.35 \\
\hline \multicolumn{3}{|c|}{$\begin{array}{l}\text { Cytokines, Chemokines and } \\
\text { Growth Factors } \$\end{array}$} \\
\hline $\mathrm{IL}-1 \beta$ & $-0.03(-0.33,0.26)$ & 0.82 \\
\hline IL-1RA & $-0.11(-0.36,0.14)$ & 0.39 \\
\hline IL-18 & $-0.003(-0.25,0.24)$ & 0.98 \\
\hline IL-6 & $0.07(-0.17,0.30)$ & 0.58 \\
\hline IL-8 & $-0.08(-0.26,0.11)$ & 0.44 \\
\hline CXCL10 & $-0.18(-0.50,0.13)$ & 0.25 \\
\hline CCL2 & $-0.02(-0.11,0.06)$ & 0.57 \\
\hline CCL5 & $-0.12(-0.22,-0.02)$ & 0.02 \\
\hline M-CSF & $0.001(-0.27,0.27)$ & 0.99 \\
\hline CCL4 & $-0.07(-0.18,0.04)$ & 0.19 \\
\hline TNFSF10 & $0.08(-0.05,0.20)$ & 0.22 \\
\hline \multirow{2}{*}{\multicolumn{3}{|c|}{ PBMC Composition" }} \\
\hline & & \\
\hline T Cells & $6.12(0.49,11.76)$ & 0.03 \\
\hline T Cells $\left(10^{6} \text { cells } / \mathrm{mL}\right)^{\pi}$ & $0.13(0.01,0.25)$ & 0.04 \\
\hline B Cells & $-0.66(-2.24,0.92)$ & 0.41 \\
\hline B Cells $\left(10^{6} \text { cells } / \mathrm{mL}\right)^{\pi}$ & $0.02(-0.02,0.05)$ & 0.33 \\
\hline Total Monocytes & $-2.32(-6.56,1.92)$ & 0.28 \\
\hline cMono & $-1.31(-3.38,0.76)$ & 0.21 \\
\hline intMono & $0.27(-0.78,1.33)$ & 0.61 \\
\hline ncMono & $-1.36(-4.59,1.87)$ & 0.41 \\
\hline \multicolumn{3}{|l|}{ T Cell Phenotypes ${ }^{\#}$} \\
\hline CD4 & $-1.02(-7.45,5.41)$ & 0.75 \\
\hline CD8 & $3.62(-1.62,8.86)$ & 0.17 \\
\hline CD38+HLA-DR+CD4 & $-0.09(-0.62,0.44)$ & 0.74 \\
\hline CD38+HLA-DR+CD8 & $0.71(-0.31,1.73)$ & 0.17 \\
\hline PD-1+TIM-3+CD4 & $0.06(-0.22,0.34)$ & 0.67 \\
\hline PD-1+TIM-3+CD8 & $0.36(-0.21,0.93)$ & 0.21 \\
\hline
\end{tabular}

*Adjusted for age, BMI, days from symptom onset, tocilizumab treatment, corticosteroid treatment and ICU status. $+\log _{10}\left(\right.$ SARS-CoV-2 copies per $\mathrm{ml}$ ); nasopharyngeal $n_{\mathrm{PT}_{\mathrm{F}}}=33, n_{\mathrm{Pt} \mathrm{M}}=30$; saliva $n_{\mathrm{PT}_{\mathrm{F}}}=20, n_{\mathrm{Pt}_{\mathrm{M}} \mathrm{M}}=18$.

'OD450; $n_{\text {PT_F }}=44, n_{\text {Pt_M }}=39$. $\S \log _{10}\left(\mathrm{pg} \mathrm{ml}^{-1}\right) ; n_{\text {PT_F }}=48, n_{\text {Pt.M }}=43$.

$\|$ As a percentage of live cells, unless indicated otherwise; $n_{\mathrm{PTF}}=46, n_{\mathrm{Pt} \mathrm{M}}=42$.

" $n_{\text {PT_F }}=33, n_{P_{-} M}=40$.

\#As a percentage of CD3-positive cells; $n_{\mathrm{PTF}}=49, n_{\mathrm{PtM}}=42$.

$P$ values were determined using two-sided $t$-test and Morel-Bokossa-Neerchal correction. 
Extended Data Table 5 | Adjusted least square means difference over time in immune response between male and female patients with COVID-19 in cohort B and male and female healthy HCW controls

\begin{tabular}{|c|c|c|c|c|c|c|c|c|c|c|}
\hline & \multicolumn{2}{|c|}{$\begin{array}{l}\text { Female Patients vs. } \\
\text { Male Patients* }\end{array}$} & \multicolumn{2}{|c|}{$\begin{array}{c}\text { Female Healthcare } \\
\text { Workers vs. Male } \\
\text { Healthcare Workers* }\end{array}$} & \multicolumn{2}{|c|}{$\begin{array}{c}\text { Female Patients vs. } \\
\text { Female Healthcare } \\
\text { Workers }^{\star}\end{array}$} & \multicolumn{2}{|c|}{$\begin{array}{c}\text { Male Patients vs. Male } \\
\text { Healthcare Workers }\end{array}$} & \multicolumn{2}{|c|}{$\begin{array}{l}\text { Difference-in- } \\
\text { Differences* }\end{array}$} \\
\hline & $\begin{array}{l}\text { Adjusted } \\
\text { Difference } \\
(95 \% \mathrm{Cl}) \\
\end{array}$ & $\begin{array}{l}\mathrm{p}- \\
\text { value }\end{array}$ & $\begin{array}{l}\text { Adjusted } \\
\text { Difference } \\
(95 \% \mathrm{Cl}) \\
\end{array}$ & $\begin{array}{l}\mathrm{p}- \\
\text { value }\end{array}$ & $\begin{array}{l}\text { Adjusted } \\
\text { Difference } \\
(95 \% \mathrm{Cl}) \\
\end{array}$ & $p$-value & $\begin{array}{l}\text { Adjusted } \\
\text { Difference } \\
(95 \% \mathrm{Cl}) \\
\end{array}$ & $p$-value & $\begin{array}{l}\text { Adjusted } \\
\text { Difference } \\
(95 \% \mathrm{Cl}) \\
\end{array}$ & $\begin{array}{l}p- \\
\text { valu } \\
e \\
\end{array}$ \\
\hline \multicolumn{11}{|l|}{ Antibody } \\
\hline Anti-S1lgG $^{\dagger}$ & $\begin{array}{r}-0.10(-0.41 \\
0.22)\end{array}$ & 0.86 & $\begin{array}{r}-0.0001(-0.13 \\
0.13)\end{array}$ & 1.00 & $\begin{array}{r}0.56(0.23 \\
0.89)\end{array}$ & $<0.001$ & $\begin{array}{r}0.66(0.28 \\
1.03)\end{array}$ & $<0.001$ & $\begin{array}{r}-0.10(-0.35 \\
0.16)\end{array}$ & 0.46 \\
\hline Anti-S1 lgM $M^{\ddagger}$ & $\begin{array}{r}0.01(-0.23 \\
0.24)\end{array}$ & 0.99 & $\begin{array}{r}0.04(-0.13 \\
0.22)\end{array}$ & 0.92 & $\begin{array}{r}0.72(0.43 \\
1.02)\end{array}$ & $<0.001$ & $\begin{array}{r}0.76(0.42 \\
1.10)\end{array}$ & $<0.001$ & $\begin{array}{r}-0.04(-0.26 \\
0.18)\end{array}$ & 0.74 \\
\hline \multicolumn{11}{|l|}{ Interferons ${ }^{\S}$} \\
\hline IFNa2 & $\begin{array}{r}0.26(0.004 \\
0.52)\end{array}$ & 0.046 & $\begin{array}{r}-0.14(-0.57 \\
0.28)\end{array}$ & 0.82 & $\begin{array}{r}0.50(0.12 \\
0.89)\end{array}$ & 0.01 & $\begin{array}{r}0.10(-0.32 \\
0.52)\end{array}$ & 0.93 & $\begin{array}{r}0.41(0.02 \\
0.79)\end{array}$ & 0.04 \\
\hline $\mathrm{IFN} \gamma$ & $\begin{array}{r}0.19(-0.14 \\
0.51)\end{array}$ & 0.45 & $\begin{array}{r}-0.07(-0.74 \\
0.61)\end{array}$ & 0.99 & $\begin{array}{r}0.64(0.13 \\
1.15)\end{array}$ & 0.01 & $\begin{array}{r}0.39(-0.22 \\
1.00)\end{array}$ & 0.35 & $\begin{array}{r}0.25(-0.32 \\
0.82)\end{array}$ & 0.39 \\
\hline IFN $\lambda 2$ & $\begin{array}{r}-0.19(-0.65 \\
0.27)\end{array}$ & 0.71 & $\begin{array}{r}-0.58(-1.45 \\
0.29)\end{array}$ & 0.31 & $\begin{array}{r}-0.09(-0.78 \\
0.60)\end{array}$ & 0.99 & $\begin{array}{r}-0.48(-1.36 \\
0.40)\end{array}$ & 0.50 & $\begin{array}{r}0.39(-0.38 \\
1.15)\end{array}$ & 0.32 \\
\hline \multicolumn{11}{|l|}{$\begin{array}{l}\text { Cytokines, } \\
\text { Chemokines }^{\S}\end{array}$} \\
\hline IL-1 $\beta$ & $\begin{array}{r}-0.07(-0.41 \\
0.28)\end{array}$ & 0.96 & $\begin{array}{r}-0.27(-0.94 \\
0.40)\end{array}$ & 0.73 & $\begin{array}{r}0.23(-0.27 \\
0.73)\end{array}$ & 0.63 & $\begin{array}{r}0.03(-0.58 \\
0.63)\end{array}$ & 0.99 & $\begin{array}{r}0.20(-0.38 \\
0.79)\end{array}$ & 0.50 \\
\hline IL-1RA & $\begin{array}{r}-0.05(-0.36 \\
0.26)\end{array}$ & 0.98 & $\begin{array}{r}-0.09(-0.52 \\
0.35)\end{array}$ & 0.96 & $\begin{array}{r}0.65(0.27 \\
1.03)\end{array}$ & $<0.001$ & $\begin{array}{r}0.61(0.21 \\
1.02)\end{array}$ & $<0.001$ & $\begin{array}{r}0.04(-0.40 \\
0.47)\end{array}$ & 0.87 \\
\hline IL-18 & $\begin{array}{r}-0.02(-0.32 \\
0.29)\end{array}$ & 0.99 & $\begin{array}{r}-0.22(-0.65 \\
0.22)\end{array}$ & 0.58 & $\begin{array}{r}0.49(0.03 \\
0.96)\end{array}$ & 0.04 & $\begin{array}{r}0.29(-0.14 \\
0.72)\end{array}$ & 0.30 & $\begin{array}{r}0.20(-0.22 \\
0.62)\end{array}$ & 0.35 \\
\hline IL-6 & $\begin{array}{r}-0.10(-0.59 \\
0.39)\end{array}$ & 0.96 & $\begin{array}{r}0.16(-0.34 \\
0.66)\end{array}$ & 0.83 & $\begin{array}{r}1.70(1.11 \\
2.28)\end{array}$ & $<0.001$ & $\begin{array}{r}1.96(1.44 \\
2.48)\end{array}$ & $<0.001$ & $\begin{array}{r}-0.26(-0.80 \\
0.28)\end{array}$ & 0.34 \\
\hline IL-8 & $\begin{array}{r}-0.08(-0.32 \\
0.16)\end{array}$ & 0.84 & $\begin{array}{r}0.18(-0.16 \\
0.52)\end{array}$ & 0.53 & $\begin{array}{r}0.70(0.38 \\
1.02)\end{array}$ & $<0.001$ & $\begin{array}{r}0.96(0.65 \\
1.26)\end{array}$ & $<0.001$ & $\begin{array}{r}-0.25(-0.58 \\
0.08)\end{array}$ & 0.13 \\
\hline CXCL10 & $\begin{array}{r}-0.22(-0.63 \\
0.18)\end{array}$ & 0.48 & $\begin{array}{r}0.12(-0.17 \\
0.41)\end{array}$ & 0.72 & $\begin{array}{r}1.05(0.56 \\
1.55)\end{array}$ & $<0.001$ & $\begin{array}{r}1.40(1.04 \\
1.75)\end{array}$ & $<0.001$ & $\begin{array}{r}-0.34(-0.75 \\
0.07)\end{array}$ & 0.10 \\
\hline CCL2 & $\begin{array}{r}-0.03(-0.14 \\
0.08)\end{array}$ & 0.91 & $\begin{array}{r}-0.03(-0.16 \\
0.11)\end{array}$ & 0.96 & $\begin{array}{r}0.09(-0.02 \\
0.21)\end{array}$ & 0.17 & $\begin{array}{r}0.10(-0.06 \\
0.25)\end{array}$ & 0.38 & $\begin{array}{r}-0.003(-0.13 \\
0.13)\end{array}$ & 0.96 \\
\hline CCL5 & $\begin{array}{r}-0.11(-0.23 \\
0.01)\end{array}$ & 0.08 & $\begin{array}{r}0.07(-0.04 \\
0.18)\end{array}$ & 0.34 & $\begin{array}{r}0.11(-0.03 \\
0.24)\end{array}$ & 0.19 & $\begin{array}{r}0.29(0.17 \\
0.40)\end{array}$ & $<0.001$ & $\begin{array}{r}-0.18(-0.30,- \\
0.06)\end{array}$ & $\begin{array}{r}0.00 \\
5\end{array}$ \\
\hline M-CSF & $\begin{array}{r}0.01(-0.33 \\
0.36)\end{array}$ & 0.99 & $\begin{array}{r}0.19(-0.66 \\
1.04)\end{array}$ & 0.94 & $\begin{array}{r}0.68(0.07 \\
1.29)\end{array}$ & 0.02 & $\begin{array}{r}0.86(0.08 \\
1.63)\end{array}$ & 0.02 & $\begin{array}{r}-0.18(-0.88 \\
0.52)\end{array}$ & 0.62 \\
\hline CCL4 & $\begin{array}{r}-0.08(-0.22 \\
0.07)\end{array}$ & 0.50 & $\begin{array}{r}0.02(-0.11 \\
0.15)\end{array}$ & 0.98 & $\begin{array}{r}0.14(-0.06 \\
0.33)\end{array}$ & 0.26 & $\begin{array}{r}0.23(0.11 \\
0.36)\end{array}$ & $<0.001$ & $\begin{array}{r}-0.10(-0.26 \\
0.06)\end{array}$ & 0.22 \\
\hline TNFSF10 & $\begin{array}{r}0.09(-0.10 \\
0.28)\end{array}$ & 0.62 & $\begin{array}{r}-0.06(-0.30 \\
0.17)\end{array}$ & 0.90 & $\begin{array}{r}0.18(-0.05 \\
0.40)\end{array}$ & 0.18 & $\begin{array}{r}0.03(-0.24 \\
0.29)\end{array}$ & 0.99 & $\begin{array}{r}0.15(-0.08 \\
0.38)\end{array}$ & 0.20 \\
\hline G-CSF & $\begin{array}{r}-0.15(-0.59 \\
0.29)\end{array}$ & 0.80 & $\begin{array}{r}-0.41(-1.36 \\
0.55)\end{array}$ & 0.69 & $\begin{array}{r}0.64(0.01 \\
1.26)\end{array}$ & 0.045 & $\begin{array}{r}0.39(-0.51 \\
1.28)\end{array}$ & 0.68 & $\begin{array}{r}0.25(-0.56 \\
1.06)\end{array}$ & 0.54 \\
\hline \multicolumn{11}{|l|}{$\begin{array}{l}\text { PBMC } \\
\text { Composition" }\end{array}$} \\
\hline T Cells & $\begin{array}{r}6.42(-1.52 \\
14.36)\end{array}$ & 0.16 & $\begin{array}{r}1.99(-5.38 \\
9.36)\end{array}$ & 0.90 & $\begin{array}{r}-17.66(- \\
27.00,-8.32)\end{array}$ & $<0.001$ & $\begin{array}{r}-22.1(-32.90 \\
-11.28)\end{array}$ & $<0.001$ & $\begin{array}{r}4.43(-3.77 \\
12.63)\end{array}$ & 0.29 \\
\hline $\begin{array}{l}\text { T Cells }\left(10^{6}\right. \\
\text { cells } / \mathrm{mL})^{\pi}\end{array}$ & $\begin{array}{r}0.11(-0.04 \\
0.25)\end{array}$ & 0.21 & $\begin{array}{r}0.10(-0.32 \\
0.52)\end{array}$ & 0.93 & $\begin{array}{r}-0.30(-0.59 \\
-0.02)\end{array}$ & 0.03 & $\begin{array}{r}-0.32(-0.73 \\
0.10)\end{array}$ & 0.21 & $\begin{array}{r}-0.01(-0.32 \\
0.35)\end{array}$ & 0.95 \\
\hline B Cells & $\begin{array}{r}-0.85(-2.85 \\
1.16)\end{array}$ & 0.70 & $\begin{array}{r}0.39(-1.55 \\
2.33)\end{array}$ & 0.96 & $\begin{array}{r}3.86(1.81 \\
5.91)\end{array}$ & $<0.001$ & $\begin{array}{r}5.09(2.08 \\
8.10)\end{array}$ & $<0.001$ & $\begin{array}{r}-1.23(-3.37 \\
0.91)\end{array}$ & 0.26 \\
\hline $\begin{array}{l}\text { B Cells }\left(10^{6}\right. \\
\text { cells } / \mathrm{mL})^{4}\end{array}$ & $\begin{array}{r}0.01(-0.02 \\
0.04)\end{array}$ & 0.95 & $\begin{array}{r}0.01(-0.02 \\
0.05)\end{array}$ & 0.72 & $\begin{array}{r}0.03(-0.01 \\
0.07)\end{array}$ & 0.33 & $\begin{array}{r}0.03(-0.01 \\
0.07)\end{array}$ & 0.15 & $\begin{array}{r}-0.001(-0.04 \\
0.03)\end{array}$ & 0.75 \\
\hline Total Monocytes & $\begin{array}{r}-3.19(-8.66 \\
2.29)\end{array}$ & 0.44 & $\begin{array}{r}0.14(-4.88 \\
5.16)\end{array}$ & 0.99 & $\begin{array}{r}6.38(-0.05 \\
12.81)\end{array}$ & 0.05 & $\begin{array}{r}9.70(1.78 \\
17.62)\end{array}$ & 0.009 & $\begin{array}{r}-3.32(-8.83 \\
2.18)\end{array}$ & 0.24 \\
\hline cMono & $\begin{array}{r}-1.35(-3.78 \\
1.09)\end{array}$ & 0.48 & $\begin{array}{r}0.08(-2.53 \\
2.70)\end{array}$ & 0.99 & $\begin{array}{r}2.32(-0.68 \\
5.32)\end{array}$ & 0.19 & $\begin{array}{r}3.75(0.11 \\
7.39)\end{array}$ & 0.04 & $\begin{array}{r}-1.43(-4.08 \\
1.22)\end{array}$ & 0.29 \\
\hline intMono & $\begin{array}{r}0.45(-0.84 \\
1.73)\end{array}$ & 0.81 & $\begin{array}{r}0.61(-0.64 \\
1.85)\end{array}$ & 0.59 & $\begin{array}{r}1.85(-0.03 \\
3.72)\end{array}$ & 0.06 & $\begin{array}{r}2.01(0.40 \\
3.62)\end{array}$ & 0.008 & $\begin{array}{r}-0.16(-1.52 \\
1.20)\end{array}$ & 0.82 \\
\hline ncMono & $\begin{array}{r}-2.24(-6.81 \\
2.33)\end{array}$ & 0.58 & $\begin{array}{r}-0.56(-3.87 \\
9.72)\end{array}$ & 0.97 & $\begin{array}{r}2.15(-2.64 \\
6.95)\end{array}$ & 0.65 & $\begin{array}{r}3.84(-2.05 \\
9.72)\end{array}$ & 0.33 & $\begin{array}{r}-1.68(-5.75 \\
2.39)\end{array}$ & 0.42 \\
\hline \multicolumn{11}{|l|}{$\begin{array}{l}\text { T Cell } \\
\text { Phenotypes }\end{array}$} \\
\hline CD4 & $\begin{array}{r}-1.14(-9.07 \\
6.79)\end{array}$ & 0.98 & $\begin{array}{r}4.72(-7.96 \\
17.39)\end{array}$ & 0.77 & $\begin{array}{r}-1.54(-9.46 \\
6.39)\end{array}$ & 0.96 & $\begin{array}{r}4.32(-9.68 \\
18.32)\end{array}$ & 0.86 & $\begin{array}{r}-5.86(-17.26 \\
5.55)\end{array}$ & 0.31 \\
\hline CD8 & $\begin{array}{r}3.21(-3.23 \\
9.66)\end{array}$ & 0.57 & $\begin{array}{r}-0.59(-6.86 \\
5.67)\end{array}$ & 0.99 & $\begin{array}{r}3.65(-3.06 \\
10.37)\end{array}$ & 0.49 & $\begin{array}{r}-0.15(-8.71 \\
8.41)\end{array}$ & 1.00 & $\begin{array}{r}3.81(-3.23 \\
10.85)\end{array}$ & 0.29 \\
\hline $\begin{array}{l}\text { CD38+HLA- } \\
\text { DR+CD4 }\end{array}$ & $\begin{array}{r}-0.19(-0.90 \\
0.52)\end{array}$ & 0.90 & $\begin{array}{r}-0.14(-0.53 \\
0.25)\end{array}$ & 0.79 & $\begin{array}{r}1.09(0.38 \\
1.80)\end{array}$ & $<0.001$ & $\begin{array}{r}1.14(0.36 \\
1.92)\end{array}$ & 0.001 & $\begin{array}{r}-0.05(-0.67 \\
0.56)\end{array}$ & 0.87 \\
\hline $\begin{array}{l}\text { CD38+HLA- } \\
\text { DR+CD8 }\end{array}$ & $\begin{array}{r}0.62(-0.58 \\
1.81)\end{array}$ & 0.54 & $\begin{array}{r}0.23(-0.33 \\
0.80)\end{array}$ & 0.71 & $\begin{array}{r}2.25(0.58 \\
3.92)\end{array}$ & 0.003 & $\begin{array}{r}0.86(0.48 \\
3.24)\end{array}$ & 0.003 & $\begin{array}{r}0.39(-0.54 \\
1.31)\end{array}$ & 0.41 \\
\hline PD-1+TIM-3+CD4 & $\begin{array}{r}0.02(-0.38 \\
0.42)\end{array}$ & 0.99 & $\begin{array}{r}-0.01(-0.42 \\
0.40)\end{array}$ & 0.99 & $\begin{array}{r}0.59(0.16 \\
1.02)\end{array}$ & 0.003 & $\begin{array}{r}0.57(-0.07 \\
1.20)\end{array}$ & 0.10 & $\begin{array}{r}0.03(-0.42 \\
0.47)\end{array}$ & 0.90 \\
\hline PD-1+TIM-3+CD8 & $\begin{array}{r}0.32(-0.39 \\
1.02) \\
\end{array}$ & 0.65 & $\begin{array}{r}-0.003(-0.32 \\
0.31) \\
\end{array}$ & 1.00 & $\begin{array}{r}1.31(0.54 \\
2.09) \\
\end{array}$ & $<0.001$ & $\begin{array}{r}0.99(0.21 \\
1.77) \\
\end{array}$ & 0.006 & $\begin{array}{r}0.32(-0.27 \\
0.91) \\
\end{array}$ & 0.29 \\
\hline
\end{tabular}

${ }^{*}$ Adjusted for age and BMI.

${ }^{\dagger} A_{450 \mathrm{~nm}} ; n_{\mathrm{PT} F}=44, n_{\mathrm{Pt}, \mathrm{M}}=39, n_{\mathrm{HCW}_{\mathrm{F}}}=74, n_{\mathrm{HCW}-\mathrm{M}}=13$.

FOD450; $n_{\text {PT_F }}=44, n_{\text {Pt_M }}=39, n_{\text {HCW }_{-}}=18, N_{\text {HCW_M }_{-}}=3$.

$\S \log _{10}\left(\mathrm{pg} \mathrm{ml}^{-1}\right) ; n_{\mathrm{PTF}}=48, n_{\mathrm{Pt} \mathrm{M}}=43, n_{\mathrm{HCWF}_{\mathrm{F}}}=28, n_{\mathrm{HCW} \text { M }}=15$

$\|$ As a percentage of live cells, unless otherwise indicated; $n_{\mathrm{PT}_{-} \mathrm{F}}=46, n_{\mathrm{Pt} \mathrm{M}}=42, n_{\mathrm{HCW}_{-} \mathrm{F}}=51, n_{\mathrm{HCW}_{-} \mathrm{M}}=6$.

In $n_{\text {PT F }}=33, n_{\text {Pt M }}=40, n_{\text {HCWF }}=51, n_{\text {HCW }}=6$.

\#As a percentage of CD3-positive cells; $n_{\mathrm{PT}_{-} \mathrm{F}}=49, n_{\mathrm{Pt}_{-} \mathrm{M}}=42, n_{\mathrm{HCW}_{\mathrm{F}}}=51, n_{\mathrm{HCW}_{\mathrm{M}} \mathrm{M}}=6$

$P$ values were determined using two-sided $t$-test with Tukey correction for multiple pairwise comparisons. 
Extended Data Table 6 | Adjusted least square means difference between male and female patients with COVID-19 in cohort A by patient trajectory

\begin{tabular}{|c|c|c|c|c|c|c|c|c|c|c|}
\hline & \multicolumn{2}{|c|}{$\begin{array}{c}\text { Female Deteriorated vs. } \\
\text { Male Deteriorated* }\end{array}$} & \multicolumn{2}{|c|}{$\begin{array}{c}\text { Female Stable vs. Male } \\
\text { Stable* }^{\star}\end{array}$} & \multicolumn{2}{|c|}{$\begin{array}{c}\text { Female Deteriorated vs. } \\
\text { Female Stable }^{\star}\end{array}$} & \multicolumn{2}{|c|}{$\begin{array}{c}\text { Male Deteriorated vs. } \\
\text { Male Stable }^{\star}\end{array}$} & \multicolumn{2}{|c|}{$\begin{array}{c}\text { Difference-in- } \\
\text { Differences }{ }^{\star}\end{array}$} \\
\hline & $\begin{array}{l}\text { Adjusted } \\
\text { Difference (95\% } \\
\mathrm{Cl})\end{array}$ & $\begin{array}{l}\mathrm{p}- \\
\text { value }\end{array}$ & $\begin{array}{l}\text { Adjusted } \\
\text { Difference } \\
(95 \% \mathrm{Cl})\end{array}$ & $\begin{array}{l}\mathrm{p}- \\
\text { value }\end{array}$ & $\begin{array}{l}\text { Adjusted } \\
\text { Difference } \\
(95 \% \mathrm{Cl})\end{array}$ & $\begin{array}{l}\mathrm{p}- \\
\text { value }\end{array}$ & $\begin{array}{l}\text { Adjusted } \\
\text { Difference (95\% } \\
\mathrm{Cl})\end{array}$ & $\begin{array}{l}\mathrm{p}- \\
\text { value }\end{array}$ & $\begin{array}{l}\text { Adjusted } \\
\text { Difference } \\
(95 \% \mathrm{Cl})\end{array}$ & $\begin{array}{l}p- \\
\text { valu } \\
e\end{array}$ \\
\hline \multicolumn{11}{|l|}{ PBMC } \\
\hline $\mathrm{ncMono}^{2}$ & $\begin{array}{r}-4.22(-10.68 \\
2.24)\end{array}$ & 0.30 & $\begin{array}{r}-1.91(-6.20 \\
2.39)\end{array}$ & 0.63 & $\begin{array}{r}-1.02(-6.14 \\
4.10)\end{array}$ & 0.95 & $\begin{array}{r}1.30(-4.82 \\
7.42)\end{array}$ & 0.94 & $\begin{array}{r}-2.32(-8.51 \\
3.89)\end{array}$ & 0.45 \\
\hline $\begin{array}{l}\text { CD38+HLA- } \\
\text { DR+CD4 }\end{array}$ & $\begin{array}{r}1.72(-0.73 \\
4.17)\end{array}$ & 0.25 & $\begin{array}{r}0.27(-1.32 \\
1.86)\end{array}$ & 0.97 & $\begin{array}{r}0.80(-1.13 \\
2.74)\end{array}$ & 0.68 & $\begin{array}{r}-0.65(-2.92 \\
1.63)\end{array}$ & 0.87 & $\begin{array}{r}1.45(-0.89 \\
3.79)\end{array}$ & 0.22 \\
\hline $\begin{array}{l}\text { CD38+HLA- } \\
\mathrm{DR}+\mathrm{CD} 8\end{array}$ & $\begin{array}{r}2.23(-1.01 \\
5.46)\end{array}$ & 0.26 & $\begin{array}{r}0.39(-1.71 \\
2.50)\end{array}$ & 0.96 & $\begin{array}{r}0.45(-2.10 \\
3.01)\end{array}$ & 0.96 & $\begin{array}{r}-1.38(-4.39 \\
1.63)\end{array}$ & 0.60 & $\begin{array}{r}1.84(-1.26 \\
4.93)\end{array}$ & 0.24 \\
\hline $\begin{array}{l}\text { PD-1+TIM- } \\
3+C D 4\end{array}$ & $\begin{array}{r}1.20(-0.44 \\
2.85)\end{array}$ & 0.22 & $\begin{array}{r}-0.15(-1.22 \\
0.92)\end{array}$ & 0.98 & $\begin{array}{r}0.74(-0.56 \\
2.04)\end{array}$ & 0.42 & $\begin{array}{r}-0.61(-2.14 \\
0.92)\end{array}$ & 0.70 & $\begin{array}{r}1.35(-0.22 \\
2.92)\end{array}$ & 0.09 \\
\hline $\begin{array}{l}\text { PD-1+TIM- } \\
3+C D 8\end{array}$ & $\begin{array}{r}0.80(-1.70 \\
3.30)\end{array}$ & 0.82 & $\begin{array}{r}0.67(-0.96 \\
2.30)\end{array}$ & 0.68 & $\begin{array}{r}-0.40(-2.38 \\
1.58)\end{array}$ & 0.95 & $\begin{array}{r}-0.53(-2.86 \\
1.79)\end{array}$ & 0.93 & $\begin{array}{r}0.13(-2.26 \\
2.52)\end{array}$ & 0.91 \\
\hline IFN $\gamma-\mathrm{CD} 8$ & $\begin{array}{r}5.92(-1.23 \\
13.08)\end{array}$ & 0.13 & $\begin{array}{r}-0.92(-5.76 \\
3.92)\end{array}$ & 0.95 & $\begin{array}{r}3.51(-2.16 \\
9.17)\end{array}$ & 0.35 & $\begin{array}{r}-3.33(-10.12 \\
3.46)\end{array}$ & 0.55 & $\begin{array}{r}6.84(-0.12 \\
13.80)\end{array}$ & 0.05 \\
\hline \multicolumn{11}{|l|}{$\begin{array}{l}\text { Cytokines, } \\
\text { Chemokines }^{\S}\end{array}$} \\
\hline IL-8 & $\begin{array}{r}-0.22(-1.20 \\
0.77)\end{array}$ & 0.93 & $\begin{array}{r}-0.31(-0.93 \\
0.31)\end{array}$ & 0.53 & $\begin{array}{r}-0.22(-1.02 \\
0.57)\end{array}$ & 0.87 & $\begin{array}{r}-0.31(-1.18 \\
0.56)\end{array}$ & 0.76 & $\begin{array}{r}0.09(-0.83 \\
1.01)\end{array}$ & 0.84 \\
\hline IL-18 & $\begin{array}{r}-0.28(-0.84 \\
0.28)\end{array}$ & 0.52 & $\begin{array}{r}-0.15(-0.51 \\
0.20)\end{array}$ & 0.64 & $\begin{array}{r}0.05(-0.40 \\
0.51)\end{array}$ & 0.99 & $\begin{array}{r}0.18(-0.32 \\
0.68)\end{array}$ & 0.75 & $\begin{array}{r}-0.13(-0.66 \\
0.39)\end{array}$ & 0.61 \\
\hline CXCL10 & $\begin{array}{r}-0.14(-1.56 \\
1.29)\end{array}$ & 0.99 & $\begin{array}{r}-0.57(-1.46 \\
0.31)\end{array}$ & 0.31 & $\begin{array}{r}0.92(-0.23 \\
2.07)\end{array}$ & 0.15 & $\begin{array}{r}0.48(-0.78 \\
1.73)\end{array}$ & 0.73 & $\begin{array}{r}0.44(-0.88 \\
1.76)\end{array}$ & 0.50 \\
\hline sCD40L & $\begin{array}{r}-0.11(-0.76 \\
0.54)\end{array}$ & 0.97 & $\begin{array}{r}-0.29(-0.69 \\
0.12)\end{array}$ & 0.24 & $\begin{array}{r}-0.47(-0.99 \\
0.06)\end{array}$ & 0.09 & $\begin{array}{r}-0.65(-1.22,- \\
0.07)\end{array}$ & 0.02 & $\begin{array}{r}0.18(-0.42 \\
0.78)\end{array}$ & 0.55 \\
\hline CCL5 & $\begin{array}{r}0.07(-0.36 \\
0.51)\end{array}$ & 0.97 & $\begin{array}{r}-0.16(-0.43 \\
0.12)\end{array}$ & 0.41 & $\begin{array}{r}0.39(0.03 \\
0.74)\end{array}$ & 0.03 & $\begin{array}{r}0.16(-0.23 \\
0.54)\end{array}$ & 0.70 & $\begin{array}{r}0.23(-0.18 \\
0.64)\end{array}$ & 0.25 \\
\hline TNFSF10 & $\begin{array}{r}0.51(-0.02 \\
1.05)\end{array}$ & 0.06 & $\begin{array}{r}0.05(-0.29 \\
0.38)\end{array}$ & 0.98 & $\begin{array}{r}0.35(-0.08 \\
0.79)\end{array}$ & 0.14 & $\begin{array}{r}-0.12(-0.59 \\
0.36)\end{array}$ & 0.91 & $\begin{array}{r}0.47(-0.03 \\
0.97)\end{array}$ & 0.07 \\
\hline MCSF & $\begin{array}{r}0.001(-1.02 \\
1.03)\end{array}$ & 1.00 & $\begin{array}{r}-0.16(-0.80 \\
0.48)\end{array}$ & 0.51 & $\begin{array}{r}0.56(-0.26 \\
1.39)\end{array}$ & 0.27 & $\begin{array}{r}0.41(-0.50 \\
1.31)\end{array}$ & 0.62 & $\begin{array}{r}0.16(-0.79 \\
1.11)\end{array}$ & 0.73 \\
\hline IL-15 & $\begin{array}{r}0.33(-0.30 \\
0.95) \\
\end{array}$ & 0.50 & $\begin{array}{r}-0.17(-0.56 \\
0.22) \\
\end{array}$ & 0.64 & $\begin{array}{r}0.34(-0.17 \\
0.85) \\
\end{array}$ & 0.28 & $\begin{array}{r}-0.16(-0.71 \\
0.40) \\
\end{array}$ & 0.87 & $\begin{array}{r}0.50(-0.09 \\
1.08) \\
\end{array}$ & 0.09 \\
\hline
\end{tabular}

*Adjusted for age and days from symptom onset.

${ }^{\dagger}$ As percentage of CD3-positive cells unless otherwise indicated. $n_{F_{-} \text {deteriorated }}=6, n_{M_{-} \text {deteriorated }}=6, n_{F_{-} \text {stabilized }}=16, n_{M_{-} \text {stabilized }}=11$.

₹As a percentage of live cells.

$\S \log _{10}\left(\mathrm{pg} \mathrm{ml}^{-1}\right)$.

$P$ values were determined using two-sided $t$-test with Tukey correction for multiple comparisons. 


\section{Extended Data Table $7 \mid$ Definitions of each cell subset in flow cytometry with specific markers}

\begin{tabular}{|c|c|c|}
\hline & Cell population & Definition by markers \\
\hline $\begin{array}{l}\text { Flow cytometry staining } \\
\text { panels }\end{array}$ & Live singlet gate & PBMC/Single Cells/Single Cells/Live... \\
\hline \multirow{11}{*}{$\begin{array}{l}\text { 1: PBMC cell composition } \\
\text { staining }\end{array}$} & B cells & .../CD19+CD3- \\
\hline & T cells & .../CD19-CD3+ \\
\hline & NKT cells & .../CD19-CD3+/CD3+CD56+ \\
\hline & NK cells & .../CD19-CD3-/CD56+CD66b- \\
\hline & Classical Monocytes (cMono) & .../CD19-CD3-/CD56-CD66b-/CD14+CD16- \\
\hline & Intermediate Monocytes (intMono) & .../CD19-CD3-/CD56-CD66b-/CD14+CD16var \\
\hline & Non-Classical Monocytes (ncMono) & .../CD19-CD3-/CD56-CD66b-/CD14-CD16+ \\
\hline & Plasmacytoid DCs (pDC) & .../CD19-CD3-/CD56-CD66b-/CD14-CD16-/CD304+ \\
\hline & Macrophages & .../CD19-CD3-/CD56-CD66b-/CD14-CD16-/CD304-/CD11b+ \\
\hline & DC1 & $\begin{array}{l}\text {../CD19-CD3-/CD56-CD66b-/CD14-CD16-/CD304-/CD141+HLA- } \\
\text { DR+ }\end{array}$ \\
\hline & DC2 & .../CD19-CD3-/CD56-CD66b-/CD14-CD16-/CD304-/CD1c+HLA-DR+ \\
\hline \multirow{16}{*}{$\begin{array}{l}\text { 2: T cell subsets staining } \\
\text { (by surface markers) }\end{array}$} & CD8 T cells & .../CD3+/CD8+CD4- \\
\hline & Naïve CD8T & .../CD3+/CD8+CD4-/CD3+CD45RA+/CD127+CCR7+/CD3+PD1- \\
\hline & Temra CD8T & .../CD3+/CD8+CD4-/CD3+CD45RA+/CD127-CCR7- \\
\hline & Central Memory CD8T (CD8Tcm) & .../CD3+/CD8+CD4-/CD3+CD45RA-/CD127+CCR7+ \\
\hline & Effector Memory CD8T (CD8Tem) & .../CD3+/CD8+CD4-/CD3+CD45RA-/CD127+CCR7- \\
\hline & Terminally Differentiated CD8T (PD-1+TIM-3+CD8) & .../CD3+/CD8+CD4-/CD3+CD45RA-/TIM3+PD1+ \\
\hline & Follicular CD8T (FollCD8) & .../CD3+/CD8+CD4-/CD3+CD45RA-/CXCR5+PD1+ \\
\hline & TCR-activated CD8T (CD38+HLA-DR+CD8) & .../CD3+/CD8+CD4-/CD38+HLA-DR+ \\
\hline & CD4 T cells & .../CD3+/CD8-CD4+ \\
\hline & Naïve CD4T & .../CD3+/CD8-CD4+/CD3+CD45RA+/CD127+CCR7+/CD3+PD1- \\
\hline & Temra CD4T & .../CD3+/CD8-CD4+/CD3+CD45RA+/CD127-CCR7- \\
\hline & Resting Natural Regulatory CD4T (CD4rn Treg) & .../CD3+/CD8-CD4+/CD3+CD45RA+/CD127-CD25hi/CD3+HLA-DR- \\
\hline & Central Memory CD4T (CD4Tcm) & .../CD3+/CD8-CD4+/CD3+CD45RA-/CD127+CCR7+ \\
\hline & Effector Memory CD4T (CD4Tem) & .../CD3+/CD8-CD4+/CD3+CD45RA-/CD127+CCR7- \\
\hline & Terminally Differentiated CD4T (PD-1+TIM-3+CD4) & .../CD3+/CD8-CD4+/CD3+CD45RA-/TIM3+PD1+ \\
\hline & $\begin{array}{l}\text { Effector Regulatory CD4T (CD4effTreg) } \\
\text { Natural Regulatory CD4T (CD4n Treg) } \\
\text { TCR-activated CD4T (CD38+HLA-DR+CD4) }\end{array}$ & $\begin{array}{l}\text {../CD3+/CD8-CD4+/CD3+CD45RA-/CD127-CD25hi } \\
\text { Treg/CD3+HLA-DR+ } \\
\text {../CD3+/CD8-CD4+/CD3+CD45RA-/CD127-CD25hi } \\
\text { Treg/CD3+HLA-DR- } \\
\text {.../CD3+/CD8-CD4+/CD38+HLA-DR+ }\end{array}$ \\
\hline \multirow{13}{*}{$\begin{array}{l}\text { 3: Cytokine producing } \mathrm{T} \\
\text { cells staining (intracellular } \\
\text { staining) }\end{array}$} & Granzyme B-expressing CD8T & .../CD3+/CD8+CD4-/GranzymeB+ \\
\hline & IFNy- expressing CD8T & ../CD3+/CD8+CD4-//FNy+ \\
\hline & TNFa-expressing CD8T & .../CD3+/CD8+CD4-/TNFa+ \\
\hline & IL2- expressing CD8T & .../CD3+/CD8+CD4-/IL2+ \\
\hline & IL6-expressing CD8T & .../CD3+/CD8+CD4-//L6+ \\
\hline & CXCR3-expressing CD8T & .../CD3+/CD8+CD4-/CXCR3+ \\
\hline & IFNy- expressing CD4T & .../CD3+/CD8-CD4+/IFNy+ \\
\hline & TNFa-expressing CD4T & .../CD3+/CD8-CD4+/TNFa+ \\
\hline & IL2- expressing CD4T & .../CD3+/CD8-CD4+/IL2+ \\
\hline & IL6-expressing CD4T & .../CD3+/CD8-CD4+/IL6+ \\
\hline & IL4-expressing CD4T & .../CD3+/CD8-CD4+/IL4+ \\
\hline & IL17-expressing CD4T & .../CD3+/CD8-CD4+/IL17+ \\
\hline & CXCR3-expressing CD4T & .../CD3+/CD8-CD4+/CD3+CXCR3+ \\
\hline
\end{tabular}




\section{Reporting Summary}

Nature Research wishes to improve the reproducibility of the work that we publish. This form provides structure for consistency and transparency in reporting. For further information on Nature Research policies, see our Editorial Policies and the Editorial Policy Checklist.

\section{Statistics}

For all statistical analyses, confirm that the following items are present in the figure legend, table legend, main text, or Methods section.

n/a Confirmed

$\square$ The exact sample size $(n)$ for each experimental group/condition, given as a discrete number and unit of measurement

$\square$ X A statement on whether measurements were taken from distinct samples or whether the same sample was measured repeatedly

$\square \times$ The statistical test(s) used AND whether they are one- or two-sided

X Only common tests should be described solely by name; describe more complex techniques in the Methods section.

$\square$ A description of all covariates tested

$\square$ A description of any assumptions or corrections, such as tests of normality and adjustment for multiple comparisons

x A full description of the statistical parameters including central tendency (e.g. means) or other basic estimates (e.g. regression coefficient) AND variation (e.g. standard deviation) or associated estimates of uncertainty (e.g. confidence intervals)

For null hypothesis testing, the test statistic (e.g. $F, t, r$ ) with confidence intervals, effect sizes, degrees of freedom and $P$ value noted

- Give $P$ values as exact values whenever suitable.

$\mathbf{x} \square$ For Bayesian analysis, information on the choice of priors and Markov chain Monte Carlo settings

$\boldsymbol{x}$ For hierarchical and complex designs, identification of the appropriate level for tests and full reporting of outcomes

$\boldsymbol{x}$ Estimates of effect sizes (e.g. Cohen's $d$, Pearson's $r$ ), indicating how they were calculated

Our web collection on statistics for biologists contains articles on many of the points above.

\section{Software and code}

Policy information about availability of computer code

Data collection EPIC EHR software (retrospective EMR review and clinical data aggregation) and REDCap 9.3.6 (clinical data aggregation).

Data analysis $\quad$ R (version 3.6.3), ggplot2 (version 3.3.0), Graphpad Prism (version 8), SAS (version 9.4), Attune NxT (version 3.1.2), FlowJo (version 10.6, Tree Star).

For manuscripts utilizing custom algorithms or software that are central to the research but not yet described in published iterature, software must be made available to editors and reviewers. We strongly encourage code deposition in a community repository (e.g. GitHub). See the Nature Research guidelines for submitting code \& software for further information.

\section{Data}

Policy information about availability of data

All manuscripts must include a data availability statement. This statement should provide the following information, where applicable:

- Accession codes, unique identifiers, or web links for publicly available datasets

- A list of figures that have associated raw data

- A description of any restrictions on data availability

All the flow cytometry data will be available via ImmPort website (study ID: SDY1648). All the data (viral load, antibody titer, ELISA data) used to generate figures and tables in this study are included in the Supplementary Information Table 1. 


\section{Field-specific reporting}

Please select the one below that is the best fit for your research. If you are not sure, read the appropriate sections before making your selection.

\section{Life sciences study design}

All studies must disclose on these points even when the disclosure is negative.

Sample size

No statistical methods were used to calculate the sample size. Sample size was determined based on the number of patients admitted to YaleNew Haven Hospital (YNHH) between March 18th and May 9th that were enrolled and consented with the current study under IRB and HIC approved protocol \#2000027690. Patients were identified though screening of EMR records for potential enrollment. Individuals with active chemotherapy against cancers, pregnant patients, patients with background hematological abnormalities, patients with autoimmune diseases (e.g. rheumatoid arthritis), and patients with a history of organ transplantation and on immunosuppressive agents were not included, and in total 98 patients were included in this study. Informed consent was obtained by trained staff and sample collection commenced immediately upon study enrollment. Clinical specimens were collected approximately every 4 days where an individual's clinical status permitted, and was continued until patient discharge or expiration.

Data exclusions Two extreme outlier samples for cytokine ELISA in the entire study. Measurements from these individuals were outliers (beyond 1.5x the interquartile range) in more than half of the cytokines measured. This strongly suggested that a technical error occurred during these two experiments or poor sample quality. Likewise, for flow cytometry, data on myeloid panel and T cell surface staining panel for two individuals were outliers in more than half of the parameters measured, which suggested the poor staining quality during the experiments. Thus, data of these samples were excluded from the analyses.

Replication The measurements were not replicated - longitudinal analyses of samples from human individuals.

Randomization This is not relevant as this is an observational study.

Blinding At the time of sample acquisition and processing, scientists were completely unaware of the patients' conditions. Blood acquisition is performed and recorded by a separate team. Information of patients' conditions are not available until after processing and analysing raw data by flow cytometry and ELISA. A clinical team, separate from the experimental team, performs chart review to determine patients' relevant statistics. Cytokines and facs analyses were blinded. Patients clinical information and clinical scores coding were only revealed after data collection.

\section{Reporting for specific materials, systems and methods}

We require information from authors about some types of materials, experimental systems and methods used in many studies. Here, indicate whether each material, system or method listed is relevant to your study. If you are not sure if a list item applies to your research, read the appropriate section before selecting a response.

Materials \& experimental systems

\begin{tabular}{l|l|l}
\hline $\mathrm{n} / \mathrm{a}$ & Involved in the study \\
\hline $\boldsymbol{x}$ & $\boldsymbol{x}$ Antibodies \\
\hline $\boldsymbol{x}$ & $\square$ Eukaryotic cell lines \\
\hline $\boldsymbol{x}$ & $\square$ Palaeontology and archaeology \\
\hline & $\square$ Animals and other organisms \\
$\boldsymbol{x}$ & $\boldsymbol{x}$ Human research participants \\
$\boldsymbol{x}$ & $\square$ Clinical data \\
\hline
\end{tabular}

\author{
Methods \\ n/a Involved in the study \\ $\boldsymbol{x} \square$ ChIP-seq \\ $\square \times$ Flow cytometry \\ $\mathbf{x} \square$ MRI-based neuroimaging
}

\section{Antibodies}

Antibodies used

All antibodies used in this study are against human proteins. BB515 anti-hHLA-DR (G46-6) (1:400) (BD Biosciences), BV785 antihCD16 (3G8) (1:100) (BioLegend), PE-Cy7 anti-hCD14 (HCD14) (1:300) (BioLegend), BV605 anti-hCD3 (UCHT1) (1:300) (BioLegend), BV711 anti-hCD19 (SJ25C1) (1:300) (BD Biosciences), AlexaFluor647 anti-hCD1C (L161) (1:150) (BioLegend), Biotin anti-hCD141 (M80) (1:150) (BioLegend), PE-Dazzle594 anti-hCD56 (HCD56) (1:300) (BioLegend), PE anti-hCD304 (12C2) (1:300) (BioLegend), APCFire750 anti-hCD11b (ICRF44) (1:100) (BioLegend), PerCP/Cy5.5 anti-hCD66b (G10F5) (1:200) (BD Biosciences), BV785 anti-hCD4 (SK3) (1:200) (BioLegend), APCFire750 or PE-Cy7 or BV711 anti-hCD8 (SK1) (1:200) (BioLegend), BV421 anti-hCCR7 (G043H7) (1:50) (BioLegend), AlexaFluor 700 anti-hCD45RA (HI100) (1:200) (BD Biosciences), PE anti-hPD1 (EH12.2H7) (1:200) (BioLegend), APC anti-hTIM3 (F38-2E2) (1:50) (BioLegend), BV711 anti-hCD38 (HIT2) (1:200) (BioLegend), BB700 anti-hCXCR5 (RF8B2) (1:50) (BD Biosciences), PECy7 anti-hCD127 (HIL-7R-M21) (1:50) (BioLegend), PE-CF594 anti-hCD25 (BC96) (1:200) (BD Biosciences), BV711 anti-hCD127 
(HIL-7R-M21) (1:50) (BD Biosciences), BV421 anti-hIL17a (N49-653) (1:100) (BD Biosciences), AlexaFluor 700 anti-hTNFa (MAb11) (1:100) (BioLegend), PE or APC/Fire750 anti-hIFNy (4S.B3) (1:60) (BioLegend), FITC anti-hGranzymeB (GB11) (1:200) (BioLegend), AlexaFluor 647 anti-hIL-4 (8D4-8) (1:100) (BioLegend), BB700 anti-hCD183/CXCR3 (1C6/CXCR3) (1:100) (BD Biosciences), PE-Cy7 antihIL-6 (MQ2-13A5) (1:50) (BioLegend), PE anti-hIL-2 (5344.111) (1:50) (BD Biosciences), BV785 anti-hCD19 (SJ25C1) (1:300) (BioLegend), BV421 anti-hCD138 (MI15) (1:300) (BioLegend), AlexaFluor700 anti-hCD20 (2H7) (1:200) (BioLegend), AlexaFluor 647 anti-hCD27 (M-T271) (1:350) (BioLegend), PE/Dazzle594 anti-hlgD (IA6-2) (1:400) (BioLegend), PE-Cy7 anti-hCD86 (IT2.2) (1:100) (BioLegend), APC/Fire750 anti-hlgM (MHM-88) (1:250) (BioLegend), BV605 anti-hCD24 (ML5) (1:200) (BioLegend), BV421 anti-hCD10 (HI10a) (1:200) (BioLegend), BV421 anti-CDh15 (SSEA-1) (1:200) (BioLegend), AlexaFluor 700 Streptavidin (1:300) (ThermoFisher), BV605 Streptavidin (1:300) (BioLegend).

All antibodies used in this study are commercially available, and all have been validated by the manufacturers and used by other publications. Likewise, we titrated these antibodies according to our own our staining conditions. The following were validated in the following species: BB515 anti-hHLA-DR (G46-6) (BD Biosciences) (Human, Rhesus, Cynomolgus, Baboon), BV785 anti-hCD16 (3G8) (BioLegend) (Human, African Green, Baboon, Capuchin Monkey, Chimpanzee, Cynomolgus, Marmoset, Pigtailed Macaque, Rhesus, Sooty Mangabey, Squirrel Monkey), PE-Cy7 anti-hCD14 (HCD14) (BioLegend) (Human), BV605 anti-hCD3 (UCHT1) (BioLegend) (Human, Chimpanzee), BV711 anti-hCD19 (SJ25C1) (BD Biosciences) (Human), AlexaFluor647 anti-hCD1c (L161) (BioLegend) (Human, African Green, Baboon, Cynomolgus, Rhesus), Biotin anti-hCD141 (M80) (BioLegend) (Human, African Green, Baboon), PE-Dazzle594 anti-hCD56 (HCD56) (BioLegend) (Human, African Green, Baboon, Cynomolgus, Rhesus), PE anti-hCD304 (12C2) (BioLegend) (Human), APCFire750 anti-hCD11b (ICRF44) (BioLegend) (Human, African Green, Baboon, Chimpanzee, Common Marmoset, Cynomolgus, Rhesus, Swine), PerCP/Cy5.5 anti-hCD66b (G10F5) (BD Biosciences) (Human), BV785 anti-hCD4 (SK3) (BioLegend) (Human), APCFire750 or PE-Cy7 or BV711 anti-hCD8 (SK1) (BioLegend) (Human, Cross-Reactivity: African Green, Chimpanzee, Cynomolgus, Pigtailed Macaque, Rhesus, Sooty Mangabey), BV421 anti-hCCR7 (G043H7) (BioLegend) (Human, African Green, Baboon, Cynomolgus, Rhesus), AlexaFluor 700 anti-hCD45RA (HI100) (BD Biosciences) (Human), PE anti-hPD1 (EH12.2H7) (BioLegend) (Human, African Green, Baboon, Chimpanzee, Common Marmoset, Cynomolgus, Rhesus, Squirrel Monkey), APC antihTIM3 (F38-2E2) (BioLegend) (Human), BV711 anti-hCD38 (HIT2) (BioLegend) (Human, Chimpanzee, Horse), BB700 anti-hCXCR5 (RF8B2) (BD Biosciences) (Human), PE-Cy7 anti-hCD127 (HIL-7R-M21) (BioLegend) (Human), PE-CF594 anti-hCD25 (BC96) (BD Biosciences) (Human, Rhesus, Cynomolgus, Baboon), BV711 anti-hCD127 (HIL-7R-M21) (BD Biosciences) (Human), BV421 anti-hIL-17a (N49-653) (BD Biosciences) (Human), AlexaFluor 700 anti-hTNFa (MAb11) (BioLegend) (Human, Cat, Cross-Reactivity: Chimpanzee, Baboon, Cynomolgus, Rhesus, Pigtailed Macaque, Sooty Mangabey, Swine), PE or APC/Fire750 anti-hIFNy (4S.B3) (BioLegend) (Human, Cross-Reactivity: Chimpanzee, Baboon, Cynomolgus, Rhesus), FITC anti-hGranzymeB (GB11) (BioLegend) (Human, Mouse, Cross-Reactivity: Rat), AlexaFluor 647 anti-hIL-4 (8D4-8) (BioLegend) (Human, Cross-Reactivity: Chimpanzee, Baboon, Cynomolgus, Rhesus), BB700 anti-hCD183/CXCR3 (1C6/CXCR3) (BD Biosciences) (Human, Rhesus, Cynomolgus, Baboon), PE-Cy7 anti-IL-6 (MQ2-13A5) (BioLegend) (Human), PE anti-hIL-2 (5344.111) (BD Biosciences) (Human), BV785 anti-hCD19 (SJ25C1) (BioLegend) (Human), BV421 anti-hCD138 (MI15) (BioLegend) (Human), AlexaFluor700 anti-hCD20 (2H7) (BioLegend) (Human, Baboon, Capuchin Monkey, Chimpanzee, Cynomolgus, Pigtailed Macaque, Rhesus, Squirrel Monkey), AlexaFluor 647 anti-hCD27 (M-T271) (BioLegend) (Human, Cross-Reacitivity: Baboon, Cynomolgus, Rhesus), PE/Dazzle594 anti-hlgD (IA6-2) (BioLegend) (Human), PE-Cy7 anti-hCD86 (IT2.2) (BioLegend) (Human, African Green, Baboon, Capuchin Monkey, Common Marmoset, Cotton-topped Tamarin, Chimpanzee, Cynomolgus, Rhesus), APC/Fire750 anti-hlgM (MHM-88) (BioLegend) (Human, African Green, Baboon, Cynomolgus, Rhesus), BV605 anti-hCD24 (ML5) (BioLegend) (Human, Cross-Reactivity: Chimpanzee), BV421 anti-hCD10 (HI10a) (BioLegend) (Human, African Green, Baboon, Capuchin monkey, Chimpanzee, Cynomolgus, Rhesus), BV421 anti-hCD15 (SSEA-1) (BioLegend) (Human), AlexaFluor 700 Streptavidin (1:300) (ThermoFisher), BV605 Streptavidin (1:300) (BioLegend).

\section{Human research participants}

Policy information about studies involving human research participants

Population characteristics

Recruitment

Ethics oversight
Fifty-one female (age 64.0 \pm 16.9 ) and 47 male (age 61.9 \pm 16.7 ) patients were included. The detailed demographic information can be found in Extended Data Table 1.

Patients admitted to the Yale New Haven Hospital (YNHH) between the 18th of March through the 9th of May 2020, were recruited to the Yale IMPACT study (Implementing Medical and Public Health Action Against Coronavirus CT) after testing positive for SARS-CoV2 by qRT-PCR. (serology was further confirmed for all patients enrolled). Patients were identified though screening of EMR records for potential enrollment with no self selection. Informed consent was obtained by trained staff and sample collection commenced immediately upon study enrollment. Clinical specimens were collected approximately every 4 days where an individual's clinical status permitted, and was continued until patient discharge or expiration.

Yale Human Research Protection Program Institutional Review Boards. Informed consents were obtained from all enrolled patients and healthcare workers. $\bullet$ Our research protocol was reviewed and approved by the Yale School of Medicine IRB and HIC (\#2000027690). Informed consent was obtained by trained staff and records maintained in our research database for the duration of our study. There were no minors included on this study. 


\section{Plots}

Confirm that:

$\boldsymbol{x}$ The axis labels state the marker and fluorochrome used (e.g. CD4-FITC).

$\boldsymbol{x}$ The axis scales are clearly visible. Include numbers along axes only for bottom left plot of group (a 'group' is an analysis of identical markers).

$\mathbf{x}$ All plots are contour plots with outliers or pseudocolor plots.

$\boldsymbol{x}$ A numerical value for number of cells or percentage (with statistics) is provided.

\section{Methodology}

Sample preparation

Instrument

Software

Cell population abundance

Gating strategy
Freshly isolated PBMCs were stained for live and dead markers, blocked with Human TruStan FcX, stained for surface markers and then fixed with PFA 4\%. For intracellular cytokine staining following stimulation, cells were surface stained, washed and fixed in 4\% PFA. After permeabilization with 1X Permeabilization Buffer cells were stained for intracellular cytokines analysis.

Cells were acquired on an Attune NXT (ThermoFisher).

Data were analysed using FlowJo software version 10.6 software (Tree Star).

Cell population abundance: Cells populations were reported in various formats including as a number or concentration of the patient's blood sample (x106cells $/ \mathrm{mL}$ ), as a proportion of live, single PBMC (\% of Live), or as a proportion of a parent gate (\% of CD4 T cells, \% of Monocytes, etc.). The full gating path for clarification is included in the extended figures.

SSC-A and FSC-A parameters were used to select leukocytes from isolated PBMCs. Live and dead cells were defined based on aqua staining. Singlets were separated based on SSC/ FSC parameters. Leukocytes were gated based on to identify lymphocytes (CD3/CD4/CD8/CD19/CD56 markers), granulocytes (CD16,CD14, HLA-DR markers) and pDCs, and cDCs (CD304, CD1c, CD141). TCR-activated T cells, Terminally-differentiated T cells, and additional subsets.were defined using HLA-DR, CD38, CCR7,CD127, PD1, TIM-3, CXCR5, CD45RA, CD25. Intracellular T cell gating strategy to identify CD4 and/or CD8 T cells secreting TNFa, IFN-y, IL-6, IL-2, GranzymeB, IL-4, and/or IL-17 were defined using the specif markers: CD3, CD4, CD8, TNF, IFN, IL-6, IL-2, IL-4, IL-17 and granzyme B.

Tick this box to confirm that a figure exemplifying the gating strategy is provided in the Supplementary Information. 